\title{
6. KunStPÄDAgOgische ANALYSE DER Ausstellung „KAiser HeinRiCh II. 1002-1024“6
}

Mit diesem Kapitel erfolgt eine weitere Fokussierung. Sollte durch das vorherige Kapitel eine vergleichende Darstellung unterschiedlicher Konzeptionen das weite Feld der Möglichkeiten schlaglichtartig beleuchten, steht nun eine Ausstellung als Reflexionsmedium im Zentrum der Betrachtung. Anhand dieser Präsentation sollen einzelne Aspekte vertiefend betrachtet werden.

Die Wahl fiel auf die vom Haus der Bayerischen Geschichte in Augsburg konzipierte Landesausstellung „Kaiser Heinrich II. 10021024",' die vom 9. Juli bis zum 20. Oktober in Bamberg präsentiert wurde. Diese Entscheidung basiert auf mehreren Erwägungen. Zum einen kann das Haus der Bayerischen Geschichte mittlerweile auf eine langjährige Tradition der Konzeption von Ausstellungen zurückblicken. ${ }^{2}$ Die daraus gewonnenen Erfahrungen fließen wiederum in neue Präsentationskonzepte ein. Begleitend hierzu werden die Ausstellungen im Rahmen einer Langzeitstudie in Form von Besucherbefragungen ausgewertet. ${ }^{3}$ Die Kommunikation der Ausstellungsinhalte nimmt dabei einen sehr hohen Stellenwert ein. Das Haus der Bayerischen Geschichte verfolgt einen konsequenten Weg der Besucherorientierung, mit dem Ziel, über die fachwissenschaftlichen Besucher hinaus vor allem ein breites

1 Kirmeier, Josef/Schneidmüller, Bernd/Weinfurter, Stefan/Brockhoff, Evamaria (Hrsg.): Kaiser Heinrich II. 1002-1024. Augsburg 2002.

2 Haus der Bayerischen Geschichte (Hrsg.): 20 Jahre Haus der Bayerischen Geschichte - 20 Jahre Geschichtsarbeit in Bayern. Augsburg, 2003. Siehe auch: http://www.hdbg.de (letzter Zugriff: 06.12.04).

3 Bereits 1985 wurden erstmals Besucher von Ausstellungen des Hauses der Bayerischen Geschichte nach soziologischen Kriterien befragt. Seitdem erfolgte eine kontinuierliche wissenschaftliche Begleitung der Besucherströme in den Ausstellungen. Die Untersuchungen wurden zunächst von Prof. Dr. Siegfried Lamnek (München/Eichstätt) und ab 1993 von Dipl. Soz. Werner Fröhlich (Sozialwissenschaftliches Institut München) durchgeführt. 
Publikum anzusprechen. Die Bedürfnisse der potentiellen Besucher flieBen somit in die Ausstellungskonzeptionen ein.

Ein weiterer Grund für die Heinrichsausstellung lag in der besonderen Konzeption, die drei unterschiedliche Präsentationsstrategien mit archäologischer Rekonstruktion, Inszenierung sowie Schatzkammer vereinte. Damit war in Bamberg vor Ort im direkten Nebeneinander eine Vergleichbarkeit dieser Ansätze möglich. Im Besucherurteil führte diese Ausstellung zu äußerst kontroversen Meinungen von höchstem Lob bis zu vernichtender Kritik. ${ }^{4}$ Der inszenierte Bereich zur Lebenswelt Heinrichs II. in der Alten Hofhaltung provozierte unterschiedlichste Reaktionen und Stimmungen, auch häufig zu denselben Raumensembles. Diese Gegensätzlichkeit des Besucherurteils legt es nahe zu ergründen, wie sich diese Urteile bilden und in welchem Kontext diese zu betrachten und zu bewerten sind.

\subsection{Darstellung der Ausstellungsanalyse}

Erst allmählich beginnen sich mit fortschreitender museumstheoretischer Auseinandersetzung vereinzelt im deutschsprachigen Raum Analysemethoden und Begriffsinstrumentarien für Museumspräsentationen zu entwickeln. ${ }^{5}$ Gegenwärtig spiegelt sich dieser Mangel an Beschreibungsmodellen sowohl in der alltäglichen Museumspraxis als auch in den Ausstellungskritiken der Feuilletons wider. Eine Ursache hierfür liegt nach Ansicht von Scholze in der ausgeprägt fachwissenschaftlichen und nur eingeschränkt museologischen Ausrichtung der Museen und ihres Personals (Scholze 2004, S. 13). Im Hinblick auf Ausstellungsrezensionen stellt Waidacher zwar fest, dass viele Kritiker über ausgezeichnete Kenntnisse in den Fachbereichen, die sich mit den ausgestellten

4 Die Kommentare in den Besucherbüchern ließen diese gegensätzlichen Meinungen, die sich sowohl im Hinblick auf positive wie auch negative Äußerungen rein quantitativ weitgehend die Waage hielten, sehr deutlich zu Tage treten. Vgl. Besucherbücher zur Landesausstellung „Heinrich II.“ vom 10.07-13.09.02 in der Alten Hofhaltung sowie im Diözesanmuseum.

5 Ein Analysemodell basierend auf den Methoden der Semiotik entwickelte zum Beispiel Scholze im Rahmen ihrer Dissertation. Die zentralen Begriffe Deskription, Denotation, Konnotation und Metakommunikation verwendet sie, um den Prozess der Codierung des Mediums Ausstellung anhand vor vier Ausstellungsbeispielen nachvollziehbar zu machen. Siehe Kapitel 4, Anm. 1. 
Objekten selbst befassen, verfügen. Er ergänzt jedoch, dass die Rezension erfordere, die Ausstellung als Ganzes zu betrachten, die ihr zugrunde liegenden Gesetze zu berücksichtigen und analytisch darzustellen. Dieser Ansatz fehlt aber vielen Besprechungen musealer Präsentationen.

„Tatsächlich wird die Leserschaft zwar immer wieder über Picassos Blaue Periode, die formalen Gesetze Etruskischer Ornamentik oder die Reproduktionsgewohnheiten flügelloser Fliegen belehrt; aber kaum je erhält sie Informationen über das Ausstellungskonzept, seine Umsetzung, das Design, die Beleuchtung, die Texte - all dies, wie man erwarten sollte, gemessen an den Absichten und Zielen der Ausstellung und an den gegebenen Möglichkeiten.“6

Über inhaltliche sowie objektbezogene Belange hinaus bedeutet dies, den Blick zu weiten und auch gestalterische oder besucherorientierte Aspekte zu berücksichtigen. ${ }^{7}$ Jede Form der analytischen Betrachtung kann lediglich einzelne Teilaspekte beleuchten, ohne das Gesamtphänomen wiedergeben zu können. Andererseits sind für genaues Betrachten und kritisches Beschreiben von Ausstellungen Begriffsinstrumentarien notwendig, die die Ausstellungen unter einer spezifischen Fragestellung beleuchten.

\section{Das kunstpädagogische Analysekonzept}

Im Zentrum dieser Studie stehen pädagogische sowie gestalterische Fragestellungen von Ausstellungsinszenierungen unter der Perspektive kommunikativer sowie metakommunikativer Aspekte. Das Fundament dafür bilden die in den Kapiteln drei und vier erfolgten Überlegungen. Die Ausstellungsanalyse spannt einen Bogen und befasst sich unter der dargestellten, spezifischen Fragestellung mit drei elementaren Bezugsgrößen musealer Kommunikation, nämlich den Ausstellungsmachern als Sendern der Botschaft, der Botschaft selbst sowie den Besuchern als Empfängern der Botschaft.

6 Friedrich Waidacher: Ausstellungen besprechen. http://www.vl-museen. de/m-online/00/00-2.pdf (letzter Zugriff: 01.12.04).

7 Ein umfangreicher Fragenkatalog als Leitfaden für eine Ausstellungskritik unter besucherorientierter Perspektive wurde im Jahr 1990 während einer Tagung der American Association of Museum erstellt. Vgl. McLean 1993, S. 163-166. Diese Zusammenstellung von Fragen und Hinweisen wurde von Waidacher zur praktischen Anwendung für Ausstellungskritiker modifiziert und ergänzt. Siehe Kapitel 6, Anm. 6. 
Im ersten Teil der Analyse geht es darum, das Umfeld der Heinrichsausstellung zu beleuchten. Zunächst soll die ausführende Institution, das Haus der Bayerischen Geschichte, vorgestellt und Leitgedanken auch im Hinblick auf museumspädagogische Belange beschrieben werden. Diese Grundgedanken spiegeln sich im Entstehungsprozess der Ausstellung wider, der anhand wichtiger Etappen punktuell nachvollzogen wird. Ebenso werden die Gestalter, die wesentlich das Erscheinungsbild der Ausstellung mitbestimmen, charakterisiert. Nach einem Überblick über Inhalte und Ziele der Ausstellung soll das Gesamtkonzept der Gestaltung vorgestellt werden. Die Ausstellung verteilte sich auf mehrere Orte um den Bamberger Domplatz, deren spezifische Charakteristiken skizziert werden. Im Gegensatz zur Präsentation im Diözesanmuseum sowie in der Staatsbibliothek, in der eine traditionelle, zurückhaltende Gestaltung angestrebt war, bildeten die Räume der Alten Hofhaltung den Ort der Inszenierung der Lebenswelt des Herrschers Heinrich II. Aus diesem Grund befasst sich die Analyse schwerpunktmäßig mit diesem Teilbereich der Ausstellung.

Im zweiten Teil der Analyse dienen als Gliederungskriterium die vier Dimensionen kommunikativer Strategien mit Anschaulichkeit, Handlungsorientierung, Ganzheit und Differenzierung. Dabei stehen exemplarisch ausgewählte Inszenierungseinheiten in der Alten Hofhaltung im Zentrum der Betrachtung. Eine Beschreibung einzelner Arrangements, Ausstellungsräume oder -abschnitte, ergänzt mit Abbildungen, bilden dafür die Grundlage. Jedoch muss auch hier angemerkt werden, dass keine vollständige Darstellung im Sinne eines Nacherlebens geliefert werden kann. Die Entscheidung für bestimmte Fragmente der Ausstellung erfolgt zwar nach individuellen Gesichtspunkten, doch orientiert sich die Selektion an signifikanten Merkmalen, die jeweils Anknüpfungspunkte für eine Diskussion kommunikativer Strategien liefern. Ergänzend hierzu fließen die Ergebnisse der Besucherbefragungen ein.

Der dritte Teil der Analyse ist gleichartig aufgebaut. Unter der Perspektive metakommunikativer Aspekte soll anhand konkreter Raumbilder die politische und ökonomische Dimension der Ausstellung diskutiert werden. 


\section{Die Besucherbefragung}

Die Besucher nehmen eine besondere Stellung im Gefüge der Museumskommunikation ein, denn sie bilden das Ziel der Bemühungen. Wird eine Ausstellung nicht wahrgenommen, bleibt sie bedeutungs- und wirkungslos. Doch als Empfänger oder reine Projektionsfläche wird der Rezipient grundsätzlich missverstanden, da er aktiv an der Konstruktion von Bedeutungen beteiligt ist. Wohlfromm vergleicht in diesem Zusammenhang die Besucher mit ungleichmäßig lichtempfindlich beschichtetem Material, auf das der Text, der Film der Ausstellung projiziert wird. „Jeder Rezipient gestaltet die Oberfläche seines Trägermaterials selbst, indem er die Stellen bestimmt, auf denen sich die intentionale Aussagen des Museums oder der Ausstellung abzeichnen können." (Wohlfromm 2002, S. 36)

In diesem Sinne besteht das Anliegen der Ausstellungsanalyse darin, das Meinungsbild der Rezipienten zur Heinrichsausstellung schlaglichtartig zu beleuchten. Die Angaben hierzu stützen sich auf zwei Erhebungen. Zum einen beziehe ich mich auf Ergebnisse des Sozialwissenschaftlichen Instituts München, das mittels eines empirischen, quantitativen Ansatzes standardisierte Besucherbefragungen durchführt. Zum anderen basieren die Aussagen auf einer qualitativen Studie anhand von halb-standardisierten Interviews, die ich vor Ort mit Ausstellungsbesuchern durchführte.

Die empirische Befragung zur Heinrichsausstellung ist in eine Langzeitstudie eingebettet, die das Haus der Bayerischen Geschichte seit 1993 zusammen mit dem Sozialwissenschaftlichen Institut München durchführt. ${ }^{8}$ Die kontinuierliche Besucherbefragung soll die lückenhafte Erkenntnis über Museums- und Ausstellungsbesucher in komparativsystematischer Weise verbessern. ${ }^{9}$ Auch geht es darum zu ermitteln, wie

8 Das Sozialwissenschaftliche Institut München (SIM) ist ein unabhängiges Dienstleistungsunternehmen im Bereich der sozial- und wirtschaftswissenschaftlichen Beratung und Forschung. Von 1993 bis 2003 führte das Institut insgesamt 11 Besucherbefragungen zu Ausstellungen des Hauses der Bayerischen Geschichte durch. Einen Überblick zu den Projekten sowie Methodik siehe unter: http://www.sim-sozialforschung.de (letzter Zugriff: 06.12.04).

9 Sechs Besucherstudien zu Landesausstellungen von 1998 bis 2003 sowie ein Aufsatz zu ausgewählten Ergebnissen der Besucherforschung des Hauses der Bayerischen Geschichte sind auf der Homepage veröffentlicht. http://www.hdbg.de/basis/index_extern.html (letzter Zugriff: 06.12.04). 
die einzelnen Ausstellungen vom breiten Publikum aufgenommen werden und inwieweit es gelungen ist, den Besuchern neue Informationen zu vermitteln.

„Schließlich sollen die von den Besuchern vorgenommenen Bewertungen dazu dienen, die Konzeption der jeweiligen Ausstellung in ihrer Gesamtheit, aber auch die Ausgestaltung der Texte und der eingesetzten pädagogischen und didaktischen Elemente zu überprüfen und für zukünftige Ausstellungen fruchtbar zu machen. ${ }^{* 10}$

Die Befragung erfolgte in schriftlicher Form mittels eines achtseitigen Fragebogens, der einschließlich des soziodemographischen Abschnitts 54 Fragen umfasste. ${ }^{11}$ Der Fragebogen wurde in seiner Gestaltung möglichst einfach gehalten, um von einem breiten Personenkreis problemlos beantwortet werden zu können. Auf Filterführungen ${ }^{12}$ wurde daher fast gänzlich verzichtet. Die zu befragenden Ausstellungsbesucher wurden nach einem Zufallsverfahren ausgewählt, etwa jeder zwanzigste Besucher wurde zur Teilnahme gebeten. Die einzelnen Fragen ließen zum Teil Mehrfachantworten zu. Die Befragung erfolgte in drei Wellen von jeweils einer Woche. ${ }^{13}$ Damit wurden insgesamt 1.023 Besucher erfasst. ${ }^{14}$ Neben einem Sozialprofil der Ausstellungsbesucher sowie ausgewählten Aspekten des Besucherverhaltens und einer Bewertung der Infrastruktur und Serviceleistungen durch die Besucher ist für meine Untersuchung insbesondere das Unterkapitel „Wahrnehmung und Bewertung der Ausstellungsinhalte" des Ergebnisberichts relevant, in dem

10 Fröhlich, Werner/Nöthen, Joachim: Besucherbefragung zur Landesausstellung. Kaiser Heinrich II. 1002-1024. Bamberg 9. Juli 2002 bis 20. Oktober 2002 - Ergebnisbericht. München 2003, S. 4.

11 Eine detaillierte Darstellung der Untersuchungsmethode sowie des Erhebungsinstruments vgl. Fröhlich /Nöthen 2003, S. 4ff.

12 Mittels einer Filterführung lässt sich die Datenqualität erhöhen. Die Fragebogendramaturgie kann spezifisch für einzelne Nutzergruppen gestaltet werden. Je nach Antwort auf bestimmte Schlüsselfragen (Filterfragen) können unterschiedliche Folgefragen gestellt werden.

13 Die erste Befragungswelle wurde vom 26. August bis zum 1. September in der Haupturlaubszeit, die zweite Welle vom 23. bis 29. September kurz nach den bayerischen Sommerferien und die dritte Befragungswelle vom 7. bis 13. Oktober kurz vor Ende der Ausstellung durchgeführt. Vgl. Fröhlich/Nöthen 2003, S. 137.

14 Bei einer Gesamtbesucheranzahl 205.920 Personen bedeutet dies, das circa jeder 200. Besucher von der Befragung erfasst wurde. 
zum Beispiel Angaben zur Bewertung der optischen Präsentation durch die Besucher aufgeführt sind.

Als Pendant zur quantitativen Studie des Sozialwissenschaftlichen Instituts München dienen die halb-standardisierten Interviews mit den Besuchern, die auf einem qualitativen Ansatz basieren. Bei dieser Befragungsform ist der Fragebogen nicht endgültig festgelegt, sondern entspricht einem zwar systematisch, aber flexibel aufgebauten Frageschema, das Rückfragen des Befragten und Zusatzfragen des Interviewers gestattet. ${ }^{15}$ Der Vorteil dieser Leitfadengespräche liegt darin, ergründen zu können, wie positive oder negative Urteile zustande kommen. Eine flexible Reaktion auf unerwartete Meinungen ist möglich, so dass diese ebenfalls berücksichtigt werden und in die Auswertung einfließen können. Der Grund für die Entscheidung, mit dieser Methode zu arbeiten, liegt darin, die subjektiven Urteile der Besucher zu ergründen, um damit ein facettenreiches Bild von diesen erhalten zu können. Auch sollte ermittelt werden, inwieweit die Gestaltung die Rezeption und das Erinnerungsvermögen der Besucher beeinflusst. Ebenso interessierte, wie ausgewählte, gestalterische Elemente bewertet werden und wie diese in $\mathrm{Zu}-$ sammenhang mit weiteren Faktoren stehen.

Meine Fallstudie mit punktuellen Fragen kann keine grundlegenden Aufschlüsse über museale Rezeptions- und Wahrnehmungsbedingungen geben. Diese sind psychologischer Grundlagenforschung vorbehalten. Systematische, feldexperimentelle Forschungen fehlen jedoch bisher. ${ }^{16}$ Im Sinne eines heuristischen Verfahrens ${ }^{17}$ sollen die Interviews dazu beitragen, das noch aufzuarbeitende Analysefeld schlaglichtartig zu beleuchten und letztlich Impulse für meine theoretischen Überlegungen zu liefern.

Die Besucherbefragung führte ich vom 1. September 2002 bis 14. September 2002 durch. Täglich interviewte ich im Durchschnitt vier Personen. Befragt wurden nur Besucher, die bereits die gesamte Ausstellung, also alle fünf Ausstellungsbereiche, besucht hatten. Die Aus-

15 Vgl. Pürer, Heinz: Einführung in die Publizistikwissenschaft, Systematik, Fragestellungen, Theorieansätze, Forschungstechniken, München 1990, S. 165.

16 Klein, Hans-Joachim: Gemischtes Doppel - Evaluation der Ausstellungen Spätmittelalter am Oberrhein in der Staatlichen Kunsthalle und im Badischen Landesmuseum, beide in Karlsruhe. Karlsruhe 2002, S. 86.

17 Eberhard, Kurt: Einführung in die Erkenntnis- und Wissenschaftstheorie. Geschichte und Praxis der konkurrierenden Erkenntniswege. Stuttgart 1999, S. 109. 
wahl der Befragten erfolgte nach einem Zufallsprinzip, wobei ich darauf achtete, dass das breite Spektrum der unterschiedlichen Besuchergruppen und die unterschiedlichen Altersgruppen abgedeckt wurden. Da viele Besucher das Diözesanmuseum in ihrem Rundgang als letzten Ort besichtigten, positionierte ich mich benachbart zur Kasse im Ausgangsbereich. Die Interviews anhand des Gesprächsleitfadens dauerten circa 15 bis 30 Minuten.

Der Interviewleitfaden untergliederte sich in vier Fragekomplexe. ${ }^{18}$ Die Fragen bezogen sich auf die Gestaltung in der Alten Hofhaltung sowie im Diözesanmuseum. Diese zwei Teilbereiche wählte ich aus, da sich hier mit inszenierten Parcours und der Schatzkammer zwei unterschiedliche Präsentationskonzepte gegenüberstanden.

Der erste Block umfasste Fragen zum Gesamteindruck sowie zu positiven wie negativen Erinnerungen. Diese Fragen waren bewusst sehr weit gefasst, um die Vielfältigkeit der unterschiedlichen Eindrücke zuzulassen. Der zweite Teil der Fragen bezog sich auf das Vermittlungsangebot für die Besucher in der Ausstellung in Form von Text, Audioguide, Computer und Fühlstationen. Der dritte Fragenblock befasste sich mit Inszenierungseinheiten in der Alten Hofhaltung. Zur Unterstützung des Erinnerungsvermögens wurde den Befragten jeweils ein Photo des Raumes gezeigt. Hier wählte ich exemplarisch zwei Räume aus. Dieses waren der Raum „Der neue König - Triumphat Baioaria - Bayern triumphiert“ sowie der Raum „Der Kaiser - Decus Europae - Zierde Europas “. Die Wahl fiel auf diese zwei Räume, da sie jeweils eine gestalterische sowie inhaltliche Einheit bildeten und sich einer ungewöhnlichen Ausstellungssprache bedienten. Die Fragen zielten darauf, ob Besucher diesen Raum inhaltlich einordnen konnten, was generell in Erinnerung blieb und wie die Gestaltung bewertet wurde. Eine besondere aus dem üblichen Rahmen fallende Gestaltungseinheit waren die Keramikfiguren „Treue Weggefährten Heinrichs II.“ in einer Koje des Raumes „Unterwegs im Reich“. Diese waren zugleich Kunstwerk und didaktisches Element. Hierzu sollten die Besucher ihre Meinung abgeben. Im vierten Fragenteil sollten die Besucher zu ihrem Gesamteindruck Stellung nehmen. Dabei interessierte besonders die Bewertung der unterschiedlichen Präsentationsstrategien durch die Besucher. Da auch Alter, Bildungsstand und Beruf wesentlich die Wahrnehmung beeinflussen, hielt ich darüber hinaus die soziodemographischen Angaben der Besucher fest.

18 Interviewleitfragen für die Besucherbefragung in der Landesausstellung „Kaiser Heinrich II. 1002-1024“ siehe Anhang S. 425. 
Für die Nutzbarmachung transkribierte ich die auf Kassette aufgezeichneten Interviews. Bei der Auswertung fasse ich tendenzielle Meinungen zusammen. Bei mehrfach formulierten Äußerungen ähnlicher Art wählte ich stellvertretend ein Zitat aus und gebe dieses als Stimmungsbild wörtlich wieder. ${ }^{19}$

Die Ergebnisse beider Besucherbefragungen fließen im Anschluss an die Beschreibung und Diskussion der exemplarisch ausgewählten Inszenierungseinheiten ein. Das Nebeneinander der empirischen Studie des Sozialwissenschaftlichen Instituts München sowie des heuristischen Ansatzes wird zeigen, ob diese zu vergleichbaren Ergebnissen führen. Insbesondere interessant wird diese Gegenüberstellung dann, wenn ähnliche Fragen gestellt wurden, wie dies zum Beispiel bei der Bewertung der fünf unterschiedlichen Ausstellungsbereiche der Fall ist.

\subsection{Die Ausstellung „Kaiser Heinrich II. 1002-1024“}

Die Geschichte des Herrschers Heinrich II. wurde auf dem Bamberger Domberg an mehreren Schauplätzen erzählt: in der Alten Hofhaltung, in der Staatsbibliothek, im Diözesanmuseum und im Dom. Veranstaltet wurde diese große Erinnerungsausstellung vom Haus der Bayerischen Geschichte in Kooperation mit der Stadt Bamberg, der Staatsbibliothek Bamberg und dem Diözesanmuseum Bamberg. Die Zeit um die Jahrtausendwende wurde jedoch nicht nur in den Ausstellungsräumen verlebendigt, sondern durch ein umfangreiches Rahmenprogramm und Begleitmedien ergänzt, welche die unterschiedlichsten Interessensgruppen berücksichtigten. Diese Analyse wirft den Fokus auf die Vermittlung der Exponate und Inhalte in den Ausstellungsräumen selbst. Ohne das Begleitprogramm im Detail darstellen zu können, sollen jedoch touristische, künstlerische und museumspädagogische Angebote überblicksartig vorgestellt werden, da diese weitere Komponenten eines umfassenden Vermittlungskonzeptes bildeten.

Neben Konzerten mit mittelalterlicher Musik gab es eine Vortragsreihe zu wissenschaftlichen Spezialthemen. Handwerklich Interessierte konnten entweder bei Vorführungen zum Beispiel zur Beinbearbeitung,

19 Wie ein Besucher jedoch selbst einschränkend feststellte, ist eine wirklich faire Beurteilung der Ausstellung durch Besucher nur dann möglich, wenn er diese in Ruhe betrachten kann, da sich viele Dinge erst auf den zweiten Blick erschließen lassen. 
Buchmalerei, Kalligraphie, Wollherstellung zusehen oder selbst im Rahmen von Kursen beispielsweise zur Kamm-, Pfeil- oder Schmuckherstellung ihr Können schulen. Mit einem vielfältigen Schul- und Kinderprogramm wurde auch an die jüngeren Besucher gedacht. ${ }^{20}$

Als Begleitmedium gab es neben dem reich bebilderten Ausstellungskatalog, in dem neue Forschungsergebnisse präsentiert wurden, einen Kurzführer, in dem die Stationen der Ausstellung mit ihren bedeutenden Objekten vorgestellt wurden, ergänzt mit zeitgenössischen Zitaten aus mittelalterlichen Handschriften. Statt einer Lehrerhandreichung, wie dies in vorherigen Ausstellungen der Fall war, gab es die Spiele-CDROM „Reise nach Burgund“. ${ }^{21}$

Unkonventionelle Hinweise auf die Landesausstellung gab es im Stadtbereich im öffentlichen Raum auf dem Weg vom Bahnhof zum Domplatz mit fünf „Historischen Haltestellen“: Sumpfgewächse im Kasten, eine Stele mit Kunigundengesängen, die Mitra Benedikts VIII., die Kunigundenschale sowie ein Pilgerbedarfsautomat. Dieses künstlerische Projekt von Rosemarie Zacher ${ }^{22}$ spielte auf vergangene Lebenswelten an und ironisierte zugleich die Gegenwart, indem sie Themen der Landesausstellung in den Kontext des 21. Jahrhunderts transportierte.

„Keine Fußgängerzone ohne Pflanzkübel - aber Morastpflanzen? Musik dudelt überall und unentwegt, aber mittelalterliche Gesänge? Automaten stehen

20 Beim Kindertheater „Heinrich will nicht der Zweite sein“ stand zum Beispiel ebenfalls das Leben Heinrichs im Mittelpunkt. In den großen Sommerferien konnten die Kinder an der Kinderfreizeit „Mittelalterliche Burgfestspiele“ teilnehmen oder unter dem Motto „Mit dem Spielmobil in die Zeit Heinrichs II“ im Aktionsbereich „Kurzweyl“ mit Stelzen, Reifen, Brummkreisel Spiele wie vor tausend Jahren spielen. Auch gab es an zwei Wochenenden beim Mittelalterlichen Gehöft einen Streichelzoo mit jungen Schafen.

21 Darüber hinaus gab es weitere CD-ROM Produktionen. Das „Perikopenbuch Kaiser Heinrich II.“ sowie das „Evangeliar Ottos III.“” wurden als Handschriften zum Blättern in digitalisierter Form herausgebracht. Im Eingangsbereich der Staatsbibliothek konnte virtuell an PC-Stationen darin geblättert werden.

22 Seit 1991 arbeitet Rosemarie Zacher als freischaffende Künstlerin und Buchillustratorin. Ein charakteristisches Merkmal ihrer künstlerischen Arbeiten ist ein heiter-ironischer Grundzug. Seit 1997 entwirft sie museumspädagogische Konzepte für das Haus der Bayerischen Geschichte. 
an allen Ecken, aber gefüllt mit Licht verheißenden Pilgermuscheln? Geld gibt es an jedem Bankautomat, aber gerechten Lohn?‘23

Die „Historischen Haltestellen“ bargen erzählerische Qualitäten. Obgleich sie auf die Zeit um das Jahr 1000 Bezug nahmen, waren sie jedoch nicht mit der Absicht konzipiert über Geschichte zu belehren. Vielmehr sollten sie die Betrachter in ihrer Alltagswahrnehmung irritieren und auf die Landesausstellung aufmerksam machen.

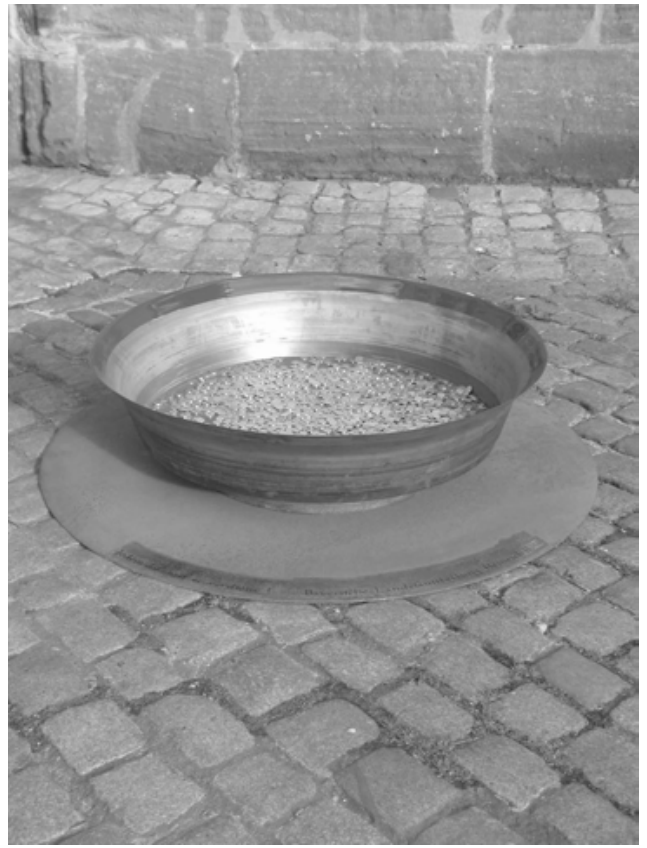

Abbildung 30:

"Historische Haltestellen" von Rosemarie Zacher im öffentlichen Raum vom Bahnhof zum Domplatz in Bamberg, Station Nr. 4 „Kunigundenschale“.

23 Schurr, Eva: Historische Haltestellen. Auf den Spuren Kaiser Heinrichs II. und Kunigundes im Stadtraum Bamberg. Faltblatt zu den Historischen Haltestellen, 2002. 


\section{Das Haus der Bayerischen Geschichte und sein Ausstellungsteam}

Das Haus der Bayerischen Geschichte in Augsburg ist heute eine etablierte und in ganz Bayern wirksame Vermittlungsinstanz für historische Bildung. ${ }^{24}$ Bereits in den Anfängen der Diskussion um das Haus der Bayerischen Geschichte nahm dieses im Hinblick auf konzeptionelle Überlegungen eine Vorreiterrolle in Deutschland ein. ${ }^{25}$ Im Jahr 1965 wurde eine Konzeption ${ }^{26}$ vorgelegt, die Elemente enthielt, wie sie dann später in den siebziger Jahren in der bundesweit geführten Museumsdiskussion „Lernort contra Musentempel“ ${ }^{\text {27 }}$ ebenfalls thematisiert wurden. Dieses Haus sollte in Abgrenzung zur altväterlichen Bildungsanstalt Museum „lebhafter auf seine Besucher einwirken als durch Ausstellung von Erinnerungsstücken; [...] zu intensiverer Beschäftigung auffordern als zu bloßem Durchschreiten; [...] andere Arten des Studiums ermöglichen als reine Betrachtung“. (Bayerische Staatskanzlei 1965, S. 24ff.). In diesem Sinne wurden ehrfurchtgebietende Säle abgelehnt und für eine flexible Innengestaltung und eine kombinierte multimediale Präsentationsweise plädiert. Schaubilder, Modelle, Karten, Reproduktionen, Kopien, aber auch aufgrund ihrer Aura unverzichtbare Originale waren in diesem Konzept ebenso vorgesehen wie filmische und Tondokumente. Das Haus sollte keinesfalls museal sein. ${ }^{28}$ Dies bedeutete, dass der historische Aus-

24 Vollhardt, Ulla-Britta: Geschichtspolitik in Bayern. Das Haus der Bayerischen Geschichte zwischen Privatinitiative und Institutionalisierung. München, 2003. In diesem Buch skizziert Vollhardt die wechselvolle Entstehungsgeschichte des Hauses der Bayerischen Geschichte von den ersten Plänen bis zur formellen Gründung 1978/83.

25 Auch die grundsätzliche Idee zu einem Haus der Geschichte wurde in Bayern bereits in den sechziger Jahren konzipiert und diskutiert, bevor Häuser der Geschichte an anderen Orten wie in Bonn 1994 oder in Stuttgart im Jahr 2002 eröffnet wurden. Glass stellt fest, dass mit Blick auf die Entstehungsgeschichte dieses bayerische Projekt alle wesentlichen Merkmale beinhaltete, die auch für die Konzeption der Nachfolgehäuser maßgeblich waren. Vgl. Glass, Christian: „Aber es soll kein Museum werden.“ Die Häuser der Geschichte in Deutschland. In: Museumskunde. 66. (2001) Heft 1/01 S. 119.

26 Bayerische Staatskanzlei (Hrsg.): Das Haus der Bayerischen Geschichte, München 1965, S. 24ff.

27 Siehe Einleitung, Anm. 19.

28 Vollhardt merkt hierzu an, das es auffällig ist, in welchem Maße der Begriff museal seit Ende der fünfziger Jahre pejorativ konnotiert war. Museal 
sagewert eines Exponats einen Vorrang vor seinem formalen Gehalt als Kunstgegenstand erhielt. Durch bewusste Auswahl von großen Leitgedanken sollte die bayerische Geschichte nicht vordringlich ästhetisch illustriert, sondern demonstriert werden. Die Visualisierung der bayerischen Staatlichkeit und eine besondere didaktische Zielsetzung sollten den besonderen Charakter des Hauses bestimmen (Vollhardt 2003, S. 79).

Nach einer langen und kontroversen Entstehungsgeschichte mit zahlreichen Transformationen kam es 1979/83 zu seiner formellen Gründung. Das Haus der Bayerischen Geschichte hat laut Auszug aus seiner Verordnung die Aufgabe:

„1. die geschichtliche und kulturelle Vielfalt Bayerns in allen Bevölkerungsschichten, vor allem der jungen Generation, in allen Landesteilen zugänglich zu machen. 2. die Gesamtstaatlichkeit Bayerns und die Entwicklung von Staat und Gesellschaft bis zur Gegenwart im historisch-politisch-kulturellen Rahmen darzustellen. 3. das Geschichtsbewußtsein zu fördern und zu pflegen und dadurch das geschichtliche Erbe für die Zukunft des Freistaates Bayern im deutschen und europäischen Rahmen fruchtbar zu machen. ${ }^{\text {“29 }}$

Heute stellt es die Ausstellungs- und Publikationszentrale des Freistaats Bayern dar. Den Schwerpunkt der landesweiten Tätigkeit des Hauses der Bayerischen Geschichte bilden Ausstellungen. In der über zwanzigjährigen Geschichte kann das Haus mittlerweile auf ein vielfältiges Ausstellungsprogramm zurückblicken. Die Kommunikation der Ausstellungsinhalte hat gemäß des Auftrags des Hauses der Bayerischen Geschichte einen sehr hohen Stellenwert. Diese schwierige und anspruchsvolle Aufgabe wird als solche wahrgenommen und spiegelt sich auch im Bewusstsein der Ausstellungsleiter wider. ${ }^{30}$

hieß verstaubt, altväterlich-pädagogisierend, kumulativ-historisch. Vgl. Vollhardt 2003, S. 183, Anm. 277.

29 Auszug aus der Verordnung für das Haus der Bayerischen Geschichte vom 11. Mai 1985, §2.

30 Dieser Gesamteindruck kam bei Gesprächen mit Ausstellungsleitern des Hauses der Bayerischen Geschichte sehr deutlich zum Ausdruck. Sowohl Herr Dr. Wolfgang Jahn (Projektleitung bei der Landesausstellung „Bayern - Ungarn tausend Jahre“ im Oberhausmuseum in Passau im Jahr 2001) wie auch Herr Dr. Josef Kirmeier betonten den hohen Stellenwert des Besuchers und den daraus resultierenden Vermittlungsauftrag. 
„Der Besucher ist sehr wichtig. Nicht nur was die Zahlen betrifft, sondern auch die Resonanz, wie dem Besucher die Ausstellung gefällt, was im Besucherbuch steht. Hier muss man die Sehgewohnheiten und Lesegewohnheiten berücksichtigen, da sich diese immer wieder ändern. Man kann heute Inhalte nicht mehr mit langen Texten vermitteln. Die Leute sind durch alle möglichen Kommunikationsmittel heutiger Zeit SMS-artig gekürzt. Dementsprechend plakativ visuell muss die Information vermittelt werden. “31

Neben einem umfangreichen pädagogischen Begleitprogramm mit Führungen und Museumswerkstatt gehört die didaktische Aufbereitung der Ausstellungsthemen $\mathrm{zu}$ den grundsätzlichen und selbstverständlichen Aufgaben (HdBG 2003, S. 48). ${ }^{32}$ Auf personeller Ebene versucht man diesem Anspruch auch dadurch gerecht zu werden, indem Geschichtslehrer von ihrem Schuldienst freigestellt sind und für einen bestimmten Zeitraum bei Ausstellungsprojekten mitwirken.

Die Projektleitung der Heinrichsausstellung übernahm Herr Dr. Josef Kirmeier. ${ }^{33}$ Zum engeren Ausstellungsteam vom Haus der Bayerischen Geschichte zählten Dipl. Hist. Markus Schütz sowie der Geschichtslehrer Herr Peter Lengle. Verantwortlich für einen museumspädagogischen Kinderpfad im Ausstellungsgelände war Frau Rosemarie Zacher. Darüber hinaus wurde dieses Team von einer Reihe temporärer Mitarbeiter ergänzt. $^{34}$ Die wissenschaftliche Fundierung der Historie leisteten die Professoren Bernd Schneidmüller und Stefan Weinfurter. Frau Dr. Gude Suckale-Redlefsen war für die kunstwissenschaftlichen Inhalte der Ausstellungsteile in der Staatsbibliothek und mehrere Abteilungen im Diözesanmuseum verantwortlich. Die Rekonstruktion des mittelalterlichen Gehöfts basierte auf der Grundlage der wissenschaftlichen Forschungen von Prof. Walter Sage. Prof. Manfred Schuller und Prof. Achim Hubel verantworteten die Erforschung des Heinrichsdoms und die Darstellung für die Ausstellung und den Katalog.

31 Interview mit Herrn Dr. Josef Kirmeier, Projektleitung der Landesausstellung „Kaiser Heinrich II. 1002-1024“ des Hauses der Bayerischen Geschichte, am 17. Oktober 2001.

32 Um den Schulen eine optimale Vorbereitung für den Ausstellungsbesuch im Klassenverband zu ermöglichen, werden in der Regel zu den Landesausstellungen Lehrerhandreichungen erarbeitet.

33 Herr Dr. Josef Kirmeier zählt zu den langjährigen Mitarbeitern am Haus der Bayerischen Geschichte. Seit 1987 beschäftigt er sich mit Ausstellungen und war bei circa 20 Projekten beteiligt.

34 Einen Überblick zum umfangreichen Mitarbeiterstab siehe Kirmeier u.a. 2002, S. 8. 
Die Gestaltung der Ausstellung übernahm die Gruppe Gut. ${ }^{35}$ Mit dieser Ausstellung setzte das Haus der Bayerischen Geschichte die erfolgreiche Zusammenarbeit mit diesem Gestaltungsbüro fort. ${ }^{36}$ Der Schwerpunkt ihrer Gestaltungsaufgaben lag in den Räumen der Alten Hofhaltung, für die sie einen inszenierten Parcours entwickelten. An den weiteren Ausstellungsorten im Diözesanmuseum sowie in der Staatsbibliothek waren aufgrund konservatorischer Bedenken keine umfangreichen, inszenatorischen Eingriffe möglich. Charakteristisch für die Arbeitsweise der Gruppe Gut ist ein ganzheitlicher Ansatz. Das Wohlbefinden der Besucher bildet dabei ein Kriterium, indem die Gestaltung ein angenehmes Raumgefühl erzeugen soll. Durch eine prägnante Raumgestaltung sollen die Besucher ihre Erinnerungen mit Raumerlebnissen verbinden können. Ebenso sollen Verknüpfungen zur persönlichen Erfahrungswelt die Merkfähigkeit der Besucher unterstützen.

„Ich sehe die Ausstellung wie einen Film. Die Leute gehen durch, es muss Höhen und Tiefen geben, vergleichbar einer Partitur. Gleichzeitig werden Emotionen stimuliert, und mit Spannung werden die nächsten Ereignisse erwartet. Es geht nicht nur darum, das einzelne Thema zu interpretieren oder zu inszenieren, sondern der Faden der gesamten Ausstellung ist wichtig.“37

In ihren Entwürfen berücksichtigt die Gruppe Gestaltungsgrundsätze, wie sie in Analogie auch bei Bildkompositionen Anwendung finden. Auf die Stimmigkeit einzelner Innenräume im Detail wird ebenso geachtet wie auf die Atmosphäre des Ausstellungsparcours im Gesamten. Dies bedeutet, Akzente zu setzen, zu verdichten oder aufzulockern. Auch

35 Das Gestaltungsbüro Gruppe Gut mit Sitz in Bozen existiert seit 1990. Die Inhaber Alfons Demetz und Uli Prugger legen ihren Schwerpunkt auf Ausstellungs- und Museumsgestaltung. Sie bieten dabei Komplettlösungen von der Konzepterstellung über die Einrichtungsgestaltung inklusive Inszenierung bis zur Entwicklung von Drehbüchern für Filmspots, Drucksorten und Presse-Präsentationen an. Projekte von Gruppe Gut sind zum Beispiel: Südtiroler Archäologiemuseum (Ötzi) in Bozen 1998, Loden Erlebniswelt in Vintl 2000, „Die Welt von Byzanz“ in der Archäologischen Staatssammlung in München 2004, „Franken im Mittelalter“ in Forchheim 2004.

36 Die Kooperation des Hauses der Bayerischen Geschichte mit der Gruppe Gut begann im Jahr 1999 mit den Planungen für die Landesausstellung „Bayern - Ungarn tausend Jahre“, die im Jahr 2001 stattfand.

37 Interview mit Herrn Uli Prugger, Gestaltungsbüro Gruppe Gut in Bozen, am 8. Juli 2002. 
Leerräume, freie Flächen und Luft fließen dabei in den Gesamteindruck ein. Bei der Anordnung der Objekte im Raum erfolgt dies nicht nach einem symmetrischen Muster, sondern ein ausgewogenes Spannungsverhältnis wird angestrebt. In der konkreten Umsetzung bedeutet dies, dass zum Beispiel eine Vitrine nicht mittig platziert, sondern an den Rand gerückt oder schräg in den Raum positioniert wird. Auch die Charakteristik des zu bespielenden Ortes bildet dabei einen wichtigen Bezugspunkt. ${ }^{38}$

Ein sensibler Umgang in der Farb- und Materialwahl stellt für die Gruppe Gut ein besonderes Anliegen dar. Die Festlegung einer bestimmten Material- und Farbfamilie erfolgt sowohl nach inhaltlichen wie auch symbolischen Kriterien. Eine Goldfolie kann auf erlesene Schätze hinweisen oder eine Vitrinenverschalung mit Kupfer eine Reminiszenz an Kupferhandel darstellen. Auch im Hinblick auf die dramaturgische Komponente einer Gefühlsregie zur Erzeugung von Atmosphäre und Stimmungen spielen Material und Farben eine wichtige Rolle. Ebenso kann die Möglichkeit, damit ein Orientierungsschema für die Besucher zu schaffen, zum Beispiel als thematische Eingrenzung, ein Entscheidungskriterium für eine Farbe sein. Grundsätzlich verfolgt die Gruppe Gut den Leitgedanken, mit möglichst reduzierten und einfachen Mitteln die gewünschte Wirkung zu erzielen.

Auf eine solide, wissenschaftliche Fundierung des Projektes legten die Ausstellungsmacher großen Wert. Dies erschien insbesondere deshalb wichtig, da der Ausstellungsteil, der sich mit dem historischen Umfeld von Heinrich II. befasste, mit nur wenigen musealen Exponaten gestaltet und inszeniert wurde. Bereits im Jahr 1997 begann eine intensive Zusammenarbeit mit Schneidmüller und Weinfurter, deren wissenschaftliches Ausstellungskonzept im September 1999 vorlag. ${ }^{39}$ Dieses stellte eine Konzeption aus der Perspektive der Geschichtswissenschaft dar und verstand sich, wie die Autoren selbst einschränkend bemerkten, „als

38 Zum Beispiel drehten die Gestalter in Passau bei der Ausstellung „Bayern - Ungarn tausend Jahre" den üblichen Museumsparcours um. Gemäß der Idee, dass die Chronologie die Hülle respektieren soll, erschien es der Gruppe Gut sinnvoll, die Ausstellung zur frühen Zeit des Mittelalters im Erdgeschoss in den niedrigen Räumen zu beginnen und im Obergeschoss in den hohen Räumen die späteren Jahrhunderte zu zeigen.

39 Schneidmüller, Bernd/Weinfurter, Stefan: Bayerns Triumph Europas Glanz/Zierde, Kaiser Heinrich II. und sein Reich. Ausstellung des Hauses der Bayerischen Geschichte 2002 in Bamberg, wissenschaftliches Ausstellungskonzept. (unveröffentl. Skript) 1999. 
Diskussionsgrundlage für die weitere Arbeit mit den Sachkennern“ (ebd., S. 4). Innenarchitektonische oder dramaturgische Überlegungen flossen in dieses Konzept nicht mit ein.

„Es entstand eine wunderbare Buchgliederung mit Einleitung, Bibliographie und Exponatangaben. Unsere Aufgabe bestand darin, dieses Konzept in die Räume einzupassen. Dieses Konzept haben wir furchtbar gequält, portioniert und neu strukturiert. Raumgröße und Raumart spielen eine Rolle.““40

Das wissenschaftliche Konzept bildete den Ausgangspunkt zur Erstellung eines zweiten Ausstellungskonzepts, welches dann auf die spezielle, räumliche Situation vor Ort in Bamberg zugeschnitten war. ${ }^{41} \mathrm{Im}$ März 2001 stellte das Haus der Bayerischen Geschichte im Rahmen eines groBen wissenschaftlichen Kolloquiums ${ }^{42}$ diese überarbeitete zweite Version vor. ${ }^{43}$ Im Fachkreis wurden Einzelaspekte diskutiert und abgesichert.

Am Kolloquium ebenfalls beteiligt waren die Gestalter sowie die Museumspädagogin. Dieses Ausstellungskonzept bildete auch die Grundlage für die ersten Raumskizzen: Die Entwürfe wurden mit wenigen Korrekturen so realisiert. Dieses lag, wie die Gestalter feststellten, an dem bereits gut durchdachten Konzept der Wissenschaftler. Grundlegende Eingriffe erfolgten nicht. Die markanteste Veränderung betraf den letzten Raum des Ausstellungsparcours im ehemaligen Marstall der Alten Hofhaltung. Ursprünglich hätten diese fast dreißig ehemaligen Pferdeboxen mit unterschiedlichsten Einzelaspekten zu ausgewählten Themen des Reiches Heinrichs II. gefüllt werden sollen. Die Gestalter kritisierten, dass am Ende des Rundganges die Besucher nicht erneut mit einer Vielzahl kleinteiliger archäologischer Objekte, wie dies zu Beginn

40 Interview mit Herrn Dr. Josef Kirmeier, Projektleitung der Landesausstellung „Kaiser Heinrich II. 1002-1024“ des Hauses der Bayerischen Geschichte, am 17. Oktober 2001.

41 Haus der Bayerischen Geschichte: Landesausstellung Heinrich II., Bamberg, 8. Juli bis 20. Oktober 2002. Konzept: Stand 12.02.01. (unveröffentl. Skript) Augsburg 2001.

42 Dieses Kolloquium fand am 8./9. März 2001 in der Otto-FriedrichUniversität Bamberg statt, veranstaltet vom Haus der Bayerischen Geschichte in Kooperation mit dem Zentrum für Mittelalterstudien der Universität Bamberg.

43 Dieses Vorgehen unterschied sich damit von der oft praktizierten Form, die Vorträge eines Kolloquiums als Ausgangspunkt für die Entwicklung eines Ausstellungskonzeptes zu nehmen und diese Vorträge gesammelt im Katalog zu publizieren. 
des Rundganges bereits der Fall war, konfrontiert werden können, da dies eine Überforderung für den bereits mit vielen Eindrücken angefüllten Besucher sei. So stellt Kirmeier fest, dass der wohl wichtigste Impuls des Kolloquiums eine beiläufige Bemerkung eines Stadtarchivars war, der darauf verwies, dass im Marstall etwas mit Pferden und Reisen gezeigt werden müsste. Damit war die Idee geboren, die vielen Einzelaspekte unter dem Begriff „Reisekönigtum“ zu bündeln.

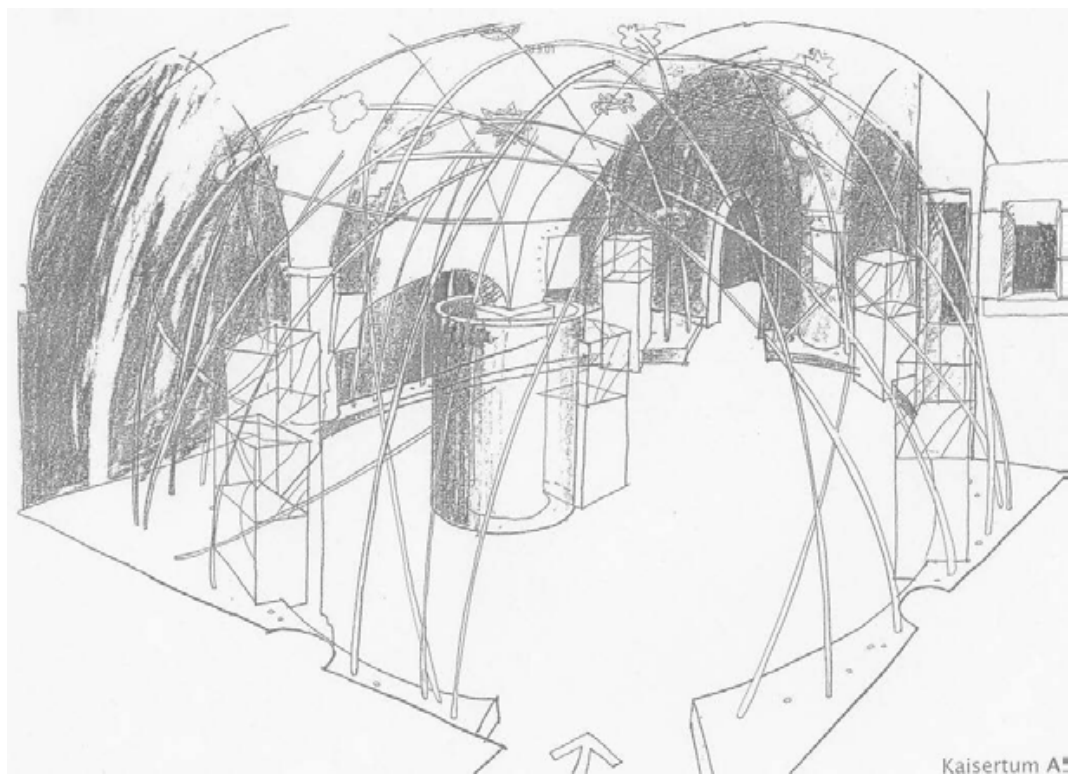

Abbildung 31: Skizze der Gestalter Gruppe Gut des Raumes

„Der Kaiser“, Stand: September 2001.

\section{Ziele und Inhalte der Ausstellung}

Die Geschichte des Herrschers Heinrich II. stand - wie der Titel besagt im Zentrum der Ausstellung. Anhand von Thesen des wissenschaftlichen Konzeptes sowie des Ausstellungskonzeptes soll dargelegt werden, worin die Schwerpunkte der Interpretation und Präsentation lagen. ${ }^{44} \mathrm{Im}$

44 Im Jahr 1996 wurde in Bamberg ein Symposium abgehalten, auf dem Kontroversen um die Person Heinrichs II. und die methodischen Möglichkeiten einer Geschichtsschreibung zur ersten Jahrtausendwende diskutiert wurden. Die Ergebnisse liegen in einem Sammelband vor: Schneidmüller, 
zeitlichen Umkreis des Millenniums fanden weitere bedeutende Großausstellungen zur mittelalterlichen Geschichte, insbesondere zur Zeit der Wende vom ersten zum zweiten Jahrtausend statt. Die bedeutendsten waren die Ausstellungen „Otto der Große, Magdeburg und Europa“45 sowie „Europas Mitte um 1000“46. In Paderborn stand unter dem Titel „Kunigunde - empfange die Krone“ die Frau an der Seite Heinrichs II. im Mittelpunkt. ${ }^{47}$ Diese Ausstellungen waren insofern für die Konzeption der Heinrichsausstellung von Bedeutung, da eine gewisse Konkurrenzsituation gegeben war sowie inhaltliche Überschneidungen zu bedenken waren.

In Abgrenzung zu diesen genannten Ausstellungen betonte das wissenschaftliche Konzept, dass das zentrale Anliegen sich auf Kaiser Heinrich II., Kaiserin Kunigunde, den Wirkverbund im Reich und die europäischen Verflechtungen konzentrieren müsse (Schneidmüller/Weinfurter 1999, S. 7). Dabei sollte jedoch nicht nur die Biographie einer einzelnen Herrscherpersönlichkeit oder die Gründung eines Reichsbistums dargestellt, sondern gleichgewichtig die gesamte Reichsgeschichte am Beginn des zweiten Jahrtausends in den Blick genommen werden. Das Thema Heinrich II. führt zu weiteren Fragestellungen, die politische, kirchliche, soziale, künstlerische und mentale Dimensionen von Vergangenheit hervortreten lassen (ebd., S. 3).

„In die Konzepte und Wirklichkeiten des spätliudolfingischen Kaisertums sind der reichsbezogene Denk- und Aktionsrahmen wie die europäischen Dimensionen der Politik am Beginn des zweiten Jahrtausends einzufügen. Der neue Osten mit Polen, Böhmen und Ungarn gehört ebenso dazu wie traditionelle Westbindungen zu Frankreich und Burgund.“ (ebd. S. 7)

Die Besinnung auf eine solche europäische Weite als Basis des Raumund Zivilisationsbewusstseins in der Zeit Heinrichs II. besitzt nach Ansicht von Schneidmüller/Weinfurter eine besondere Bedeutung für die

Bernd/Weinfurter, Stefan (Hrsg.): Mittelalter Forschungen 1. Sigmaringen, 1997. Die zahlreichen einschlägigen Forschungen sind inzwischen auch in einer Biographie zur Synthese gebracht worden: Weinfurter, Stefan: Heinrich II. (1002 1024) - Herrscher am Ende der Zeiten. Regensburg 1999. Die Ergebnisse dieser Abhandlung flossen in die Konzeption der Ausstellung ein.

45 Siehe Kapitel 5, Anm. 66.

46 Siehe Kapitel 5, Anm. 67.

47 Museum in der Kaiserpfalz vom 24.08.02-13.10.02. Wemhoff, Matthias (Hrsg.): Kunigunde - empfange die Krone. Paderborn 2002. 
historisch politische Bildung der Gegenwart. Die Ausstellung sollte durchaus auf die neuen und wichtigen mittelalterlichen Aktivitäten in Ostmitteleuropa verweisen, aber auch die bleibenden Bindungen an die alten Landschaften im Süden und Westen mit ihrem zivilisatorischen Vorsprung und ihrem herrschaftlichen Legitimationspotential herausarbeiten (ebd., S. 8).

Trotz der historisch-politischen Bedeutung ist Heinrich II. dennoch weit weniger in unserer kollektiven Erinnerung als vergleichsweise Karl der Große, Otto der Große oder Friedrich Barbarossa. Heinrich II. wurde am 6. Mai 973 als ältester Sohn und Nachfolger des bayerischen Herzogs Heinrich des Zänkers geboren. Im Jahr 1002 wählte man ihn als Heinrich II. in Mainz zum ostfränkischen König. Mit der Krönung Heinrichs II. am 7. Juni 1002 wurde erstmals ein bayerischer Herzog König und in der Folge 1014 Kaiser. Obgleich er mächtige Konkurrenten erst von seinem Herrschaftsanspruch überzeugen musste, wurden die zweiundzwanzig Jahre seines Königtums und das Jahrzehnt seiner Kaiserherrschaft zu einem Höhepunkt des mittelalterlichen Reiches: Zusammen mit den Bischöfen und Äbten verhalf er dem Reich zu kultureller Blüte. Auf Synoden und Königstreffen festigte er sein Ansehen als Beschützer der Christenheit. Über das Reich hinaus ist Heinrichs Herrscherzeit mit der endgültigen Einbindung Polens und Ungarns in das christliche Abendland verbunden. ${ }^{48}$

Bereits die zeitgenössische Wertschätzung und auch die der Nachwelt zeigte zwiespältige Züge. Einerseits wird er als großzügiger Stifter herrlicher Kunstwerke verehrt, gleichzeitig wird er aber auch als rücksichtsloser Räuber wertvoller Handschriften für seine Stiftung Bamberg dargestellt. In der Überlieferung zeigt sich eine sehr facettenreiche historische Persönlichkeit:

„Ein Herrscher am Ende der Zeiten, ein Herrscher in der Mitte des Mittelalters, Herzog, König, Kaiser, Heiliger - welch ein Aufstieg!““ [...] Ein strenger Herr, unerbittlich und unnachgiebig auf der einen Seite, Friedensstifter und Diplomat auf der anderen Seite. Er war ein Inszenator seiner von Gott gegebenen Herrscherwürde, der gekonnt auf der Klaviatur der Macht und Selbstdarstellung spielt. Ein König, der sich als Kollege seiner Bischöfe sieht und darum wie selbstverständlich in ihre Belange eingreift. Ein Herrscher, dem nach den Vorstellungen seiner Zeit - Wichtiges versagt bleibt: die Sicherung der Nachfolge durch einen Sohn. Ein Heiliger, dessen gute Werke der Legen-

48 Haus der Bayerischen Geschichte: Landesausstellung Heinrich II., Bamberg, 8. Juli bis 20. Oktober 2002. Konzept: Stand 24.07.01. (unveröffentl. Skript) Augsburg 2001. 
de nach gerade einmal ausreichten, um sein Seelenheil zu retten. Ein Kaiser schließlich, der höchstes Lob auf sich zog: als ,Zierde Europas' wird er auf dem kostbaren Sternenmantel bezeichnet, den ihm der apulische Fürst Ismahel schenkte." (Kirmeier u.a. 2002, S. 11)

Als Integrationsfigur für das Reich, Stütze für das Papsttum, kriegerischer Herr und frommer Gläubiger war er somit eine umstrittene Herrscherpersönlichkeit. Dennoch nahm ihn im Jahr 1146 Papst Eugen III. in die Reihe der anerkannten Heiligen auf. Kaiser Heinrich II. blieb der einzige Herrscher, der heilig gesprochen wurde und mit seiner Gemahlin Kunigunde bis heute verehrt wird.

Ziel der Landesausstellung war es unter anderem, dieses facettenreiche Bild nachzuzeichnen. Man wollte diesen Überlieferungen nachspüren, die durch die Rhetorik des Herrscherlobs und die Kraft der Legende geprägt sind. Die Ausstellung sollte die mittelalterliche Herrscherfigur aus unterschiedlichen Blickwinkeln - aus der Geschichte, der Kunst, der Wissenschaft, der Religion, der Liturgie - beleuchten und lebendig werden lassen. Ebenso wollte die Ausstellung den vielen Exponaten, die gegenwärtig primär als Kunstwerke aufgefasst werden, im Abstand eines Jahrtausends zumindest einen Teil ihrer historischen Aussagekraft zurückgeben (ebd., S. 12). Dazu wurde neben die beiden Schatzkammern und den Bamberger Dom als originären Ort ganz bewusst die historische und archäologische Rekonstruktion gestellt.

Die Ausstellung fand am historischen Ort inmitten baulicher Zeitzeugnisse statt. Die Ausstellung „könnte deshalb nicht sinnreicher und erlebnisnäher untergebracht sein als in den [...] Räumen rund um den Bamberger Dom “49 Sie gliederte sich in fünf Bereiche, die die vorhandenen Möglichkeiten um den Bamberger Dom nutzten. Zwei Schatzkammern zur Buch- und Sakralkunst bildeten einen allgemeinen Schwerpunkt mit Objekten aus der gesamten Herrschaft Heinrichs II. Im Bamberger Dom wurde besonders der Stiftung Heinrichs und dem ersten Dombau nachgegangen. Die thematische Zuspitzung auf spezielle Aspekte der Zeit Heinrichs II. erfolgte in den Räumen der Alten Hofhaltung. Auf dem Domplatz selbst stand ein rekonstruiertes Mittelalterliches Gehöft.

49 Grimm, Claus: Grußwort. In: Kirmeier u.a. 2002, S. 5. 


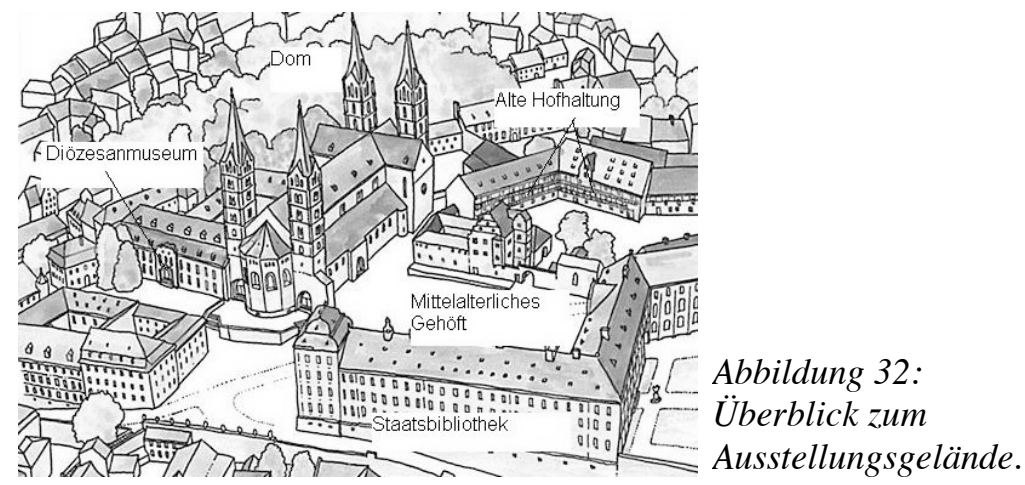

\section{Der Bamberger Dom}

Im Bamberger Dom als authentischem Ort der mittelalterlichen Gedächtniskultur befinden sich die Reliquiare mit den Häuptern Heinrichs II. und Kunigunde. Diese unmittelbaren Zeugnisse des Kaiserpaares werden bis heute verehrt. Das Grab des Kaisers als symbolische Mitte des Doms verkörpert einen Verknüpfungspunkt verschiedener Aspekte wie die religiös-liturgische und die politische Komponente von Reichsherrschaft, Kirchenschutz sowie persönlicher Memoria. Der Rundgang durch den Dom umfasste neben dem Ostchor und der Westkrypta die beiden Ostportale mit den figürlichen Darstellungen des Kaiserpaares, die Adamspforte mit den neuen Abgüssen der originalen Gewändefiguren und die Gnadenpforte mit dem Kaiserpaar neben Maria und Georg als Dompatrone im Tympanon. Im Dom wurde der Weg an jeder Station anhand einer Karte mit Standort erklärt.

\section{Das Mittelalterliche Gehöft}

In augenfälligem Kontrast zur imposanten Kulisse des Bamberger Doms befand sich auf dem Domplatz als größte Inszenierung ein Mittelalterliches Gehöft. Dieses Gehöft, bestehend aus einem Pfosten- und einem Grubenhaus, sollte den Bogen zur Alltagswelt schlagen und eine Ahnung von den Existenzbedingungen der Menschen zur mittelalterlichen Jahrtausendwende geben. Am dritten Objekt eines Steinfundamentshauses wurde während der Ausstellung gebaut. In dem Pfostenhaus mit zwei Räumen hätten angewandte Handwerkstechniken sowie die Wohnverhältnisse des 11. Jahrhunderts verdeutlicht werden sollen. Dieses Pla- 
nungen zur experimentellen Archäologie konnten jedoch so nicht realisiert werden, da zwei Wochen vor Eröffnung der Ausstellung die mittelalterlichen Nachbauten durch Funkenflug beim Schweißen in Brand gesetzt und schwer beschädigt wurden. ${ }^{50}$

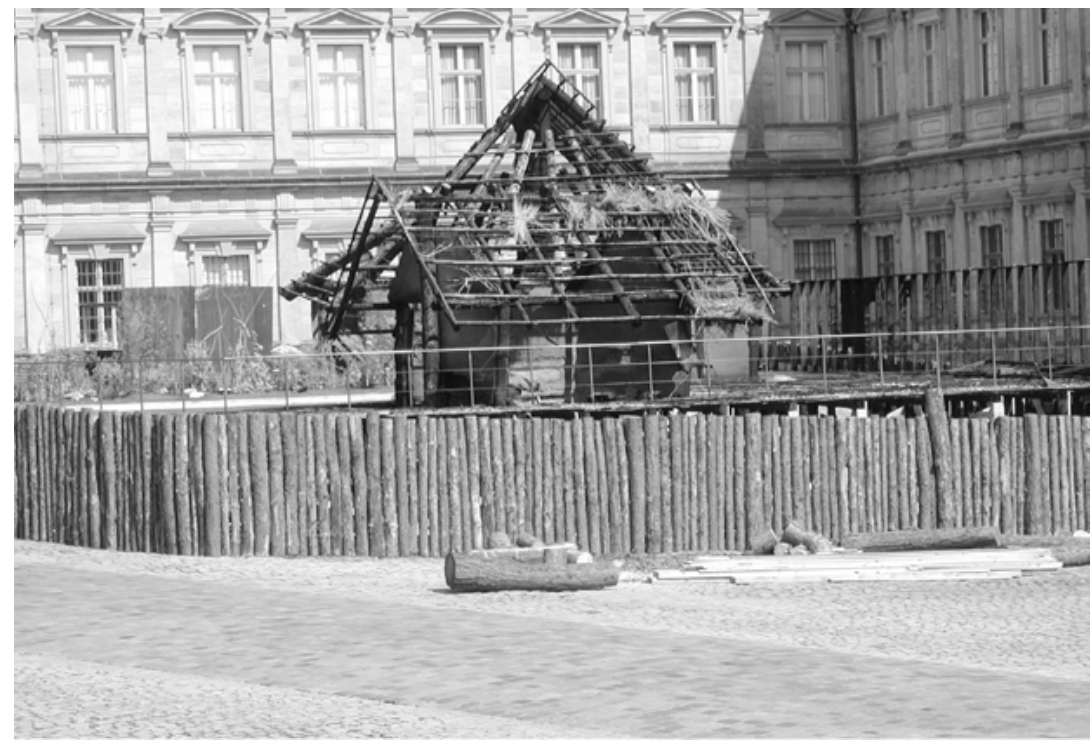

Abbildung 33: Mittelalterliches Gehöft auf dem Domplatz.

Da das mittelalterliche Gehöft jedoch mit der Illustrierung der Alltagswelt im Gesamtkonzept ein wichtiges Pendant zu den Schatzkammern sowie der Alten Hofhaltung gebildet hätte, soll das ursprüngliche Konzept des Gehöfts kurz beschrieben werden

Vom Umgang mit dem lebendigen, universell einsetzbaren Rohstoff Holz hätte in einer Schauwerkstatt die Abteilung Holzhandwerk berichtet, in der verschiedene Handwerke sowie Geräte zur Holzverarbeitung gezeigt worden wären. Der Prozess vom Bergbau über die Verhüttung und Verarbeitung zum Produkt wäre in der Abteilung Erze und Schmiede nachvollzogen worden. Ein dritter Bereich hätte sich dem Thema Beinverarbeitung gewidmet. Als zentraler Teil der Alltagsgeschichte wäre in einer weiteren Abteilung das Thema Textilherstellung von den

50 Fröhling, Stefan/Andreas Reuß: Brand auf dem Domplatz. Gefahr für die Landesausstellung. In: Bayerische Staatszeitung vom 28.06.02. 
Rohmaterialien der Farben und Stoffe über ihre Aufarbeitung und Verarbeitung bis zum fertigen Produkt illustriert worden. Ergänzt worden wären diese Abteilungen mit Rekonstruktionen von mittelalterlichen Handwerkszeugen wie zum Beispiel durch den Nachbau eines Gewichtswebstuhls oder einer Drechseldrehbank. Auch sollte es Objekte zum Anfassen geben, so zum Beispiel ein Trinkhorn sowie weitere während der Ausstellung gefertigte Objekte.

Nach dem Brand entschied die Ausstellungsleitung, die abgebrannten Balken als Mahnmal und realistisches Dokument für die Bedrohung mittelalterlicher Städte durch Feuersbrünste stehen zu lassen. Fast alle dort geplanten Präsentationen und Aktionen mussten kurzfristig umgeplant werden. Ein Gemüsebeet mit alten Getreidesorten, Kräutern und anderen Nutzpflanzen wurde auf dem Podest des abgebrannten Gehöfts verwirklicht. Die Präsentationen zum Holz- und Metallhandwerk sowie zur Beinverarbeitung und Textilherstellung wurden in reduzierter Form in einen Nachbarraum des Eingangsbereichs in der Alten Hofhaltung verlegt.

\section{Staatsbibliothek}

In zwei Ausstellungsräumen der Staatsbibliothek wurden die Bücherschätze, die Buch-Stiftungen von Heinrich II. sowie von Verwandten und Gefolgsleuten Heinrichs II., gezeigt (Räume IX siehe Abb. 34). Es wurde versucht, durch ausgesuchte Miniaturen das Charakteristische einer heinrizischen Kunst herauszuarbeiten. ${ }^{51}$ Neben der weitgehend bekannten Bedeutung Heinrichs II. als Auftraggeber sollte auch seine bisher weniger berücksichtigte Sammelleidenschaft älterer Preziosen berücksichtigt werden.

51 Im Aufsatzkatalog äußert Suckale-Redlefsen ein Unbehagen gegenüber den üblichen Modellen einer durch relativ ortsfeste Klosterwerkstätten getragenen Buchmalerei, mit denen ihrer Meinung nach der Austausch und die Wechselwirkungen kaum befriedigend zu erklären sind. SuckaleRedlefsen stellt die Buchmalerei in den Kontext einer heinrizischen Kunst. Sie verlagert damit die Abhängigkeit aus einem Werkstatt- beziehungsweise Schulzusammenhang in eine konzeptionelle Annäherung an eine Art „Hofkunst“ mit Rezeption verschiedener Werkstätten. Ob diese Thesen von der weiteren Forschung bestätigt werden, wird sich in zukünftigen Studien zeigen. Vgl. Suckale-Redlefsen, Gude: Prachtvolle Bücher zur Zierde der Kirchen. In: Kirmeier u.a. 2002, S. 52-77. 


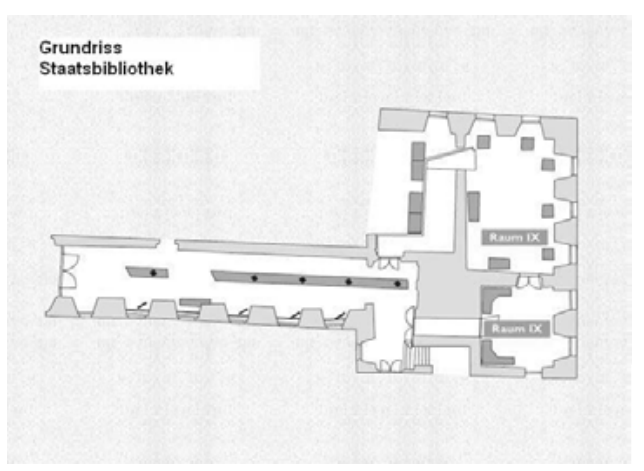

Abbildung 34:

Grundriss Staatsbibliothek.

Die Buch-Stiftungen Heinrichs II. wurden unter drei Schwerpunkten präsentiert. Teile des Bamberger Domschatzes konnten durch Leihgaben aus München sowie durch die Bestände der Bamberger Staatsbibliothek gezeigt und damit die Frühphase einer Hofkunst Heinrichs II. vorgestellt werden. Da das „Regensburger Sakramentar“52 des Bamberger Doms ausgebunden war, bot sich die einmalige Möglichkeit, mehrere Bildseiten nebeneinander und gleichzeitig den kostbaren Einband zu zeigen. Dieser Codex dokumentiert die Frühphase des heinrizischen Stiftungswerkes. Für die darauf folgenden Ausdrucksformen heinrizischer Kunst standen das „Evangeliar“ aus München ${ }^{53}$ sowie die „Bamberger Apoka-

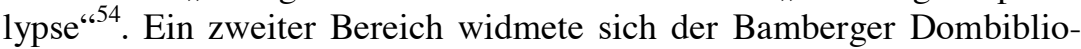
thek, die Heinrich II. einrichten ließ und die von Zeitgenossen als vorbildlich gerühmt wurde. Heinrich, der selbst eine geistliche Bildung genossen hatte, sorgte durch die Gründung der Bamberger Domschule in besonderer Weise für die Ausbildung des hohen Klerus. Neben wissenschaftlichen Lehrbüchern, von denen ein repräsentativer Teil im Diözesanmuseum vorgestellt wurde, gab es in dieser Sammlung illuminierte Kommentarhandschriften, die in der Staatsbibliothek gezeigt wurden. Neben Dom und Domschule bedachte Heinrich II. auch andere Orte mit Buchstiftungen, so zum Beispiel das Kollegiatstift St. Stephan und das Benediktinerkloster St. Michael. Seine besondere Verehrung für das Mutterkloster des Benediktinerordens Montecassino brachte er ebenfalls durch die Stiftung eines kostbaren Evangeliars zum Ausdruck. ${ }^{55}$

52 Kirmeier u.a. S. 268, Nr. 112.

53 Ebd., S. 303, Nr. 135.

54 Ebd. S. 287, Nr. 122.

55 Ebd., S. 275, Nr. 115. 
Unter dem Thema Buch-Stiftungen von Verwandten und Gefolgsleuten Heinrichs II. wurde eine Auswahl von Prunkhandschriften kaisernaher Reichsbischöfe und Äbte gezeigt, die anhand von Miniaturen mit deutlichen Bezügen zu heinrizischen Werken die Ausstrahlung dieser Kunst auf die Buchproduktion des Reiches aufzeigen sollten.

\section{Diözesanmuseum}

In fünf Ausstellungsräumen im Diözesanmuseum versammelte sich die Schatzkunst der Heinrichszeit mit Textilen und sakralen Stiftungen. Goldschmiedearbeiten und Elfenbeinschnitzereien, Handschriften und seidene Gewänder bezeugen den hohen Stand des Kunsthandwerks.

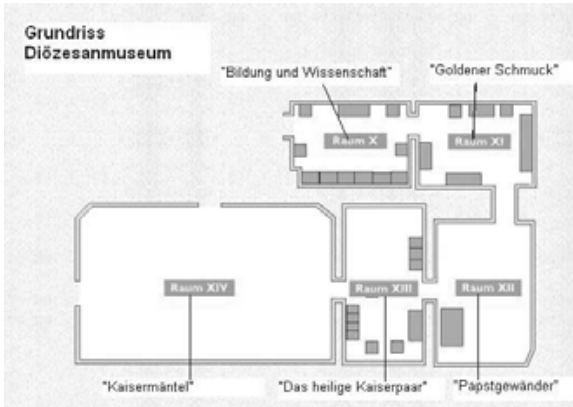

Abbildung 35:

Grundriss Diözesanmuseum.

Der erste Raum widmete sich dem Thema „Bildung und Wissenschaft“ und zeigte Handschriften, die den Grundstock für die neu eingerichtete Bibliothek der Domschule bildeten. Einige dieser Bücher stammten aus der Bibliothek Ottos III. in Piacenza oder von Gerbert von Aurillac. Andere stammten aus Frankreich und Italien. Die Handschriften sollten den geistlichen Bildungshorizont sowie das wissenschaftliche Erkenntnisinteresse Heinrichs II. und seiner Umgebung zeigen.

Der zweite Raum unter dem Titel „Goldener Schmuck“ zeigte den Kirchenschatz Heinrichs II. mit filigranen Elfenbeinschnitzereien, edelsteinbesetzten Kreuzen, Kelchen, reich verzierten Tragaltären und kostbar eingebundenen Handschriften (siehe Abb. 36). An kostbaren Exponaten zu sehen waren zum Beispiel das „Elfenbein mit der Himmelfahrt 
Christi“ ${ }^{* 56}$, der „Wattenbacher Tragalter“57 sowie der „Abtsstab des hl. Godehard“" ${ }^{65}$.

Auch in den Jahrzehnten nach Heinrich II. blieb die Reichskirche eng verbunden mit dem Papsttum, wie im dritten Raum „Papstgewänder“ mit dem Papstornat sowie weiteren Textilien deutlich wurde. Der zweite Bamberger Bischof Suidger wurde 1046 als Clemens II. zum Papst gewählt. In seinem Grab in Bamberg, dessen Inhalt erst im Jahr 1942 geborgen wurde, haben sich bedeutende Textilien erhalten. Eine Untersuchung ergab, dass der Papst in einem vollständigen Ornat bekleidet bestattet worden war. Seidengewebe wie „Pontifikalstrümpfe“"59 oder „Dalmatika“60 blieben nahezu vollständig erhalten, während die Unterkleider aus Seide zerfallen waren.

Dem Kaiser der Kirche war ein vierter Raum „Das heilige Kaiserpaar" gewidmet. Zu den von Heinrich II. erworbenen liturgischen Gegenständen reihten sich Kultobjekte aus der Zeit, als der Kaiser und seine Gemahlin Kunigunde selbst zum Gegenstand der Erinnerung und Verehrung geworden waren, so zum Beispiel die „KaiserpaarMonstranz"61 sowie das „Reliquiar des Hl. Kaisers Heinrich II.“62

Den krönenden Abschluss des Rundgangs durch das Diözesanmuseum bildete der prachtvolle Schatz der Kaisermäntel (siehe Abb. 37). Neben weiteren erlesenen Textilien wie dem „Blauen Kunigundenmantel“63 galt als Höhepunkt des Raumes der „Sternenmantel Kaiser Heinrichs II.“ " ${ }^{64}$ (siehe Abb. 57), den Fürst Ismael aus Apulien dem Kaiser bei seinem Besuch in Bamberg im Jahr 1020 überreichte. Die Stickereien auf dem kostbaren Geschenk aus byzantinischer Seide bilden das Himmelsgewölbe ab und preisen Heinrich als Zierde Europas.

56 Ebd., S. 227, Nr. 169.

57 Ebd., S. 334, Nr. 167.

58 Ebd., S. 328, Nr. 161.

59 Ebd., S. 353, Nr. 182 D.

60 Ebd., S. 352, Nr. 182 B.

61 Ebd., S. 372, Nr. 195.

62 Ebd., S. 364, Nr. 189.

63 Ebd., S. 380, Nr. 202.

64 Ebd., S. 382, Nr. 203. 


\section{Alte Hofhaltung}

In der Alten Hofhaltung spannte sich ein dramaturgischer Bogen, beginnend mit der Darstellung der Lebensumwelt um die Jahrtausendwende über die wichtigsten Etappen der zweiundzwanzigjährigen Regierungszeit Heinrichs II. bis hin zum Vermächtnis des Kaiserpaars und der Erinnerung durch die Nachwelt.

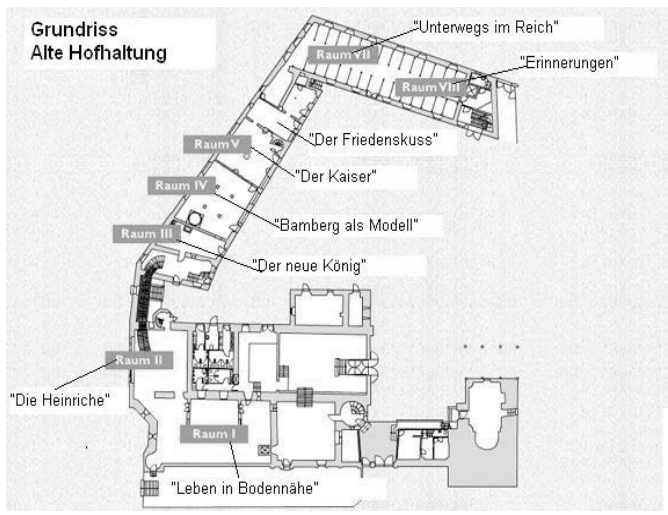

Abbildung 38:

Grundriss Alte Hofhaltung.

Im ersten Teil der Ausstellung wurde unter dem Raumtitel „Leben in Bodennähe" das soziologische Umfeld der Menschen im Mittelalter in Einzelaspekten illustriert. Archäologische Artefakte wie Schmuckstücke oder Kinderspielzeug, der Nachbau einer mittelalterlichen Vorratskammer, Informationen zu Krankheiten, zum Speiseplan und dem Problem begrenzter Konservierungsmöglichkeiten sowie einer Inszenierung zum Abgabensystem sollten den Alltag der Menschen, ihre Bedürfnisse, Ängste und Nöte schlaglichtartig beleuchten.

Im nächsten Raum „Die Heinriche“ wurde das bayerische Herzogtum Heinrichs sowie das seiner gleichnamigen Väter thematisiert. Die mit dem Herzogtum Bayern abgefundenen „Heinriche“ hatten ihren Anspruch auf die Königswürde niemals aufgegeben. Anhand der Stadt Regensburg als urbanes Zentrum zwischen Herzog, Bischof und König wurde vorgeführt, in welchem Rahmen sich das Leben in den großen Bischofssitzen mit ihrer römischen und karolingischen Tradition abspielte - von den Wegen, Waren und Welten des Handels über die Sakrallandschaft einer Bischofsstadt mit ihren Kirchen, Stiften und Pfalzan- 
lagen bis zur herrschaftlichen Repräsentation des Herzogs von Bayern in der Jugendzeit Heinrichs II.

In den anschließenden zwei Krönungsräumen „Der neue König“ wird das Herrschaftsverständnis sowie die Thronbesteigung von Heinrich II. thematisiert. Trotz erheblicher Vorbehalte mancher Fürsten setzte sich der bayerische Liudolfinger durch. Anhand des Reichsumritts, mit dem Heinrich II. in den Anfangsmonaten demonstrativ das gesamte Reich erfasste, wurde an sieben Stationen exemplarisch gezeigt, wie Heinrich seinen Machtanspruch und seine Autorität zur Geltung brachte. Die „Heilige Lanze“ ${ }^{65}$ als das wichtigste Krönungssymbol dieser Zeit wurde 1002 dabei zur zentralen und umkämpften Insignie.

Im Raum „Bamberg als Modell“ wurde am Beispiel der Gründung und Ausgestaltung Bambergs die charakteristische Herrschaft Heinrichs im Verbund mit den fortschrittlichen Organisationsformen der Kirche behandelt und damit die Funktion der Reichskirche vor Augen geführt. Selbst von adeliger Herkunft bildeten Bischöfe und Äbte das einigende Bindeglied zwischen Königtum und Adel.

Dem Kaisertum und Europa war der Raum „Der Kaiser“ gewidmet. Im Jahr 1014 erhielten Heinrich und Kunigunde in Rom von Papst Benedikt VIII. die Kaiserkrone. Mit dieser Krönung veränderte sich der Verantwortungsrahmen Heinrichs II., sein Horizont umfasste fortan Rom, das Papsttum und die benachbarten Reiche Europas. Der neue Anspruch und die Schutzfunktion gegenüber dem Papst führten zu scharfen Auseinandersetzungen mit Byzanz. Von großer Brisanz waren die Beziehungen zu Böhmen.

Der Raum „Der Friedenskuss“ thematisierte den Besuch des Papstes Benedikt VIII. und italienischer Fürsten im Jahr 1020. Damit erreichte im Jahr 1020 Heinrichs Herrschaft ihren Höhepunkt.

Im letzten Raum des Rundganges durch die Alte Hofhaltung im vorderen Bereich stand das Reisekönigtum „Unterwegs im Reich“ im Zentrum der Betrachtung. Für die Geschichtsschreiber der Heinrichszeit war das Reich schwer beschreibbar. Es besaß weder eine Hauptstadt noch feste Grenzen oder eine gemeinsame Sprache. Dennoch war dieses Reich erfahrbar: Heerzüge und Romfahrten, persönliche Kontakte über die verschiedenen Reichsteile hinweg und vor allem das beständige Bereisen dieses Herrschaftsraumes schufen trotz der großen Distanzen und der mühsamen Fortbewegungsmittel einen gemeinsamen Horizont und eine Handlungsebene. In dem permanenten Umritt lag eine große Leistung

65 Ebd., S. 177, Nr. 51. 
des Kaisers für die Integration des Reiches. Einige Facetten und Erfahrungen davon, die durchaus eine Herausforderung für Heinrich II. darstellten, wurden in dieser Abteilung vorgestellt.

Der hintere Bereich des letzten Raumes widmete sich unter dem Titel „Erinnerungen“ Kunigundes und Heinrichs Tod. Legenden rankten sich um das Leben von Heinrich und Kunigunde, die mit den historischen Personen des 11. Jahrhunderts nur wenig zu tun hatten. Zur Wirkung des einzigen heilig gesprochenen Kaiserpaars des Mittelalters gehört neben dem Kult auch eine andere, widersprüchliche Rezeption. Schon im 11. Jahrhundert erschien Heinrichs Kirchenherrschaft in einem zwiespältigen Licht. In der Tradition Joachims von Fiore konnte der Kaiser dann sogar zu einem Kopf der siebenköpfigen apokalyptischen Schlange werden.

\section{Das Präsentations- und Vermittlungskonzept}

Jede Ausstellung muss sich an die örtlichen Gegebenheiten einpassen. In Bamberg zeigte sich eine besondere räumliche Situation, die die Ausstellungsmacher zunächst vor Probleme stellte. Die Innengestaltung der Ausstellungsräume in der Staatsbibliothek durfte nicht verändert und die Vitrinen im Diözesanmuseum konnten nicht verrückt werden. Diese unveränderbare Tatsache hatte Konsequenzen für das Ausstellungskonzept. Es bedeutete, dass an diesen zwei Orten keine umfangreichen räumlichen Veränderungen vorgenommen werden konnten und somit auch keine Inszenierungen möglich waren. Diese strikte Vorgabe sahen die Ausstellungsmacher als Last, aber zugleich als Chance, indem sie eine bewusste Trennung zwischen zwei Schatzkammern einerseits und inszenierten Flächen in der Alten Hofhaltung sowie einem Mittelalterlichen Gehöft andererseits vornahmen.

„Die Einbindung mittelalterlicher Kostbarkeiten, seien es Prunkcodices oder Sakralgegenstände, in historische Erklärungszusammenhänge ist m.E. immer schwierig. Die hier vorgenommene Trennung zwischen museumspädagogischer Präsentation der historischen Ereignisse und der Zeitumstände in der Alten Hofhaltung einerseits und den kunsthistorisch zusammengestellten musealen Präsentation der Schatzstïcke in den beiden Schatzkammern andererseits gibt beiden Komplexen Eigenständigkeit und Würde.“66

66 Kirmeier, Josef: Landesausstellung „Kaiser Heinrich II.“ - Ein Resümee. In: Haus der Bayerischen Geschichte: Expertentagung „Ausstellung und 
Damit wurde eine reine Schatzkammer singulärer Glanzstücke vermieden. Vielmehr stand die Einbindung der präsentierten Prachthandschriften, Goldschmiedekunstwerke sowie einzigartiger Textilien in ihre Entstehungszusammenhänge und ursprüngliche Funktion im Vordergrund. „Der berühmte Sternenmantel Heinrichs II. begegnet nicht nur als Objekt kunsthistorischer Begierde, sondern auch als Zeichen mittelalterlicher Herrschaftspraxis.“ (Kirmeier u.a. 2002, S. 11) Den Besucher aus der Moderne herausholen, ihm die andere Umwelt des Mittelalters bewusst zu machen, war das Ziel des ersten Komplexes mit der Rekonstruktion des Mittelalterlichen Gehöfts sowie der Inszenierung der Lebenswelt Heinrichs II. in der Alten Hofhaltung. Das Mittelalterliche Gehöft mit seinen Nachbauten, Rekonstruktionen und Repliken ohne originale mittelalterliche Exponate legte den Schwerpunkt auf das sinnlich-haptische Erleben. Damit sollte die enorme Spannbreite, in der sich das Leben zwischen Lehmboden und goldbesticktem Seidengewand abspielte, den Besuchern sinnfällig vor Augen geführt werden. Das von der historischen Hofhaltung zum Leben erweckte Dorf hätte damit die Einordnung der Ausstellungsobjekte unterstützt. Aufgrund des Brandes des Mittelalterlichen Gehöfts reduzierte sich diese sinnliche Einstimmung auf die verkohlten Balken. Durch diesen unglücklichen Umstand fiel ein wichtiges Element im Gesamtkonzept der Ausstellung praktisch weg.

Die Rekonstruktion des Mittelalterlichen Gehöfts sowie der inszenierte Parcours durch die Alte Hofhaltung zur Lebenswelt um die Jahrtausendwende und der historischen Person Heinrichs II. mit Modellen und Repliken standen im extremen Gegensatz zur Präsentation in der Staatsbibliothek und dem Diözesanmuseum, die ausschließlich Originale zeigten. In Vitrinen aufgereiht wurden die wertvollen Pretiosen präsentiert. ${ }^{67}$ Aufgrund konservatorischer Bedenken konnten zwei Hauptstücke des Bamberger Domschatzes, das „Perikopenbuch Heinrichs II.“ und das „Evangeliar Ottos III.“, nicht im Original gezeigt werden. So nutzte man die Möglichkeit moderner Technologien. Im öffentlich genutzten Gang im Eingangsbereich der Staatsbibliothek standen in den Fensternischen EDV-Systeme, die den Besuchern ermöglichten, virtuell in den digitalisierten Handschriften zu blättern. An drei PC-Stationen konnten die Be-

Tourismus“ 26.-27.02.03 in Kloster Banz. http://www.hdbg.de/basis/05_ content_shop/content/6000_artikel_downloads/download-dateien/banz_ protokoll.pdf. (letzter Zugriff: 31.01.05).

67 Zum Zeigen der Bücherschätze Heinrichs II. wurden die in der Staatsbibliothek vorhandene Vitrinen genutzt. 
sucher entweder in den zwei genannten Handschriften sowie in der „Bamberger Apocalypse“ schmökern. Da auch im Diözesanmuseum keine umfangreichen baulichen Veränderungen möglich waren, nutzte man die dort vorhandenen Vitrinen. Die Exponate aus dem reichen Bestand des Diözesanmuseums wurden um Leihgaben ergänzt. Da Anzahl und Größe der Exponate nicht das gesamte Vitrinenvolumen beanspruchten, wurden diese durch eine vorgelagerte Verkleidung verborgen, so dass nur die benötigten Ausschnitte sichtbar waren. Ergänzt wurde die Präsentation in jedem Raum durch Raumtexte.

Bei der Vermittlung der Inhalte bediente man sich über Objektbeschriftungen und Raumtexte bzw. Inszenierung hinaus in den verschiedenen Ausstellungsbereichen unterschiedlicher Methoden. Gruppenführungen gab es ausschließlich im Bereich der Alten Hofhaltung. Mit dem Argument, dass bereits die Gestaltung in der Alten Hofhaltung sehr multimedial und anschaulich sei, verzichtete man dort im Gegensatz zum Diözesanmuseum und zur Staatsbibliothek auf einen Audioguide.

Als Angebot für die jüngeren Besucher gab es im gesamten Ausstellungsgelände einen Kinderpfad, der sich mit insgesamt acht Stationen auf die jeweiligen Ausstellungsorte - ausgenommen den Dom - verteilte (siehe Abb. 39). ${ }^{68}$ Den roten Faden dieses Kinderparcours bildete die Idee, als Gefolgsmann Heinrichs II. durch die Ausstellung zu reisen, um auf diesem Weg unterschiedliche Aufgaben zu erfüllen. Die Verknüpfung der einzelnen Stationen erfolgte anhand einer originell, farbenfroh und kindgerecht gestalteten Karte zum Ausfüllen, die die Kinder motivierte, in der Ausstellung selbst aktiv zu werden und auf Suche zu gehen. In der Staatsbibliothek sollten die Kinder den Anfangsbuchstaben ihres Namens in karolingischer Schrift nach einer Vorlage auf die Karte zeichnen. Im Diözesanmuseum stand ein Tisch mit zwölf Stempeln nach Motiven der Sternzeichen aus dem Sternenmantel Heinrichs II. Das eigene Sternzeichen sollte gefunden und auf die Karte gestempelt werden (siehe Abb. 40). Nach Erfüllen der sechs weiteren Aufgaben konnten sie ihren Lohn beim Münzmeister abholen, der - auch als Angebot für Erwachsene - eine Münzprägemaschine betreute.

68 Eine ausführliche Beschreibung des Kinderpfades sowie Hürden bei der Umsetzung siehe: Kaiser Brigitte: Museumspädagogik und Ausstellungsarchitektur. Der Kinderpfad in der Landesausstellung „Heinrich II.“ in Bamberg. In: Museum heute, Fakten - Tendenzen - Hilfen 24. (2002) S. 36-40. 
Die Verteilung auf fünf unterschiedliche Orte machte es außerdem nötig, dem Besucher Hilfestellung zur Orientierung im Ausstellungsgelände zu geben. Einen ersten Überblick erhielten die Besucher durch die Eintrittskarte, auf deren Rückseite eine Graphik mit den fünf Ausstellungsorten abgebildet war. Darüber hinaus waren im Ausstellungsgelände Hinweisschilder und großformatige Stelen verteilt, die jeweils den Eingangsbereich markierten und als Wegweiser eingesetzt wurden.

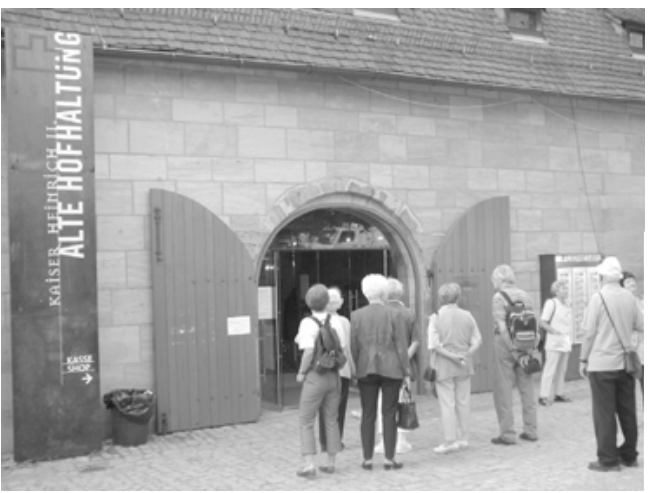

Abbildung 41:

Orientierungshilfen in Form von großformatigen Stelen aus Cortenstahl an den Eingängen der verschiedenen Ausstellungsorte.

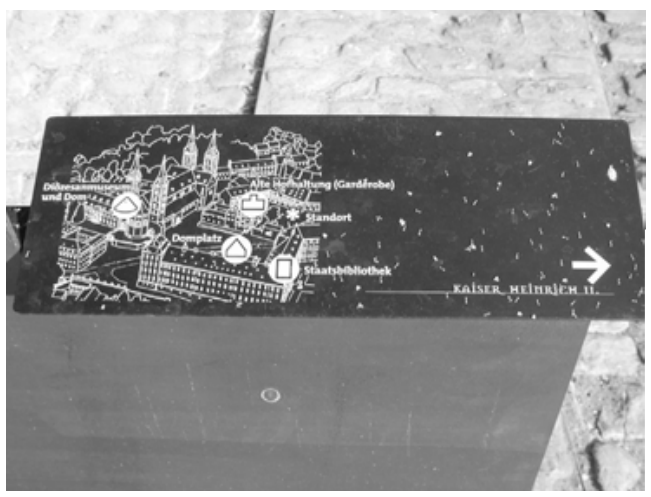

Abbildung 42:

Orientierungshilfen in Form von Hinweistafeln aus Cortenstahl mit Überblicksgraphiken zum Ausstellungsgelände. 


\subsection{Analyse unter den Dimensionen kommunikativer Strategien}

Insbesondere im Bereich der Alten Hofhaltung stand die Kommunikation der Inhalte mittels eines dramaturgisch inszenierten Parcours unter Einsatz einer Vielzahl von Medien im Vordergrund. Aus diesem Grund konzentriert sich die Ausstellungsanalyse auf diesen Teil. Neben Überlegungen grundsätzlicher Art sollen anhand exemplarisch ausgewählter Inszenierungseinheiten, die ausführlicher beschrieben werden, Reflexionen zu den vier Dimensionen kommunikativer Strategien erfolgen. Die Ergebnisse aus den zwei Besucherbefragungen ergänzen diese um einem weiteren Blickwinkel.

\section{Anschaulichkeit}

Ausstellungen als räumliche Organisation in einem vorgegebenen Gebäude stellen in besonderem Maße Anforderungen an die gestalterische Umsetzung. Diese haben die Aufgabe, nicht nur den Exponaten einen adäquaten Rahmen zu bieten, sondern die komplexen Inhalte anschaulich und begreifbar zu machen. Neben der Vermittlung durch Texte lässt die Gestaltung eine Ausstellung sinnlich erfahrbar werden. In der Alten Hofhaltung griffen die Ausstellungsmacher auf eine umfangreiche $\mathrm{Pa}-$ lette inszenatorischer sowie didaktischer Möglichkeiten zurück.

Die Architektur der Alten Hofhaltung zeichnet sich durch eine starke Eigencharakteristik aus. Die historischen Gemäuer stammen von unterschiedlichen Bauphasen vom 11. bis ins 19. Jahrhundert. ${ }^{69}$ Allein diese Tatsache bewirkte, dass jeder Raum eine eigene Wirkung entfaltete. Diese Eigencharakteristik der Räume griffen die Gestalter entweder auf oder drängten sie mit der Intention zurück, für jede thematische Einheit ein einprägsames Raumbild zu schaffen.

„Aus der Besucherforschung wurde klar, dass sich Besucher nur in sehr geringem Teil an Ausstellungsobjekte erinnern können. Aus diesem Grund arbeiten wir insbesondere in der Alten Hofhaltung mit visuellen Eindrücken.“ ${ }^{\text {70 }}$

69 Burandt, Walter: Die alte Hofhaltung in Bamberg: Kaiserpfalz und Bischofspfalz. Bamberg, 1999.

70 Interview mit Herrn Dr. Josef Kirmeier, Projektleitung der Landesausstellung „Kaiser Heinrich II. 1002-1024“ des Hauses der Bayerischen Geschichte, am 17. Oktober 2001. 
Die einzelnen Räumen standen nicht singulär nebeneinander, sondern entfalteten Bezüge über mehrere Räume hinweg. So wurden zum Beispiel die archäologischen Fundstücke nicht auf unterschiedlichen Ebenen frei in einer Vitrine, sondern in Bauchhöhe auf einer Ebene liegend gezeigt. Diese Höhe griff ein stilisiertes Landschaftsmodell auf und stellte damit fiktiv über mehrere Räume hinweg eine Verbindung her. Auch inhaltlich sollte dies den Bezug zum erdenhaften Dasein der damaligen Menschen assoziieren. Dies wiederum nahm Bezug auf ein lateinisches Zitat „Prospica Terrigenas“, welches sich als Teil einer Inschrift auf dem „Basler Antependium“" ${ }^{\text {"B }}$ befindet. Zugleich diente dieses Zitatfragment auch als Raumtitel „Prospica Terrigenas - Achte auf die Erdgeborenen“, das ebenfalls auf Bauchhöhe an der Eingangswand des ersten Ausstellungsraumes angebracht war. Dieser erdenhafte Bezug wurde erneut im Bereich „Der neue König“ aufgegriffen. Auch dort sollten die amorph geschwungenen Vitrinen und deren Einkerbungen auf der Vitrinenoberfläche Landschaft und Wege assoziieren. Damit durchschritten die Besucher erneut fiktiv die Erde. ${ }^{72}$

Trotz der einerseits akzentuierten innenarchitektonischen Gestaltung, die jedem Raum seine eigene Prägung verlieh, gab es andererseits kontinuierliche Strukturen, die sich im gesamten Ausstellungsparcours in jedem Raum wiederfanden und dem Besucher damit einen übergeordneten Orientierungsrahmen gaben.

Zur ersten thematischen Einordnung des Raumes gab es auf schriftlicher Ebene zwei Hinweise. Zum einen erfolgte dies durch die Titel der Raumtexte, die sich an den PC-Informationsystemen befanden. Einen zweiten inhaltlichen Verweis gaben Titel in lateinischer Sprache, die in die Raumgestaltung eingebunden waren, sich meist an den Vitrinen auf Bauchhöhe befanden und somit zum Teil erst auf den zweiten Blick bei genauerer Betrachtung entdeckt werden konnten.

$\mathrm{Zu}$ jeder Raumeinheit standen PC-Informationssysteme als Infopools zur Verfügung. Diese waren eine Kombination aus einer Leuchtgraphik als Raumtext sowie einer PC-Station. Die Leuchtgraphik beinhaltete drei Spalten mit circa zehn bis höchstens zwanzig Zeilen für den deutschen und englischen Text sowie eine Nebenspalte mit Platz für eine ergänzende Illustration in Form einer Karte, eines Zitats oder eines Bildes. Über diese Grundinformationen hinaus konnten die Besucher anhand dieser PC-Station weitere Informationen zu ausgewählten Objekten abrufen.

71 Kirmeier 2002, S. 130ff., Nr. 11.

72 Beschreibung der Räume "Der neue König" siehe Kapitel 6, S. $334 f$. 
Neben inhaltlichen Erläuterungen zu den Exponaten stellte dieses Medium einen Überblick zum gesamten Ausstellungsgelände sowie Grundrisse zu den einzelnen Ausstellungsräumen zu Verfügung. Damit konnten sich Besucher eine Orientierung im gesamten Ausstellungsgelände sowie jeweils in den Ausstellungsräumen verschaffen. ${ }^{73}$

„Wir wollten keine Raumtexte an die Wand hängen, sondern wie am Bahnhof einen Informationspunkt, so dass sich die Besucher hier ihre Informationen selbst abholen können. Ein weiterer Beweggrund dafür war, die Moderne auf diese Weise zu integrieren und den Bezug zum Heute zu schaffen. Dies steuert gegen eine historisch schwerfällige Ausstellung. “74

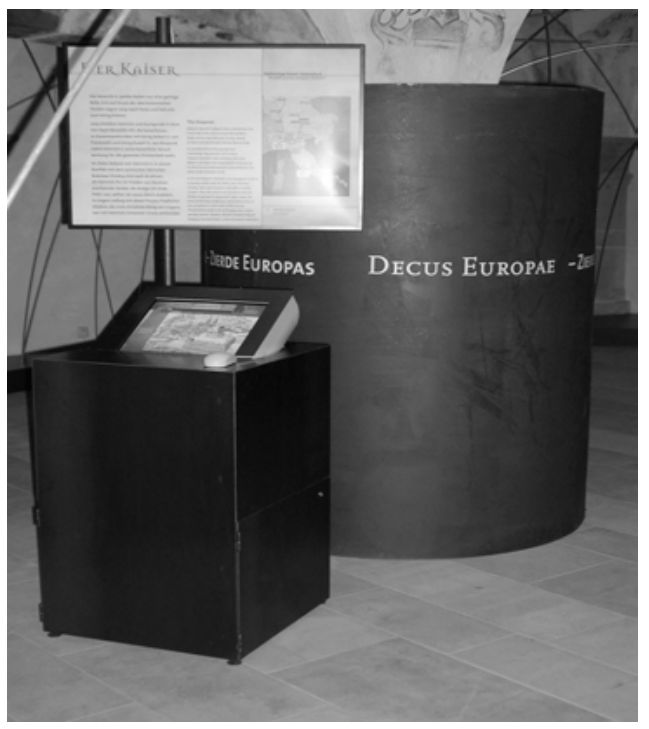

Abbildung 43:

PC-Informationssystem mit

Leuchtgraphik als Raumtext.

Neben den Raumtexten gab es weitere, zum Teil verdeckte Informationsebenen, die für das Verständnis des roten Fadens der Ausstellungsinhalte unbedeutsam waren, jedoch dem Interessierten eine Vertiefung ermöglichen sollten.

73 Diese Informationen stehen dem Publikum weiterhin auf einer Homepage zur Verfügung: http://www.heinrichII.de (letzter Zugriff: 12.01.05).

74 Interview mit Herrn Uli Prugger, Gestaltungsbüro Gruppe Gut in Bozen, am 8. Juli 2002. 


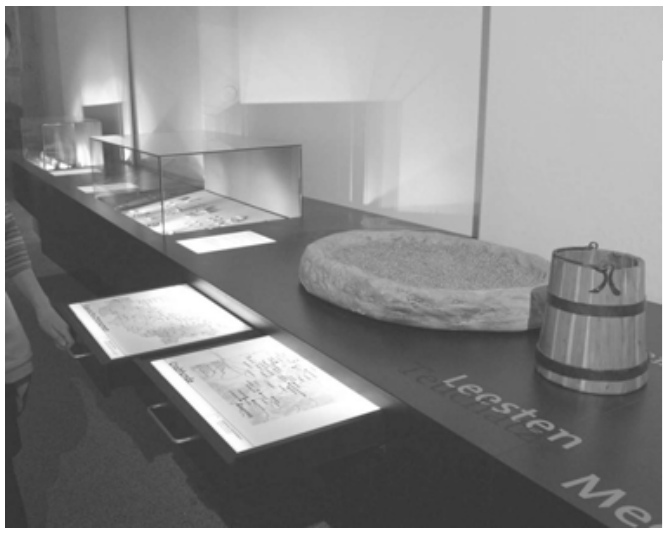

Abbildung 44:

Versteckte zweite Ebene mit Informationen:

Im Raum „Leben in

Bodennähe" befanden sich im Vitrinenunterbau zwei Schubläden. Ergänzend zu den archäologischen Exponaten enthielten diese Karten zu den slawischen Fundorten.

Die Vitrinen traten nicht dominant in den Vordergrund, sondern waren in das innenarchitektonische Gestaltungskonzept integriert. Statt Standardformen oder -größen waren sie den jeweiligen Ausstellungsobjekten angepasst. Im Wesentlichen gab es drei unterschiedliche Formen. Die individuell den Objektmaßen angepassten Wandvitrinen waren bündig in die Wandvorbauten integriert. Die Tischvitrinen bildeten geradlinige, kubusartige Formen mit meist schwarzer Verkleidung des Sockels, in deren Oberfläche die Glasquader der Vitrinen integriert waren und deren Böden unter die Oberfläche des Sockels versenkt waren. Die Raumvitrinen setzten sich aus einem schwarzen Unterbau und einem schlichten Glaskubus zusammen. Die Sockel für Großobjekte wie zum Beispiel für das „Basler Antependium“ glichen denen der Raumvitrinen.

Für die Objektbeschriftungen wählten die Veranstalter zwei Formen. Entweder lag direkt in der Vitrine zum Objekt benachbart ein Plexiglastäfelchen mit weißer Schrift oder die Beschriftung befand sich in der Nähe der Vitrine oder des Objekts als hinterleuchtete Graphik. Inhaltlich waren sie einheitlich gestaltet. In der ersten Zeile stand eine Nummer, die mit der Zahl im Katalog identisch war und der Titel des Objekts. Als nächstes folgten die objektbezogenen Informationen mit Angaben zu Datierung, Material sowie Leihgeber. Als drittes gab es in durchschnittlich vier Zeilen Kontextinformation, die zum inhaltlichen Verständnis beitrug. 


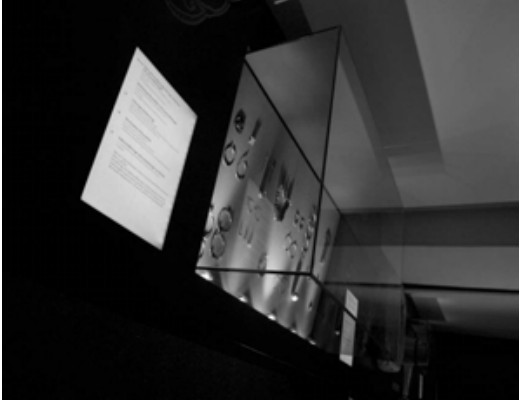

Abbildung 45: Beschriftung mit Leuchtgraphik.

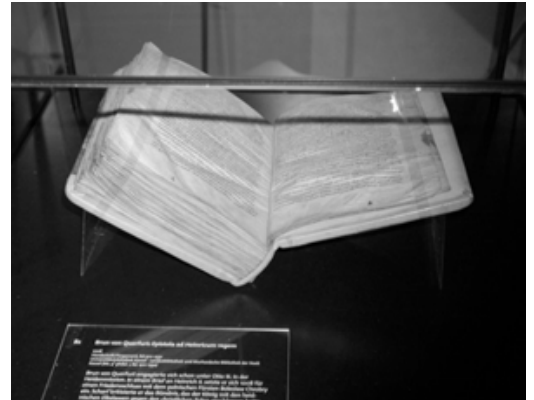

Abbildung 46: Beschriftung mit Plexiglastäfelchen in weißer Schrift.

Beim Werkstoff setzten die Gestalter auf einfache, aber gezielt ausgewählte Materialien: ungehobelte Bretter, schwarzes und braunes $\mathrm{MDF}^{75}$ sowie angerosteter Cortenstahl. Neben wenigen weiteren Farben und Stoffen bestimmten diese drei Hauptmaterialien die Farbigkeit der gesamten Ausstellung und dienten auch als Leitsystem. ${ }^{76}$ Mit den ungehobelten Brettern sollte ein Bezug zur Einfachheit der damaligen Lebenswelt in Analogie zur Rekonstruktion des Mittelalterlichen Gehöfts assoziiert werden. Der vorgerostete Stahl entsprach nach Ansicht der Gestalter dem ambivalenten Charakter Heinrichs II. als streng Gläubigem und gleichzeitig machtbewusstem Politiker, da auch dieses Material zwei konträre Eigenschaften birgt.

„Der Cortenstahl hat ebenfalls eine innere Wärme. Dieses Material ist aber auch hart und kalt, symbolisch passt dies gut zur Persönlichkeit Heinrichs II., der in den Archivalien als durchaus ambivalente Persönlichkeit dargestellt wird. [...] Es ist kein Fremdmaterial wie eine Inoxstahlplatte.“"77

75 MDF ist die Abkürzung für mitteldichte Faserplatte. Dieser Holzwerkstoff hat in alle Richtungen ein homogenes Gefüge. Die Holzfasern werden wie eine dicke Pappe zu einer Platte gepresst. MDF-Platten haben eine besonders feine Oberfläche. Die Platten werden oft farbig lackiert und im Möbelbau, im Innenausbau oder als Paneele verwendet.

76 Dies steht im Gegensatz zu einer oft praktizierten Variante, bei der Farben Themen zugeordnet werden, um inhaltliche Abgrenzungen zu markieren.

77 Interview mit Herrn Uli Prugger, Gestaltungsbüro Gruppe Gut in Bozen, am 8. Juli 2002. 
Eingangsinszenierung: „Bamberger Götzen“ in Gegenüberstellung zum „Basler Antependium“ (siehe Abb. 47)

Der erste Eindruck im Ausstellungsparcours durch die Alte Hofhaltung wurde durch die Eingangsinszenierung bestimmt. Sie zeigte eine mit blauem Licht angestrahlte „Gruppe Antropomorpher Steinfiguren“78 ${ }^{\text {“78 }}$ die auch als „Bamberger Götzen“ bezeichnet werden. Diese befanden sich auf einer Anschüttung von Steinen in Gegenüberstellung zu einer Kopie des „Basler Antependiums“ am Ende der Raumflucht. Das blaue Licht sollte den Fundort im Wasser sowie den Wasserkult andeuten. Die rechte Wandseite war mit wilden gestischen Spuren in rot, braun und weißer Farbigkeit bemalt. Inhaltlich sollte damit das primitive, unzivilisierte Dasein und auch der Kontrast zwischen heidnischer und christlicher Welt angedeutet werden. Eine in diese bemalten Wand eingelassene Vitrine zeigte Kleinobjekte zu christlichen und heidnischen Glaubenswelten.

Das Original des „Basler Antependiums“ stellt ein einzigartiges, höchst kostbares Kunstwerk dar. Durch die Art der Präsentation - ungeschützt ohne Sicherheits- und Klimavitrine, vom Besucher lediglich durch eine Holzrampe abgeschirmt - gingen die Ausstellungsmacher davon aus, dass dies neben einem Hinweis in der Objektbeschriftung den Besuchern deutlich mache, dass es sich hierbei nicht um das Original handeln könne. ${ }^{79}$

An dieser Inszenierung traten die konkurrierenden Erfahrungsformen von historischer und ästhetischer Erfahrung zutage. Als inhaltliche Einführung sollte sie einen Spannungsbogen zwischen der noch kultisch,

78 Kirmeier u.a. 2002, S. 127ff., Nr. 10.

79 Im Hinblick auf die Fähigkeit der Unterscheidung zwischen Replik und Original stellte Herr Prof. Schemmel, Direktor der Staatsbibliothek Bamberg, aufgrund seiner eigenen Erfahrungen ernüchtert fest, dass die meisten Menschen ein Faksimile von einem Original in ihrer Wertschätzung nicht unterscheiden konnten. Dabei verweist er auf ein Erlebnis, welches er im Zusammenhang mit der Präsentation eines Faksimiles einer Handschrift von Heinrich den Löwen hatte. Mit Erstaunen, Bewunderung und großer Resonanz hatte das Publikum aufgrund von Medieninformationen wahrgenommen, dass in der Staatsbibliothek dieses ausgestellt sei. Ein Faksimile mit einem Wert von lediglich circa 15000 Euro steht jedoch in keinem Verhältnis zum Original, mit einem schätzbaren Wert von circa 15 Millionen Euro. Vgl. Interview mit Herrn Prof. Dr. Bernhard Schemmel, Direktor der Staatsbibliothek Bamberg, am 20. Nov. 2001. 
heidnisch geprägten Welt der einfachen Menschen und der kunsthandwerklich hochrangigen, glanzvollen christlichen Sakralkunst bilden. Durch die Art der Präsentation erfolgte indirekt eine Bewertung, die auch die dementsprechende Wertzuschreibung bestimmte. Das Gold der Replik erstrahlte im hellen Licht. Demgegenüber traten die amorphen Steinfiguren angestrahlt mit blauem Licht in den Hintergrund und erfüllten eine hinführende Funktion. Die Replik erfuhr damit einen höheren Stellenwert als das Original. „Die Objekte könnten ebenso aus Pappmache oder Gips sein, wie das Basler Antependium. Dies wirkt ebenfalls sehr prächtig. Zwischen Original und Replik wird nicht unterschieden." ${ }^{\text {" } 0}$

Die „Gruppe Anthropomorpher Steinfiguren“ bildet eines der Glanzstücke der Sammlung des Historischen Museums in Bamberg (siehe Abb. 48). Die Figuren mit kaum erkennbaren Gesichtern und durch Rillen und Wülste angedeuteten Gewändern wurden 1858 aus der Regnitz geborgen. Die Schätzung des Alters reicht von der Jungsteinzeit bis in das erste Jahrtausend nach Christus. Die Bandbreite der Deutungen zu diesen Figuren ist groß. Sie geht von heidnischen Götzendarstellungen bis zu frühchristlichen Glaubenszeugnissen. Nach aktueller Forschungslage wird, wie im Katalog dargestellt, eine Deutung als heidnische Kultobjekte in Frage gestellt und stattdessen eine Interpretation der Steinfiguren als frühe, christliche Bildzeugnisse von Bischöfen favorisiert.

„[...] Vergleiche mit Kult- oder Grabstelen aus dem steppennomadischen wie auch slawischen Milieu [sind, Anm. d. V.] schlecht möglich, wo Figurengruppen kaum nachzuweisen sind und die Gottheit, zumindest im westslawischen Bereich, in der Einzahl verehrt wurde. Dagegen ist für die christliche Bildsymbolik die Darstellung von Personengruppen nicht ungewöhnlich.““81

Trotz der Unzulänglichkeit aller Interpretationsversuche im Hinblick auf die Frage, ob es sich bei diesen Objekten um Zeugen christlicher oder heidnischer Glaubensvorstellungen handelt, sind diese Figuren einzigartige Zeugnisse früher Religionsvorstellungen. Die Einmaligkeit dieser Exponate wurde in dieser Aufstellung nicht zur Geltung gebracht. Auch eine Objektbeschriftung, die auf diesen Sachverhalt aufmerksam machte,

80 Interview mit Frau Dr. Regina Hanemann, Direktorin der Museen in Bamberg, am 2. Sept. 2002.

81 Haberstroh, Jochen: Gruppe Anthropomorpher Steinfiguren - Die Bamberger Götzen - ein Zeugnis vorchristlicher Kultvorstellungen? In: Kirmeier u.a. 2002, S. 129. 
genügt nach Ansicht von Hanemann, Direktorin des Historischen Museums, nicht. ${ }^{82}$ Um der historischen Bedeutung entsprechend gerecht zu werden, hätten die Exponate in einer anderen Form präsentiert werden müssen: beispielsweise zentral in den Raum gerückt, auf Sockeln hinter Vitrinenglas präsentiert und lichtdramaturgisch anders in Szene gesetzt.

Ein derartige Präsentationsform hätte jedoch wiederum nicht in das dramaturgische Gesamtkonzept der Ausstellung gepasst, in der es nicht darum ging, die Einzigartigkeit von Exponaten in den Vordergrund $\mathrm{zu}$ rücken. Vielmehr wurde den erzählerischen Qualitäten der Objekte ein höherer Stellenwert eingeräumt. Das Anliegen des ersten Raumes in der Alten Hofhaltung bestand darin, die Lebensumwelten um die Jahrtausendwende in ausgewählten Einzelaspekten zu illustrieren. Eine ähnliche Diskrepanz zwischen der historischen Bedeutung des Exponats sowie der Art der Präsentation zeigte sich auch am Ende des Rundganges durch die Alte Hofhaltung im letzten Ausstellungsraum, dem ehemaligen Marstall.

Der Raum: „Unterwegs im Reich“ (siehe Abb. 49), Koje „Der Sarkophagtrog aus dem Bamberger Dom“ (siehe Abb. 50)

Inhaltlich untergliederte sich dieser Raum in zwei Bereiche. Die vorderen acht gegenüberliegenden Kojen gehörten zum Thema Reisekönigtum. Der hintere Bereich widmete sich dem Andenken an das Herrscherpaar und der Legendenbildung. Die heutige Architektur ist auf das Jahr 1740 zurückzuführen. ${ }^{83}$ Zur Verdeckung der barocken Architektur installierten die Gestalter an die Decke Bandeisen, an denen weiße und graue Stoffbahnen hingen. Damit wurde die barocke Formensprache der Architektur, die nicht zur mittelalterlichen Thematik passte, verdeckt. Der Kojencharakter selbst blieb dadurch jedoch erhalten. Gleichzeitig diente dieser Vorhang als Träger für Hintergrundinformationen in Form von Texten und Graphiken. Das Erscheinungsbild im Marstall wurde somit durch eine serielle Aneinanderreihung der ehemaligen Pferdeboxen geprägt, die unterschiedlich mit in Vitrinen präsentierten Archiva-

82 Interview mit Frau Dr. Regina Hanemann, Direktorin der Museen in Bamberg, am 2. Sept. 2002.

83 Die Pferdeboxen des heutigen Marstalles mit ihren Arkadenbögen nehmen Bezug auf die barocke Eingangstür, über die mehrere Jahreszahlen gemalt sind, unter anderem das Jahr 1740. Eine dendrochronologische Untersuchung bestätigte diese Jahreszahl als Erbauungszeit des Stalles. Vgl. Burandt 1999, S. $61 \mathrm{ff}$. 
lien oder musealen Exponaten, PC-Stationen, Hands-on Objekten oder Inszenierungen bestückt waren. Im dramaturgischen Konzept bildete der Marstall einen abschließenden Höhepunkt mit einem abwechslungsreichen Angebot zum Sehen, Hören und Anfassen. Entgegen der sogenannten Ausstellungsmüdigkeit sollte die Vielfalt dieses Angebots die Leute nochmals in ihrer Aufmerksamkeit wachrütteln.

Eingereiht in dieses Konglomerat unterschiedlichster Exponate sowie Präsentationsformen befand sich in einer Koje im Marstall der „Sarkophagtrog aus dem Bamberger Dom“" ${ }^{* 4}$. Dieses Ausstellungsstück zählte zu den herausragenden Objekten in der Alten Hofhaltung. In der Nachbarschaft zu Hands-on Objekten und Medienstationen wurde es jedoch in seiner Besonderheit marginalisiert.

Die Eingangsinszenierung sowie die Präsentation des Sarkophagtrogs bilden zwei Beispiele für den Wahrnehmungskonflikt zwischen historischer und ästhetischer Erfahrung. Das Ansprechen unterschiedlicher Sinne und die abwechslungsreiche Präsentation lässt sich aus dramaturgischen Überlegungen einer besucherorientierten Perspektive rechtfertigen. Der Einsatz von Repliken sowie die illustrative Nutzung der Objekte entsprach im Bereich der Alten Hofhaltung den Zielen der Ausstellungsmacher:

„Die historische Ausstellung sieht ihre Aufgabe darin, die Objekte in dieser Form zu nutzen. Die kunsthistorische Ausstellung würde andere Perspektiven haben. Sie würde die Reichenauer Buchmalerei vergleichen. Sie würde diese jedoch nicht in den Kontext eines Herrschers und seiner Lebensverhältnisse stellen. ${ }^{85}$

Die Dramaturgie des narrativen Ansatzes erhielt einen höheren Stellenwert als die Einzigartigkeit der Exponate. Das Ziel der Ausstellungsmacher bestand in der Alten Hofhaltung darin, die Lebenswelt um die Jahrtausendwende anhand von inszenierten Raumbildern zu illustrieren. Dieses Anliegen lag höher als die Betonung der Kostbarkeit der Exponate. Aus der Perspektive der Ausstellungsmacher und im Hinblick auf

84 Kirmeier u.a., 2002, S. 256ff., Nr. 103. Die Zuschreibung des 1969/72 gefundenen Sarkophags an Heinrich II., Kunigunde oder anderen Würdenträgern ist bis heute offen, formal lässt er sich einer ottonisch-romanischen Oberschichtbestattung zuweisen.

85 Interview mit Herrn Dr. Josef Kirmeier, Projektleitung der Landesausstellung „Kaiser Heinrich II. 1002-1024“ des Hauses der Bayerischen Geschichte, am 17. Oktober 2001. 
die für die Alte Hofhaltung formulierten Vermittlungsziele kann deshalb diese Form der Präsentation gerechtfertigt werden.

Demgegenüber bestand das Ziel der Präsentation im Diözesanmuseum, die Pretiosen der Ausstellung ihrem hohen Wert entsprechend im Stile einer Schatzkammer zu zeigen. Allerdings wurde die Präsentation im Diözesanmuseum nur bedingt diesem Anliegen gerecht. Die äußerst hochrangigen Exponate wurden nebeneinander aufgereiht präsentiert (siehe Abb. 36). Damit entstand ein serieller Charakter, der eine Sakralisierungen und Auratisierung der Objekte behinderte. „Wenn ich alles auf einen Sockel stelle, mache ich es gleichwertig. ${ }^{\text {" }} 6$ Obgleich in diesem Fall nicht die Gefahr der Verwechslung mit einer Replik bestand, wurde die Kostbarkeit der Exponate nicht in vollem Maße zur Wirkung gebracht. Vergleichsweise sinnvoll wäre eine aneinanderreihende Präsentation von musealen Exponaten, wenn diese auch in ihrem historischen Kontext nichts Exklusives, sondern Massenprodukte waren. ${ }^{87}$

In diesem Zusammenhang verweist Hanemann auf die Präsentation des Teppichs von Bayeux. ${ }^{88}$ Erst nachdem die Besucher in Bayeux einen langen Informationsparcours mit Texten und Filmen durchschritten haben, werden sie zum Höhepunkt, dem originalen Teppich, vorgelassen. „Am Ende schaut man diesen Teppich wirklich ehrfürchtig an, man hat alles darüber gelernt." Die Präsentation des Teppichs von Bayeux erfüllt konservatorische Anforderung und dennoch wird das Erlebnis dieses Teppichs besucherorientiert inszeniert. Auch die Kaisermäntel des Diözesanmuseums böten hier nach Ansicht Hanemanns reichhaltiges Potential. $^{89}$

86 Interview mit Herrn Kurt Ranger, Büro Kurt Ranger Design in Stuttgart, am 20. März 2002.

87 Beispielsweise trifft dies auf viele erhaltene Keramiken der Griechen zu, die auch damals zur Alltagsware zählten.

88 In Bayeux, in der unteren Normandie in Frankreich gelegen, befindet sich das Museum „Teppich von Bayeux“. Auf dem aus dem 12. Jahrhundert stammenden Teppich, der 70 Meter lang ist, ist die Geschichte der Schlachten zwischen Engländern und Normannen zu Zeiten Wilhelm des Eroberers dargestellt.

89 Interview mit Frau Dr. Regina Hanemann, Direktorin der Museen in Bamberg, am 2. Sept. 2002. 


\section{Ergebnisse der Besucherbefragung}

Der Ausstellungsparcours zur Veranschaulichung der Lebenswelt um die Jahrtausendwende und der Herrscherpersönlichkeit Heinrichs II. bediente sich intensiv einer Vielzahl von Gestaltungsmitteln unter Einsatz optischer, haptischer sowie akustischer Medien. Dies führt zu der Frage, wie dieser Parcours vom Publikum wahrgenommen und bewertet wurde und was im Gesamtbild in Erinnerung blieb.

Ein Punkt der Besucherbefragung des Sozialwissenschaftlichen Instituts München ${ }^{90}$ befasste sich mit der „Bewertung der optischen Präsentation der Ausstellung“. ${ }^{91}$ Sie kommt zu dem Ergebnis, dass die überwiegende Mehrheit der Befragten die Ausstellung positiv einschätzte. Mit „sehr gut“ bewerten 28 Prozent, mit „gut“ 47 Prozent der Befragten die optische Präsentation (ebd., S. 82).$^{92}$ Insgesamt vermittelte die Ausstellung laut SIM ein harmonisches Gesamtbild (ebd. S. 83). Die Ergebnisse deuten darauf hin, dass die Besucher einen gewissen Gesamteindruck bezüglich der Ausstellung entwickelten, der sich auf die Bewertung der einzelnen Kriterien eher positiv oder eher negativ auswirkt.

„Die Bewertung der optischen Präsentation der Ausstellung hängt überdies eng mit der Einschätzung der eigenen Kenntnisse der europäischen Geschichte zusammen. Befragte, die ihre Kenntnisse eher als gering oder mittelmäßig bezeichnen, bewerteten die optische Präsentation etwas besser als die Befragten, die über hohe Kenntnisse verfügen." (ebd. S. 84)

„Versierte Ausstellungsbesucher/innen“, die aufgrund häufigen Ausstellungsbesuchs bessere Vergleichsmöglichkeiten haben und eventuell mehr auf Details der Präsentation achten und diese dann in ihre Bewertung mit einfließen lassen, beurteilten die optische Präsentation der Ausstellung kritischer als Befragte, die nur gelegentlich in einer Ausstellung waren (ebd. S. 85).

90 Um den Textfluss nicht zu behindern, werde ich im weiteren Text auf die Besucherbefragung des Sozialwissenschaftlichen Instituts München mit dem Kürzel „SIM“ verweisen.

91 Fröhlich/Nöthen 2003, S. 82-85.

92 Die Besucher konnten zwischen sieben verschiedenen Bewertungen wählen: sehr gut, gut, befriedigend, ausreichend, mangelhaft, ungenügend, keine Angabe. 
Auch in meinen persönlichen Interviews wurde die Gestaltung überwiegend positiv bewertet, obgleich auch Kritik angebracht wurde. Wirklich vernichtende Urteile, wie dies vereinzelt im Besucherbuch der Fall war, wurden im Gespräch mir gegenüber nicht geäußert. Das abwechslungsreiche dramaturgische Konzept der Alten Hofhaltung fand im Großen und Ganzen Anerkennung. Hervorgehoben wurde, dass dies eine lebendige Form sei, sich mit geschichtlichen Dingen zu befassen, die Lebenswelt kennenzulernen und das eigene Wissen zu erweitern.

„Dies sind interessante Informationen, die über den Schulunterricht und deren politgeschichtliche Inhalte hinausweisen.“ (Mutter, geb. 1960)

Die erste Frage im Rahmen der Interviews zielte auf das persönliche Erinnerungsvermögen. In Abhängigkeit von Vorwissen sowie persönlichen Präferenzen fielen die Antworten erwartungsgemäß sehr heterogen aus. Auch flossen in die Bewertungen momentane, subjektive Stimmungen ein. Bestätigt werden kann die Feststellung, dass als wichtige Einflussgröße auf die Wahrnehmung die Biographie des Besuchers fungiert.

„Tendenziell scheinen daher bei begünstigenden Bestimmungsgründen für die Merkfähigkeit im gegebenen Fall eher Individualeigenschaften und -präferenzen eine Rolle zu spielen. Dazu gehört das geäußerte starke grundlegende Interesse für kunst- und kulturgeschichtliche Museen. Sind solche thematischen Neigungen habituell ausgebildet, so tritt in nachvollziehbarer Weise bei entsprechenden Anlässen auch eine konzentrierte und nachhaltige Objektrezeption in Erscheinung. “93

Bei der Auswertung der Frage nach der prägnantesten Erinnerung kristallisierten sich drei Hauptgruppen heraus. Dieses waren inhaltsbezogene, objektbezogene oder gestaltungsbezogene Erinnerungen.

Die erste Gruppe mit inhaltsbezogenen Erinnerungen zählte historische Fakten auf, wie zum Beispiel die Vereinigung von kirchlicher und staatlicher Macht in der Person Heinrichs II. oder die beeindruckende Größe des Reichs.

Die zweite Gruppe mit objektbezogenen Erinnerungen führte ästhetisch beeindruckende Objekte an. Sehr oft wurden die kunstvoll gestalteten Handschriften in der Staatsbibliothek erwähnt, die aufgrund des Alters, der Aufwendigkeit und Kunstfertigkeit im Gedächtnis haften

93 Klein, Hans Joachim: Gemischtes Doppel. Evaluation der Ausstellung Spätmittelalter am Oberrhein in der Staatlichen Kunsthalle und im Badischen Landesmuseum, beide in Karlsruhe. Karlsruhe 2002, S. 94. 
blieben. Auffallend häufig zählte der „Sternenmantel Kaiser Heinrichs II.“ zu den am besten erinnerten Objekten. Es faszinierten die Größe, das Alter, die Motive und der gute Erhaltungszustand. ${ }^{94}$ Noch weitere Objekte wurden genannt, wie zum Beispiel der „Sarkophagtrog“, die „Replik der Reichskrone“" sowie die „Nachbildung der Heiligen Lanze“.

Eine dritte Gruppe verwies bei der Frage nach der prägnantesten Erinnerung auf gestalterische Aspekte der Ausstellung. Hier wurden zum Beispiel die Hands-on Angebote, die karikierende „Nachrichtensendung zum Papstbesuch in Bamberg“" oder die auffallende Innenarchitektur des Raumes „Der Kaiser“" genannt.

Diese eingangs weit gestellte Frage lässt erkennen, dass im Hinblick auf die Neigungen der Besucher drei Kategorien gebildet werden können. Aus diesem Grund habe ich mich für folgende Differenzierung entschieden. Dieses sind

\section{- historisch orientierte Menschen}

- objektorientierte Menschen

- allgemein visuell orientierte Menschen

Historisch orientierte Menschen lenken ihre Wahrnehmung zunächst auf Texte und wollen Zusammenhänge erfahren: Museale Objekte werden als Dokument und Ergänzung wahrgenommen. Hierbei ist der Laie vom Fachwissenschaftler zu unterscheiden. Diese Besuchergruppe zählt zu den äußerst Kritischen, die aufgrund ihrer historischen Fachkompetenz den Inhalt sachlich hinterfragen. Inszenatorische, abstrakte Elemente stoßen eher auf Ablehnung und Unverständnis, da der Bezug zur historischen Ausstellung fehlt.

Die zweite Gruppe konzentriert sich auf die Objekte der Ausstellung. Ihr primäres Interesse richtet sich darauf, die Originale zu betrachten. Der ästhetische Genuss der Objekte steht im Vordergrund. Das Erfassen von historischen Zusammenhängen und Ereignissen wird eher als anstrengend empfunden. Das Lesen über die Geschichte kann ihrer Meinung nach später an einem anderen Ort erfolgen.

Die dritte Gruppe der visuell orientierten Menschen lässt sich vom Gesamteindruck leiten. Texte werden nur ausschnitthaft gelesen, die mu-

94 Die häufige Nennung dieses Objekts lag sicherlich nicht nur an objektimmanenten Faktoren. Der Mantel befand sich am Ende des Rundgangs und war somit am frischesten in Erinnerung. Außerdem ist er vergleichsweise sehr groß und steht dominant in einer Vitrine zentral im Raum. 
sealen Objekte stehen in der Aufmerksamkeit gleichwertig neben anderen Medien. Sie lässt assoziative Stimmungen auf sich wirken, ihr Besuch entspricht einem freizeitorientiertem Verhalten.

Bei dieser Einteilung in drei unterschiedliche Interessensgruppen muss kritisch angemerkt werden, dass dies letztlich eine Vereinfachung der Wirklichkeit ist. Überschneidungen sind möglich; so kann ein Besucher sowohl objektorientiertes Verhalten zeigen und gleichzeitig aber auch den Unterhaltungswert der Ausstellung schätzen. Trotzdem hilft diese Kategorisierung dabei, Besuchermeinungen in Bezug zu Interessensschwerpunkten einzuordnen. In Abhängigkeit davon kommen die Besucher zu völlig unterschiedlichen Bewertungen. Im fortlaufenden Text werde ich mich auf diese Einteilung beziehen.

\section{Handlungsorientierung}

Über die innenarchitektonische, optische Gestaltung hinaus wird mit dem Begriff Handlungsorientierung auf die Tatsache verwiesen, dass sich über das Ansprechen aller Sinne und durch eigenes Tun eine Intensivierung des Erlebnisses vollzieht. Im Ausstellungsrundgang durch die Alte Hofhaltung sollte diesem Anliegen entsprochen werden, indem es neben Angeboten zum Sehen auch Objekte zum Anfassen, Fühlen sowie Hören gab.

Die PC-Stationen in Form von Infopools für Hintergrundinformationen, die sich über das gesamte Ausstellungsgelände verteilten, bildeten eine erste Möglichkeit für die Besucher, über die Hauptinformation der Raumtexte hinaus individuellen Interessen im Hinblick auf Objekte nach eigener Auswahl zu vertiefen (siehe Abb. 43). Neben diesen selektiv abrufbaren Informationen gab es in der Alten Hofhaltung integriert in die Ausstellungsarchitektur verdeckte Informationsebenen. Diese waren für das Verständnis des roten Fadens der Ausstellung sekundär und erst durch Öffnen von kleinen Türen oder Schubläden zugänglich. So gab es ergänzend zu den Vitrinen mit archäologischen Funden von Schmuckstücken für Arme und Reiche sowie Kinderspielzeug im Vitrinenunterbau zwei Schubläden mit Karten zu slawischen Fundorten (siehe Abb. 44). ${ }^{95} \mathrm{Im}$ anschließenden Raum „Die Heinriche“ verbarg sich hinter einer Klappe der Vitrinenwand eine Replik des „Privilegs Kaiser Ot-

95 Kirmeier u.a. 2002, S. 137ff., Nr. 17. 
tos II.“ “96 Im Raum „Bamberg als Modell“ hingen an drei Außenwänden insgesamt acht stilisierte Kaseln aus Cortenstahl, stellvertretend für die acht Altäre, die im Bamberger Dom im Jahr 1012 geweiht wurden. Jede Kasel enthielt drei Klappen, die dem interessierten Besucher die näheren Umstände zur Weihe des jeweiligen Altars schilderten. ${ }^{97}$
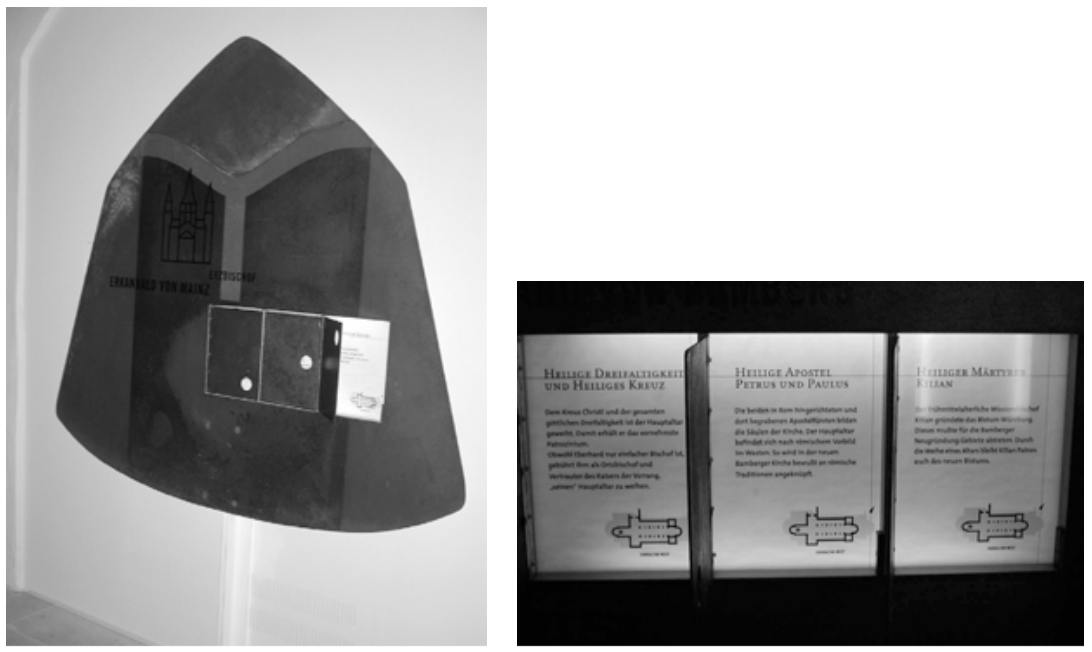

Abbildung 51/52: Stilisiert Kasel mit drei Klappen zum Öffnen mit Informationen zur Weihe der Altäre im Bamberger Dom.

Angebote zum Hören verteilten sich ebenfalls über den gesamten Ausstellungsparcours. Im ersten Raum „Leben in Bodennähe“ konnten die Besucher mittels Kopfhörer, integriert in das Landschaftsmodell, einer plastischen Beschreibung der fatalen Folgen einer Mutterkornvergiftung lauschen. Bei der Hörstation im Raum „Der neue König“ gab es eine Rekonstruktion der Musik zur Krönungszeremonie. Wie einschränkend in der Objektbeschriftung hingewiesen wurde, können die teils virtuosen wie auch schlichten Melodien lediglich aus verschiedenen Handschriften rekonstruiert werden, da diese im Gegensatz zu den Texten nicht überlie-

96 Ebd., S. 165ff., Nr. 42.

97 Neben einer Graphik mit einem Grundriss des Doms und der Kennzeichnung des Standpunktes des Altars informierte der Text, wem der Altar geweiht wurde, welcher Bischof dies durchführte und welche Bedeutung der Heilige im zeitgenössischen Umfeld hatte. 
fert sind. ${ }^{98}$ Im letzten Raum „Unterwegs im Reich“ konnten die Besucher in zwei Kojen betitelt mit „Ein Reich und viele Sprachen“99 an PCStationen einer hypothetischen Rekonstruktion der zur Zeit Heinrichs II. gebräuchlichen Volkssprachen lauschen. Dieses Angebot gab es nur über Kopfhörer, so dass sich in diesen Räumen keine kontinuierlichen Klangkulissen ausbreiteten. Ein Ausnahme bildete die Vertonung des Films „Nachrichtensendung zum Papstbesuch in Bamberg“100 im Raum „Der Friedenskuss", die über Lautsprecher sowohl diesen Raum wie auch die jeweiligen Nachbarräume beschallte.

Die Angebote zum Riechen beschränkten sich auf den Raum „Der neue König“. Hier konnte eine Klappe geöffnet werden und an einem mit Salböl getränkten Wattebausch gerochen werden.

Mehrere Stationen luden zum Anfassen und Fühlen ein. Im ersten Raum gab es eine sogenannte „Abgabenwanne“, in der Holzbottiche mit unterschiedlichen Getreidearten, Säckchen mit Salz und Leinenstoff lagen. Auch im nächsten Raum konnten die Besucher bei der Inszenierung zum Thema „Handelswege und Handelswaren“, die zugleich ein optisches Pendant zur Gehöftabgabe bildete, ihren Tastsinn einsetzen (siehe Abb. 53). In einer Koje im Raum „Unterwegs im Reich“ konnte ein Nasalhelm aufgesetzt und ein Schwert angefasst werden, benachbart zu einer Koje mit einer Vitrine mit musealen Exponaten eines Reiterkriegers des 10./11. Jahrhunderts (siehe Abb. 54/55). ${ }^{101}$

Neben der Aktivierung der Sinne wird unter dem Begriff Handlungsorientierung auch eine Anknüpfung an die Interessenslagen der Besucher verstanden, die einen Gegenwarts-, Lebens- oder Situationsbezug der Themen oder Fachinhalte impliziert. Gegenwartsbezüge inhaltlicher Art mit dem Ziel, ein Vergleichstableau zwischen dem Geschehenen und dem Aktuellen zu inszenieren, wurden in der Ausstellungsdramaturgie nicht explizit hervorgehoben. Man stellte jedoch an mehreren Stellen in

98 Ebd., S. 180ff., Nr. 54. Welche Hymnen beim Übergang von der Krönung zur Krönungsmesse zum „Te Deum“ zu singen waren, teilen die Quellen nicht mit, dennoch gibt es im Repertoire durchaus Kompositionen zum Empfang. Somit kann der Charakter der Zeremonie partiell vermittelt werden.

99 Ebd., S. 253ff., Nr. 102.

100 Beschreibung des Films zum Papstbesuche siehe Kapitel 6, S. 364ff.

101 Ebd., S. 241ff., Nr. 92-97. 
der Ausstellung Bezüge zur Gegenwart indirekt über die Gestaltung her. $^{102}$

\section{Die Rauminszenierung „Der Kaiser“ (siehe Abb. 56)}

Mit dem Raum „Der Kaiser“ versuchten die Gestalter eine Assoziationskette zwischen gegenwärtigen Vorstellungsbildern, Inhalt sowie Ausstellungsobjekten zu schaffen. Inhaltlich war dieser Raum dem Kaisertum Heinrichs II. und dem Thema Europa gewidmet.

Der ursprüngliche, leere Ausstellungsraum wurde durch ein mit Wappen, Spruchbändern, Ranken und Blüten gestaltetes Gewölbe auf Rundpfeilern mit einem zentralen Mittelpfeiler charakterisiert. Da diese aus dem Jahr 1925 stammende phantasievolle Wandmalerei inhaltlich nicht in die Ausstellungsdramaturgie passte, ${ }^{103}$ bestand das Anliegen darin, diese markante Wandmalerei durch innenarchitektonische Elemente in den Hintergrund zu drängen. Umgesetzt wurde dieses Vorhaben durch den Einbau einer Kuppel aus dünnen Metallstäben. An diesen Stäben waren Sterne befestigt, deren Motive dem „Sternenmantel Kaiser Heinrichs II." entnommen waren (siehe Abb. 57). ${ }^{104}$ Unterstrichen wurde die Atmosphäre des Raumes durch eine Beleuchtung der Sterne mit blauem Licht, das in dem sonst abgedunkelten Raum die Sterne zum Leuchten brachte. ${ }^{105}$

102 Dazu zählt zum Beispiel auch der Einsatz von Terminals zum Abrufen von Informationen, Beschreibung der PC-Informationssysteme siehe Kapitel 6, S. 317f.

103 Diese ehemalige, ruinöse Gesindeküche setzte der Bamberger Marienritterorder wieder instand. Vgl. Burandt 1999, S. 67.

104 Auf dem Sternenmantel als Abbild des Himmelsfirmaments breiten sich goldene Sterne strahlenförmig über den halbkreisförmigen Umhang aus und fügen sich zu einem astrologischen Programm. Die Stickereien auf dem Mantel wurden bei Restaurierungen im 15. Jahrhundert jedoch verändert. Bei der Aufbringung der goldbestickten Motive hielt man sich an deren Anordnung aus dem Mantel des 11. Jahrhunderts. Von den ursprünglichen astrologischen Texten blieben nur wenige erhalten. Baumgärtel-Fleischmann, Renate: Ausgewählte Kunstwerke aus dem Diözesanmuseum Bamberg. Bamberg 1992, S. 12-15.

105 Dies bedeutete auch für die Gestalter ein Wagnis, mit der Gefahr, damit eine Raumwirkung vergleichbar einer Disko- oder Kaufhausbeleuchtung zu erzeugen. Interview mit Herrn Uli Prugger, Gestaltungsbüro Gruppe Gut in Bozen, am 8. Juli 2002. 
Diese Kuppel bildete einen Raum, innerhalb dessen sich vier Vitrinen und drei Leuchtgraphiken aufreihten. Neben der „Replik der Reichskrone"106 als dreidimensionalem Exponat zeigten diese Archivalien, die im Zusammenhang mit der Kaiserkrönung standen, das „Heinricianum““107, die „Bamberger Tafel““108, die „Kaiserbulle Heinrichs II.““109, das „Sacramentarium Udalricianum“ “110 sowie die Handschrift „Epistola ad Heinricum Regem“ von Brun von Querfurt. ${ }^{111}$

Ergänzend zu den Handschriften gab es zwei Leuchtgraphiken zu den Themen „Herrschertreffen“ und „Polenzüge“. Eine weitere Leuchtgraphik zeigte als Doppelseite das Krönungsbild und das Widmungsgedicht aus dem „Perikopenbuch Heinrichs II.“112 mit beigefügter Übersetzung des Gedichts .

Am unteren Saum des Sternenmantels ist eine lateinische Inschrift eingestickt: „O DECUS EUROPAE CESAR HEINRICE BEARE AUGEAT IMPERIUM TIBI REX QUI REGNAT IN EVUM“"113. Damit wird Kaiser Heinrich als Zierde Europas gepriesen. Diese Inschrift diente den Ausstellungsmachern als Grundlage für den lateinischen Raumtitel „Decus Europae - Zierde Europas“ auf der CortenstahlUmmantelung der mittigen Säule.

Einerseits fand mit der Idee der Installation einer „Sternenkuppel“ eine Verknüpfung mit dem „Sternenmantel“, eines der hochkarätigen

106 Kirmeier u.a. 2002, S. 214ff., Nr. 72.

107 Ebd., S. 218ff., Nr. 74. Mit dem „Heinriciarum“ bestätigte Kaiser Heinrich II. dem Papst sämtliche Rechte und Besitzungen der römischen Kirche.

108 Ebd., S. 216ff., Nr. 73. In der „Bamberger Tafel“ werden Kunigunde und Heinrich II. als Nachkommen zweier großer Kaisergeschlechter dargestellt.

109 Ebd., S. 221ff., Nr. 78. Die älteste erhaltene Goldbulle im Abendland befindet sich an einer Urkunde für das Kloster Göß.

110 Ebd., S. 222ff., Nr. 79. Im „Sacramentarium Udalricianum“ sind die Namen der Teilnehmer an den Italienzügen Heinrichs II. festgehalten.

111 Ebd., S. 226ff., Nr. 82. In dieser Handschrift übt Brun von Querfurt harsche Kritik an der unerbittlichen Haltung Heinrichs II. gegen den Polenherrscher Boleslaw Chrobry.

112 Ebd., S. 219ff., Nr. 75.

113 Die Inschrift ist im rechten Teil aus Platzgründen nicht vollständig. Der Ergänzung zu zwei Hexametern durch den Aachener Kanonikus Franz Bock (1823 - 1899) wurde bisher nicht widersprochen: „Heil sei dir, zur Zierde Europas, Kaiser Heinrich, dein Reich mehre der König, der da herrschet ewiglich." Ebd., S. 382, Nr. 203. 
Ausstellungsexponate im Diözesanmuseum, statt. Damit wurde der Sternenmantel inhaltlich mit dem Europagedanken und der Huldigung Heinrichs als Kaiser in Verbindung gebracht. Darüber hinaus bestand das Anliegen der Gestalter jedoch auch darin, einen Anknüpfungspunkt zur gegenwärtigen Vorstellungswelt zu schaffen. Mit den Sternen sollten Assoziationen zur Europaflagge und Weltkugel hergestellt werden.

\section{Der Raum „Der nеие König“ (siehe Abb. 58)}

Dieses Thema umfasste zwei Räume, die jedoch aufgrund der geschlossenen Raumwirkung mit Kreuzrippengewölbe, Sandsteinboden sowie leicht schiefen Wänden eine Einheit bildeten. Die Atmosphäre des Raumes wurde durch ein warmes, gelbes Licht unterstrichen. Die amorphen Formen der beigefarbenen Vitrinen mit schlangenförmigen Einkerbungen sollten den Königsumritt Heinrichs II. durch die Länder visualisieren, der mit insgesamt sieben, exemplarisch ausgewählten Stationen vorgestellt wurde. Diese sieben Stationen wurden auf von der Decke herabhängenden Textfahnen näher beschrieben. Vergleichbar mit Haltestellen eines U-Bahn-Fahrplans erhielt jede Station eine Nummer, die jeweiligen Orte waren rot markiert (siehe Abb. 59). Damit stellten die Gestalter auf subtile Art einen Bezug zur Erfahrungswelt der Besucher her.

„Hier arbeiteten wir ganz bewusst mit der Assoziation eines Fahrplans mit sieben Stationen. [...] Man würde dies zwar nicht unbedingt sofort einem Fahrplan zuordnen, aber trotzdem ist dies als Merkhilfe für den Besucher sehr unterstützend.“114

Die kurzen Beschreibungen mit circa zehn bis fünfzehn Zeilen wurden mit charakteristischen Symbolen für die jeweiligen Orte illustrierend ergänzt. Die Stationen vier, fünf und sechs zeigten in Ergänzung zu den Textfahnen jeweils stilisierte, in beiger Farbe gestaltete dreidimensionale Modelle, die nochmals auf dieser haptischen Ebene die Inhalte visualisierten. Bis auf die erste Station, die als Exponat die „Nachbildung der Heiligen Lanze“"115 zeigte (siehe Abb. 59), waren die weiteren drei Stationen mit Archivalien ergänzt. Die Zahl der originalen Exponate war in diesen zwei Räumen gering. Statt dessen lag der Schwerpunkt der Gestaltung darauf, die Aussage anhand visueller Mittel zu verdichten.

114 Interview mit Herrn Uli Prugger, Gestaltungsbüro Gruppe Gut in Bozen, am 8. Juli 2002.

115 Ebd., S. 177ff. Nr. 51. 
„Ein Objekt muss eine Geschichte erzählen. Wenn man sehr viel Information zusätzlich zum Verständnis liefern muss, dann ist es besser, man nimmt es heraus. Natürlich gibt es dann noch die Kompromisse aufgrund von Leihgebern sowie aufgrund des historischen Kontexts."

Das Leitobjekt - museales Exponat, Archivalie oder Modell - kam folglich in jeder Station in dreifacher Weise vor: Als dreidimensionales Objekt, durch den inhaltlichen Bezug im Text und die graphische Darstellung auf der Textfahne. Hier setzten die Gestalter den Multiplikatoreffekt zur Verdeutlichung der Inhalte ein.

\section{Ergebnisse der Besucherbefragungen}

Die SIM-Studie fragte nach einer Bewertung der Ausstellungstexte, der Nutzung des Audiosystems und der Informationssysteme sowie nach einer Bewertung der eingesetzten Medien in der Ausstellung.

Die Bewertung der Ausstellungstexte wurde unter zwei Gesichtspunkten erfasst, nämlich der Verständlichkeit und der Ausführlichkeit. Dies bezog sich auf eine Gesamtbewertung, ohne zunächst zwischen dem Angebot der PC-Stationen sowie der Raumtexte zu differenzieren. Die Bewertung der Texte, obgleich abhängig von verschiedenen soziodemographischen Merkmalen, fiel insgesamt sehr positiv aus. „94 \% der Befragten bewerteten die Verständlichkeit mit sehr gut bzw. gut.“ (ebd. S. 147) ${ }^{117}$ Die Befragten mit einem hohen Interesse an Geschichte bzw. an Kunst und Malerei schätzten die Verständlichkeit der Texte häufig besser ein als Befragte mit niedrigem bzw. mittlerem Interesse (ebd., S. 92). Die Ausführlichkeit der Texte wurde von der überwiegenden Mehrheit der Befragten mit $83 \%$ ebenfalls als angemessen empfunden (ebd. S. 147). ${ }^{118}$

Das den Besuchern im Diözesanmuseum sowie in der Staatsbibliothek zur Verfügung gestellte Audiosystem, das über Kopfhörer genutzt wer-

116 Interview mit Herrn Uli Prugger, Gestaltungsbüro Gruppe Gut in Bozen, am 8. Juli 2002.

117 Im Hinblick auf die Verständlichkeit der Texte konnten die Besucher zwischen fünf Bewertungskategorien wählen: sehr gut, gut, weniger gut, schlecht, keine Angabe.

118 In Hinblick auf die Ausführlichkeit der Texte konnten die Besucher zwischen vier Bewertungskategorien wählen: Zu knapp, gerade recht, zu ausführlich, keine Angabe. 
den konnte, wurde laut Angaben von SIM von $71 \%$ der Befragen verwendet. Insbesondere Gruppenbesucher, die mit ihrer Familie in der Ausstellung waren, griffen auf dieses Audiosystem zurück. Die versierten Besucher verwendeten es ebenfalls häufiger als die Gelegenheitsbesucher (ebd. S. 148). Von der Mehrheit der Befragten wurde dieses System als hilfreich eingeschätzt und die vermittelten Informationen von $79 \%$ der Befragten für angemessen gehalten (ebd.).

In den persönlichen Interviews kam zum Ausdruck, dass die Bewertung des Audiosystems maßgeblich davon abhängig war, ob die Besucher dieses Angebot selbst nutzten oder darauf verzichteten. Auffällig war, dass die Benutzer dieses System allgemein positiv bewerteten und die Hintergrundinformationen als hilfreich bei der Erschließung der Objekte empfanden. Dagegen zeigten sich die Nichtbenutzer zum Teil über die Benutzer verärgert, da diese sehr lange vor den Objekten verweilten und somit den Blick auf die Exponate verstellten. Positiv im Vergleich zu Führungen wurde die Möglichkeit bewertet, dass der Text beliebig oft angehört werden könne. Von den ablehnenden Nichtbenutzern wurde als Begründung für den Vorzug von Texttafeln angeführt, dass hier quer gelesen und eine selektive Auswahl getroffen werden könne. Die Länge und der Inhalt der Information seien überschaubar und dies sei beim Audioguide ähnlich, wie bei Führungen, naturgemäß nicht der Fall. Angemerkt wurde auch, dass ein Audioguide in der Alten Hofhaltung statt der Führungen das Erlebnis der Ausstellung für den Individualbesucher verbessert hätte, da sich der Geräuschpegel erheblich reduziert hätte.

Das PC-Informationssystem nutzten laut SIM $57 \%$ der Besucher (ebd., S. 148). Vor allem die Befragten mit hohen Kenntnissen in europäischer Geschichte und längerer Verweildauer nutzten dieses Angebot. Die über das Computersystem vermittelten Informationen wurden von circa zwei Drittel der Befragten als angemessen beurteilt. Insgesamt wurde dieses System als hilfreich eingeschätzt (ebd., S. 149). Der Einsatz moderner Medien wurde von der überwiegenden Mehrheit der Befragten ebenfalls mit $81 \%$ positiv bewertet (ebd. S. 151).

Auch bei den persönlichen Interviews kam zum Ausdruck, dass das Angebot eines PC-Informationssystems für vertiefende Hintergrundinformationen allgemein von den Besuchern geschätzt wurde. Hier störte die Nichtbenutzer die Integration von Medienstationen nicht, wie dies 
bei dem Einsatz der Audioguides der Fall war. ${ }^{119}$ Insbesondere wurde anerkennend hervorgehoben, dass moderne Medien Einzug in historische Ausstellungen gefunden haben, was bisher eher in naturwissenschaftlichen Ausstellungen der Fall sei.

Die Frage, ob die Besucher den Computer zum vertiefenden Nachlesen nutzten, wurde allerdings überwiegend verneint. Es wurde allein die Tatsache positiv bewertet, dass es möglich gewesen wäre. Primär wurde der Computer dazu eingesetzt, sich eine allgemeine Orientierung über das Ausstellungsgelände zu verschaffen. Von einigen Besuchern wurde bedauert, dass das Recherchieren in Ruhe aufgrund des großen Besucherandrangs kaum möglich war. Als Verbesserung wurde die Einrichtung eines speziellen Medienraums zum Recherchieren vorgeschlagen. Es wurde beobachtet, dass viele Besucher die Computer ausprobierten, aber nicht wirklich zur Informationsrecherche nutzten. Bei großem Besucherandrang hat der Text an der Wand im Gegensatz zum Computerbildschirm den Vorteil, dass diesen mehrere Leute gleichzeitig lesen können. Vor dem Monitor können maximal zwei Leute stehen. Außerdem wird im Wandtext die gesamte Information auf einmal präsentiert, am Computer muss geblättert werden. Das Lesen des Textes an der Wand fällt aufgrund der Typographie wesentlich leichter als das Erfassen von Texten auf einem Bildschirm. Auch ist aufgrund der strengen Reduzierung des Wandtextes eine Vorauswahl getroffen und die Information überschaubarer.

Die Präsentation von Archivalien, so zum Beispiel das „Perikopenbuch Kaiser Heinrichs II.“ oder das „Evangeliar Ottos III.“ mittels Computer, die das Betrachten des gesamten Werkes ermöglicht, wurde als sinnvolle und bereichernde Form des Ausstellens von alten Handschriften beurteilt. Auch die Medienstationen im Raum „Unterwegs im Reich“ mit den Hörbeispielen zu den verschiedenen Sprachen des Reiches wurden positiv erwähnt.

Ein Fragenblock der persönlichen Interviews mit den Besuchern befasste sich mit dem Thema "Wahrnehmen mit allen Sinnen“. ${ }^{120}$ Die Idee der versteckten Texte wurde mittlerweile bereits in verschiedensten Variationen in Ausstellungen praktiziert. Das historisch interessierte Publikum stand diesem weitgehend tolerant gegenüber und beurteilte es als

119 Die Benutzerführung für Menschen mit wenig Computererfahrung war allerdings schwierig. Erschwert wurde dies dadurch, dass im Computerprogramm die Funktionstaste „Zurück“ fehlte.

120 Dieser Komplex wurde in der SIM-Befragung nicht thematisiert. 
eine didaktische Spielerei, die für Kinder schön sein mag, jedoch für sich selbst nicht nötig sei.

„Bei mir wirkt dies nicht.“ (Freiberuflich, geb. 1970)

Ein Großteil der Besucher hielt dies aber für eine gute Idee, um auf Informationen neugierig zu machen. Die meisten jedoch mussten eingestehen, dass das Öffnen der Türchen sie lediglich zum Anlesen der Texte animierte. Eine Besucherin verglich das Öffnen der Türchen mit einem Adventskalendereffekt. Dies motiviere jedoch nicht unbedingt zum Lesen, zumal die Texte, zum Beispiel im Raum „Bamberg als Modell“, nicht unbedingt von allgemeinem Interesse waren. Vereinzelt störte das laute Klicken der Magneten. Auch wurde beobachtet, dass manche nicht wagten, wenn alle Türen geschlossen waren, diese anzufassen.

Unklar war, weshalb zum Beispiel die Replik einer Archivalie „Privileg Kaiser Ottos II.“ angefasst werden konnte. Das Anfassen trug weder zum Erschließen des inhaltlichen Zusammenhangs bei, noch ermöglichte es die sinnliche Erfahrung des Befühlens von mittelalterlichem Papier, da es sich um eine Replik handelte.

Die Bewertung der weiteren Hands-on Angebote durch die verschiedenen Besuchergruppen fiel ebenfalls, wie bei den Texten hinter den Türchen, positiv oder wertneutral aus. Ablehnende Stellungnahmen gab es keine. Der eher auf Unterhaltung ausgerichtete Besucher hätte sich gerne noch mehr gewünscht. Die Dinge zum Anfassen wurden als solche zwar wahrgenommen, doch führte dies nicht unbedingt dazu, diese auch ausprobieren $\mathrm{zu}$ wollen.

„Das Ausprobieren hat mich nicht gereizt, ich bin eher ein Mensch, der mit den Augen arbeitet.“ (Freiberuflich, geb. 1970)

Obwohl mit der Aufforderung „Anfassen erwünscht“ ein deutlicher Hinweis gegeben war, hinderte viele Erwachsene das über Jahrzehnte eingeprägte museale Dogma „Berühren verboten“ dennoch daran, dies tatsächlich zu tun. Kinder standen diesem unverkrampft gegenüber. Das Heben des Schwerts und das Aufsetzen des Nasalhelms begeisterte jedoch nicht nur die Kinder. Im Gegensatz zur Möglichkeit des Anfassens der Replik einer Archivalie erscheint dieses Angebot sinnvoll, da damit die Schwere eines derartigen Helms gespürt werden kann. 
Obgleich über die Gestaltung Gegenwartsbezüge hergestellt wurden, fehlten diese auf inhaltlicher Ebene. Bei einem Teil der Besucher kam zum Ausdruck, dass sie sich diese zum tieferen Verständnis an manchen Stellen gewünscht hätten. Zum Verständnis von Mengen und Zahlen hätten zum Beispiel Vergleiche mit aktuellen Zahlen das Vorstellungsvermögen unterstützt, um diese Informationen aus heutiger Sicht einordnen zu können. So gab es auf der Texttafel „Grundherrschaft“ zwar Aussagen darüber, wieviel Naturalabgaben Bauern zu leisten hatten. Es fehlten aber die Angaben, wieviel ein Bauer innerhalb eines Jahres verdiente und welchen Teil er im Verhältnis davon abliefern musste. ${ }^{121}$

Die Gestaltung des Raumes „Der Kaiser“ wurde als angenehm empfunden, auch von den eher kritischen, primär an historischen Zusammenhängen interessierten Besuchern. Obwohl die Gestaltung mit der Sternenkuppel den Raum sehr prägte, trat sie für die Besucher nicht unbefriedigend in den Vordergrund. Die Abgrenzung des Raumes sowie das dezente Licht wurden als konzentrationsfördernd empfunden. Die Besucherurteile waren unabhängig davon, ob Bezüge zwischen Gestaltung, Inhalt und dem Exponat „Sternenmantel“" hergestellt werden konnten. Auch das blaue Licht, welches, wie die Gestalter befürchteten, vielleicht unangenehm an Discolicht hätte erinnern können, wurde nicht negativ erwähnt.

„Die Motive aus dem Sternenmantel haben sich mir nicht erschlossen, ästhetisch fand ich dies gut. Ein abgeschlossener Raum, der in sich stimmig ist, erzeugt ein heimeliges Gefühl und fördert die Konzentration beim Betrachten der einzelnen Gegenstände.“ (Informatiker, geb. 1961)

Erst auf meine Frage, worin die Intention der Gestalter gelegen haben könnte, wurden die Befragten motiviert, darüber nachzudenken.

„Darüber habe ich mir keine Gedanken gemacht. Ich habe es einfach auf mich wirken lassen.“ (Student, geb. 1985)

Assoziationen zu Europa stellten sich bei einigen Besucher ein, doch darüber hinaus regte dies noch zu weiteren Vermutungen an, beispielsweise, dass die Gestaltung als Symbol für die Rast- und Ruhelosigkeit der Zeit gelten könne. Den Bezug zum „Sternenmantel“ konnten nur diejenigen Besucher herstellen, die diesen bereits kannten. Obwohl die

121 Diese Texttafel ergänzte die „Abgabenwanne“ mit den Hands-on Angeboten im Raum „Leben in Bodennähe“. Siehe Kapitel 6, S. 331. 
Interpretation der gestalterischen Elemente von den Besuchern als schwierig empfunden wurde, wurde diese Form als legitim bewertet.

Im Raum „Der neue König“, in dem die Gestalter sowohl auf den Multiplikatoreffekt wie auch auf Fahrplan-Assoziationen bei der Vermittlung der Inhalte setzten, war das Erinnerungsvermögen der Besucher an Einzelheiten der Räume dementsprechend auffallend gut: Die inhaltliche Aussage war klar, Stationen der Reise konnten aufgezählt und die „Heilige Lanze" als auffallendstes Exponat zugeordnet werden. Eine weitergehende Einordnung in den historischen Kontext war jedoch nur möglich, wenn bereits Vorwissen vorhanden war. Die Gestaltungsidee der schlangenförmigen Einkerbungen auf den amorph geschwungenen Vitrinen als Visualisierung des Königsumritts wurde von keinem der befragten Besucher so interpretiert.

\section{Ganzheit}

Ausgehend von der Annahme, dass menschliches Erleben generell ganzheitlich ist, spielt für das Erleben einer Ausstellung das gesamte Umfeld eine bedeutsame Rolle. In konsequenter Weiterführung führt dies dazu, dass über die inhaltliche Konzeption der Ausstellungsräume hinaus Überlegungen bedeutsam werden, die die bewusste oder auch unbewusste Interaktion mit der gesamten Ausstellungsumwelt betreffen. Diese beginnen mit der Frage, welche Orientierungsmöglichkeiten den Besuchern vor Ort zur Verfügung gestellt werden. Eine weitere wichtige Komponente bildet die Berücksichtigung der psychischen und physischen Dispositionen, welche unter dem Begriff Ausstellungsmüdigkeit zusammengefasst werden.

Im Hinblick auf die Heinrichsausstellung flossen diese ganzheitlichen Gesichtspunkte in die konzeptionellen Überlegungen ein. So wurden Orientierungsmöglichkeiten im Gelände den Besuchern ausreichend zur Verfügung gestellt. Die Hinweisschilder im Ausstellungsgelände (siehe Abb. 41/42), eine Graphik zum Ausstellungsgelände auf der Rückseite der Eintrittskarte wie auch die Übersichtpläne an den PCStationen dienten diesem Zweck. ${ }^{122}$

122 Zum Thema Orientierungshilfen im Gelände siehe auch Kapitel 6, S. 315. 
Das Problem der Ausstellungsmüdigkeit spielte vor allem in der Gestaltung des Parcours durch die Alte Hofhaltung eine bedeutsame Rolle. Dramaturgische Kriterien bei der Aufbereitung des Stoffes, um das Interesse der Besucher wach zu halten, wurden auf mehreren Ebenen in unterschiedlichen Formen berücksichtigt. Dieses Anliegen zeigte sich bereits bei der Entwicklung des Ausstellungskonzeptes ${ }^{123}$ und spiegelte sich in der konzeptionellen Gestaltung des gesamten Parcours sowie auch der Einrichtung einzelner Räume wider. Inhaltlich bindet der Rundgang die einzelnen Räume in eine geschlossene Dramaturgie ein. Dies beginnt mit den Lebenswelten über wichtige Stationen der Herrschaft hin zur Rezeption durch die Nachwelt. ${ }^{124}$ Durch den rhythmisierten Einsatz didaktischer Angebote wie Fühl- oder Hörstationen sowie dramaturgischer Elemente mit einem Wechsel von Raum-, Farb- oder Lichtstimmungen wurden die menschlichen Sinne unterschiedlich angesprochen und eine Gefühlsregie aufgebaut. Diese Spannung konnte jedoch nur in der Gesamtwirkung des Parcours erlebt werden.

„Dieser Raum [„,Der neue König“ Anm. d. V.] hatte bereits leer eine sehr angenehme Ruhe und Stimmung. Diese Spannung wird erst deutlich, wenn man die anderen Räume kennt. Man muss auch die anderen Räume spüren, damit man dort zu diesem Gefühl kommt. Nur dieser Raum wäre ohne den Kontext der Ausstellung nicht möglich. “" ${ }^{125}$

Es wurde versucht, neben ruhigen Angeboten im Wechsel ein anregendes Ambiente zu schaffen. Bevor die Besucher in den letzten Raum des Rundganges, dem Marstall, mit einem vielfältigen Angebot zum Sehen, Hören, Lesen und Fühlen gelangten, durchschritten sie vorher einen reduziert gestalteten, schmalen Durchgangsraum.

„Dieser Ruheraum dient zum Verschnaufen, bevor es in den Schlussraum geht, der noch mal eine Steigerung im Parcours darstellt. “126

123 Siehe Kapitel 6, S. 299.

124 Problematisch war jedoch die Entschlüsselung dieses roten Fadens, der sich nicht sofort auf den ersten Blick erschloss. Dies kam bei der Besucherbefragung in der persönlichen Interviews deutlich zum Ausdruck.

125 Interview mit Herrn Uli Prugger, Gestaltungsbüro Gruppe Gut in Bozen, am 8. Juli 2002.

126 Interview mit Herrn Uli Prugger, Gestaltungsbüro Gruppe Gut in Bozen, am 8. Juli 2002. 
Dieser Raum zeigte drei großformatige mit Cortenstahl gestaltete Silhouetten, die jeweils auf einer Leuchtgraphik Anekdoten aus dem Leben Heinrichs II. schilderten. ${ }^{127}$ Ein stilisierter Esel stand für die Geschichte „Der Maultiere Seelenheil“, der Umriss eines Bären symbolisierte die Anekdote „Der Mönch, der Kaiser und des Bären Appetit“" und die Silhouette eines Kelchs verwies auf die Legende „Ein geheiligter Raub“. Diese Geschichten regten zum Schmunzeln an und sorgten so für Entspannung.

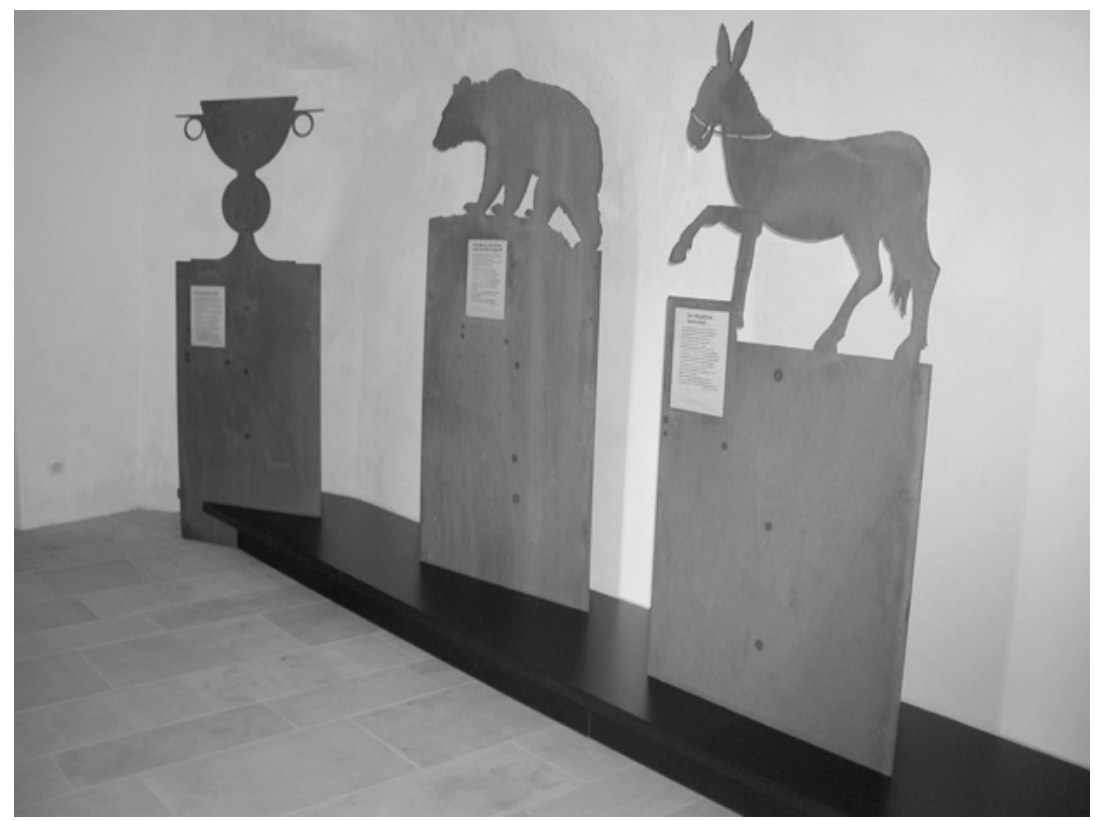

Abbildung 60: Durchgangsraum zwischen den Räumen „Der Friedenskuss“ und „Unterwegs im Reich“.

Im Raum „Die Heinriche“ lässt sich anhand der übersichtlichen Einheit einer Vitrinenwand aufzeigen, wie die Gestalter hier das Anliegen umsetzten, dem Sehen Abwechslung zu bieten. An einer Wand entlang stand ein raumhohes, orangefarbenes Paneel, gestaltet mit einer angedeuteten, unregelmäßigen Ziegelstruktur in Andeutung der Regensburger Stadtmauer (siehe Abb. 61). In dieses Wandpaneel waren Vitrinen unter-

127 Ebd., S. 236ff., Nr. 86. 
schiedlicher Größe und Formen integriert. Eine längliche, querformatige Vitrine zeigte Kleinfunde wie Alltagsgegenstände und Schmuck aus dem Regensburger Damenstift Niedermünster. ${ }^{128}$ In der benachbarten, länglich hochformatigen Vitrine befand sich ein Fenster aus dem Kloster St. Emmeran. ${ }^{129}$ Kleine Gucklöcher in unterschiedlicher Höhe mit Münzen aus der Zeit Heinrichs II. forderten die Besucher zum genauen Hinsehen auf (siehe Abb. 62/63). ${ }^{130}$ Sowohl zum Anfassen als auch zum Sehen gab es anschließend hinter einer Klappe zum Öffnen die bereits erwähnte Replik des „Privilegs Kaiser Ottos II““. ${ }^{131}$ Am Ende dieser stilisierten Stadtmauer stand die Stahlwanne mit der Inszenierung zum Thema „Handelswege und Handelswaren“, die ebenfalls ergänzend zum optischen Eindruck zum Berühren einlud (siehe Abb. 53).

„Diese Abfolge sorgt bewusst für Abwechslung. Es sind verschiedene Möglichkeiten des Sehens. Nach einem Ausschnitt folgt ein Fenster, dann kleine Gucklöcher - der Besucher muss hingehen, sich bücken und genau fokussieren, danach kann er ein Fenster mit der Hand öffnen, dann wieder folgt eine normale Vitrine. Dieser Rhythmus hilft, weniger schnell zu ermüden. Der Gegensatz dazu wären fünf gleichmächtige Vitrinen.“'132

Die Aneinanderreihung unterschiedlicher, kleinteiliger Exponate im Gegensatz zu großen Objekten gab dem Auge Abwechslung im Sehen. Zudem ergänzt mit Hands-on Objekten wurde neben dem Augensinn auch der Tastsinn angesprochen.

Obwohl die Ausstellungsmacher versuchten, unter einer ganzheitlichen Perspektive auf die psychischen und physischen Bedürfnisse der Besucher zu achten und diese Komponente dementsprechend auch im Ausstellungskonzept zu integrieren, klafften dennoch an manchen Stellen Konzept und Wirklichkeit auseinander. Insbesondere in der Alten Hofhaltung erwiesen sich die hohen Besucherzahlen problematisch für Raumklima und -atmosphäre.

128 Ebd., S. 159ff., Nr. 37, 38, 39. Dieses waren eine Emailscheibenfibel, ein Spielstein sowie zwei Schankgefäße.

129 Ebd., S. 162, Nr. 40. Das Fenster hat sich als besonders altes Holzfenster erhalten.

130 Ebd., S. 163ff., Nr. 41.

131 Ebd., S. 165ff., Nr. 42.

132 Interview mit Herrn Uli Prugger, Gestaltungsbüro Gruppe Gut in Bozen, am 8. Juli 2002. 
Diese Diskrepanz zwischen einerseits angestrebter Raumwirkung und andererseits Erleben des Raumes durch die Besucher zeigte sich insbesondere in den zwei Räumen zum Thema „Der neue König“ (siehe Abb. 58). Die angenehme, fast weihevolle Atmosphäre des Raumes konnte sich am besten entfalten, wenn man sich alleine darin befand. Aufgrund der großen Anzahl von Besuchern war dieses jedoch während der Öffnungszeiten kaum der Fall. Im Gegenteil bildete die Enge des Raumes geradezu ein Nadelöhr, an dem sich die Besuchergruppen in Stoßzeiten stauten. Dies führte dazu, dass viele Besucher versuchten, möglichst schnell diese drangvolle Enge hinter sich zu lassen und kaum Zeit blieb, sich auf die Exponate und das Thema des Raumes einzulassen. Ein Besucher bemerkte hierzu, dass es doch unsinnig sei, diese kleine Räume durch zusätzliche Einbauten noch weiter zu verkleinern. Dementsprechend negativ fielen manche Besucherkommentare aus.

\section{Ergebnisse der Besucherbefragungen}

In der standardisierten SIM-Untersuchung gab es keine Kategorie, die das Thema Wohlbefinden oder psychische Komponente erfasste, so dass die Aussagen hierzu sich ausschließlich auf die persönlichen Interviews mit den Ausstellungsbesuchern stützen. Sehr deutlich kam hier zum Ausdruck, wie sehr die äußeren Faktoren der Ausstellungsumwelt die Urteile über die gesamte Ausstellung beeinflussen. Ärger über schlecht lesbare Objektbeschriftungen an vereinzelten Objekten führte bei manchen Besuchern dazu, die Ausstellung im Gesamten schlecht zu beurteilen. Das, was zunächst als marginal oder sekundär erscheinen mag, wird dann im Besucherurteil über die Ausstellung die bestimmende Größe.

Die am häufigsten vorgebrachte Kritik, die zum Teil zu sehr aufgebrachten Reaktionen bei Besuchern führte, galt den schlechten klimatischen Bedingungen und der drangvollen Enge in den Ausstellungsräumen. ${ }^{133}$ Führungen blockierten Engstellen, so dass Einzelbesucher nicht weitergehen konnten. Die hohe Geräuschkulisse, auch aufgrund von Führungen, störte die eigene Konzentration. Auch wurde mehrfach der Wunsch nach mehr Ruhepunkten in der Ausstellung zum Verweilen, Betrachten und Verarbeiten geäußert.

Ein zweiter, oft geäußerter Kritikpunkt galt der Beleuchtung der Räume. Vielen Besuchern war das Licht in den Räumlichkeiten zu dun-

133 Sehr deutlich kam diese Unzufriedenheit in den Besucherbüchern zum Ausdruck. 
kel, dies wurde als bedrückend empfunden. Vor allem für alte Leute führte dies zu Orientierungsproblemen. Für Rollstuhlfahrer und Kinder waren die Objekte oft zu hoch präsentiert.

Kritik riefen zudem die Objektbeschriftungen hervor. In der Alten Hofhaltung konnten die Bezifferungen in den Leuchtkästen bzw. Objektbeschriftungen den Objekten nicht eindeutig zugeordnet werden, da es in den Vitrinen keine Hinweisnummern gab (siehe Abb. 45). ${ }^{134} \mathrm{Im}$ Diözesanmuseum wurde ebenfalls die Objektbeschriftung kritisiert. Hier war sie zwar eindeutig zuzuordnen, jedoch war die schwarze Schrift auf grauem Grund zu klein und schlecht beleuchtet.

Teilweise waren die haptischen Elemente nicht auf den ersten Blick zu erkennen. Erst mit der Beobachtung anderer Personen stellte eine Besucherin fest, dass die Löcher in der Vitrinenwand im Raum „Die Heinriche“ keine Lichtquellen, sondern Gucklöcher zum Betrachten der Münzen waren. Die Schubläden mit den Karten zu dem Thema „Slawen in Bayern“ im Raum „Leben in Bodennähe“ blieben auch von manchen Besuchern unentdeckt (siehe Abb. 44).

Inhaltliche Kritik wurde primär von historisch orientierten Menschen vorgebracht. Zur Erleichterung des Einstiegs hätten sich diese eine einführende Information am Anfang der Ausstellung gewünscht. Ein chronologischer Überblick zu wichtigen Lebensdaten von Heinrich II fehlt beispielsweise. Ebenso blieb einigen der rote Faden der Ausstellung verborgen. Die Systematik der Gestaltung erschloss sich den Besuchenden nicht sofort. Eine Hinführung über den Aufbau der Ausstellung und die damit verbundenen Ziele wäre als hilfreich empfunden worden.

„Nachdem ich die Systematik des gestalterischen Aufbaus verstanden habe, empfand ich es als sehr schön gemacht, so zum Beispiel die Schritte zur Legitimation. Es wäre jedoch einfacher gewesen, man wäre auf den roten Faden mehr hingelenkt worden.“ (Betriebswirt, geb. 1957)

Dass sich Zusammenhänge und Hintergründe erst bei genauerer Betrachtung erschlossen, scheint auch die SIM-Untersuchung zu bestätigen. Diese kommt zur Feststellung, dass die optische Präsentation umso positiver bewertet wurde, je länger sich die Befragten in der Ausstellung aufhielten (Nöthen/Fröhlich 2002, S. 85).

134 Dieses war zum Beispiel im Raum „Leben in Bodennähe“ bei der Tafel: „Die Sorge ums tägliche Brot“, Objekte Nr. 29 a-d oder bei den Tischvitrinen mit den archäologischen Funden, Objekte Nr. 15-27, der Fall. 


\section{Differenzierung}

Unter dem Begriff Differenzierung sollen in dieser Analyse insbesondere zwei Aspekte betrachtet werden. Zum einen verweist dieser Begriff auf den konstruktiven Charakter der Interpretation entgegen monokausaler Erklärungszusammenhänge zu Gunsten einer Anerkennung vielfältiger Unterschiede und sogar Widersprïche. Zum anderen bedeutet Differenzierung eine methodische Maßnahme, mittels derer den unterschiedlichen Bedürfnissen und Interessen der Besucher entsprochen wird und damit die Heterogenität des Publikums ins Blickfeld gerät.

Der Rundgang durch die Alte Hofhaltung verfolgte einen narrativen Ansatz. Gegliedert nach einem chronologischen Darstellungsmuster wurden wichtige Etappen des Herrscherdaseins entfaltet, ohne das konstruktive Moment der Geschichtsdarstellung zu thematisieren. Fragen provozierende oder irritierende Elemente wurden nicht explizit ausgebreitet. So merkt Sauerländer kritisch im Vergleich mit der "Gothic“ Ausstellung in London im Victoria \& Albert Museum an:

„Wir stellen in Deutschland die Ottonen, die Salier, die Staufer aus - das ist ferne auratisierte Vergangenheit, allenfalls von Kaisernostalgie umwoben. Aus einer englischen Ausstellung wie Gothic schlägt einem die Gegenwärtigkeit von Bräuchen entgegen, die bis in das späte Mittelalter zurückreichen.“"135

So hätte sich zum Beispiel die im historischen Urteil ambivalente Herrscherpersönlichkeit Heinrichs II. angeboten, diese kontroversen Beschreibungen noch intensiver $\mathrm{zu}$ thematisieren. Zeitliche Vor- und Rückgriffe zum Zwecke eines Vergleichs wären möglich gewesen, so zum Beispiel die provokante Frage nach einer Verquickung von Geld, Macht und Kirche sowie die Erkundung der Gründe für die Heiligsprechung Heinrichs II. im Jahr 1146 nur zweiundzwanzig Jahre nach seinem Tod. Weiterhin hätte sich auch die Rezeptionsgeschichte bis in unsere Gegenwart fortführen lassen. Die im Raum „Der neue König“ präsentierte „Nachbildung der Heiligen Lanze“ markierte die erste Station in Polling im Februar/März 1002, als der bayerische Herzog Heinrich II. den Leichenzug Kaiser Ottos III. empfing (siehe Abb. 59). Heinrich II. erzwang die Herausgabe der Heiligen Lanze sowie der übrigen Herrscherinsignien und demonstrierte so seinen Anspruch auf die Königs-

135 Sauerländer, Willibald: Laut, farbig und nicht ohne Witz. Eine theatralische Inszenierung des Mittelalters: die große „Gothic“-Ausstellung. In Süddeutsche Zeitung vom 01.12.03. Siehe Kapitel 5, Anm. 71. 
würde. ${ }^{136}$ Die „Heilige Lanze“ erweckte im Nationalsozialismus erneut Begehrlichkeiten. Als Kultwaffe ließ Hitler diese aus der Wiener Schatzkammer zum Burgberg nach Nürnberg bringen. ${ }^{137}$ Mit einer Thematisierung dieses Zusammenhangs hätte die Bedeutung der Symbolkraft dieses Objekts eine weitere Dimension erhalten.

Das historische Erzählprinzip wurde an einer Stelle der Ausstellung verlassen und zwar am Ende des Rundganges in einer Koje im Raum „Unterwegs im Reich“. Dieses Element bedeutete einen Bruch in der Erzählstrategie, da neben dem historisch-narrativem Ansatz der künstlerischen Interpretation Raum gegeben wurde.

\section{Raum „Unterwegs im Reich“}

Koje mit Inszenierung: „Treue Weggefährten Heinrichs II“

Die künstlerische und zugleich didaktische Inszenierung „Treue Weggefährten Heinrichs II. “" ${ }^{138}$ von Rosemarie Zacher ${ }^{139}$ befand sich im letzten Raum des Rundganges durch die Alte Hofhaltung in einer Koje im Marstall mit dem Leitthema „Unterwegs im Reich“. Mit zwei anderen benachbarten Kojen bildete sie eine thematische Einheit zum Thema Verwaltung und Bischöfe. Diese Koje erfüllte eine Doppelfunktion und fiel aus dem üblichen Rahmen der Gesamtgestaltung. Einerseits war sie ein didaktisches Element zur Illustration der großen Zahl von zweiundsechzig Bischöfen, die unter der Regentschaft Heinrichs II. zwischen 1002 und 1024 geweiht wurden. Zugleich aber war dies auch eine künstlerische Interpretation, die versuchte, sich den unterschiedlichen Charakteren der Bischöfe anzunähern und diese zur Anschauung zu bringen.

Zweiundsechzig individuell gestaltete Keramikfiguren, circa dreißig Zentimeter groß, waren auf einer Ebene kniehoch mit gleichmäßiger Beleuchtung präsentiert. Davor stand ein schwarzes Pult mit drei Druckknöpfen mit jeweils einer Zahl. Nur beim Drücken des richtigen Knopfes

136 Kirmeier u.a, 2002, S. 177ff. Nr. 51. Nach dem Tod Ottos III. 1002 galt die Heilige Lanze als zentraler Bestandteil des königlichen Reliquienschatzes und als wichtigstes Herrschaftssymbol. Die Heilige Lanze verhieß Sieg und sollte zum ewigen Leben führen.

137 Die „Heilige Lanze“ zählt zu den Reichskleinodien. Sie sind ein Beispiel für die symbolische Politik der Mittelalterbeschwörungen im Nationalsozialismus. Siehe Kapitel 5, S. $239 f$.

138 Ebd., S. 239ff. Nr. 89.

139 Siehe Kapitel 6, Anm. 22. 
erstrahlte das Licht der Leuchtgraphik, auf der die große Anzahl der „Weggefährten Heinrichs II.“ namentlich aufgelistet waren. Eine sechszeilige Beschreibung auf der Stoffbahn gab ergänzende historische Informationen.
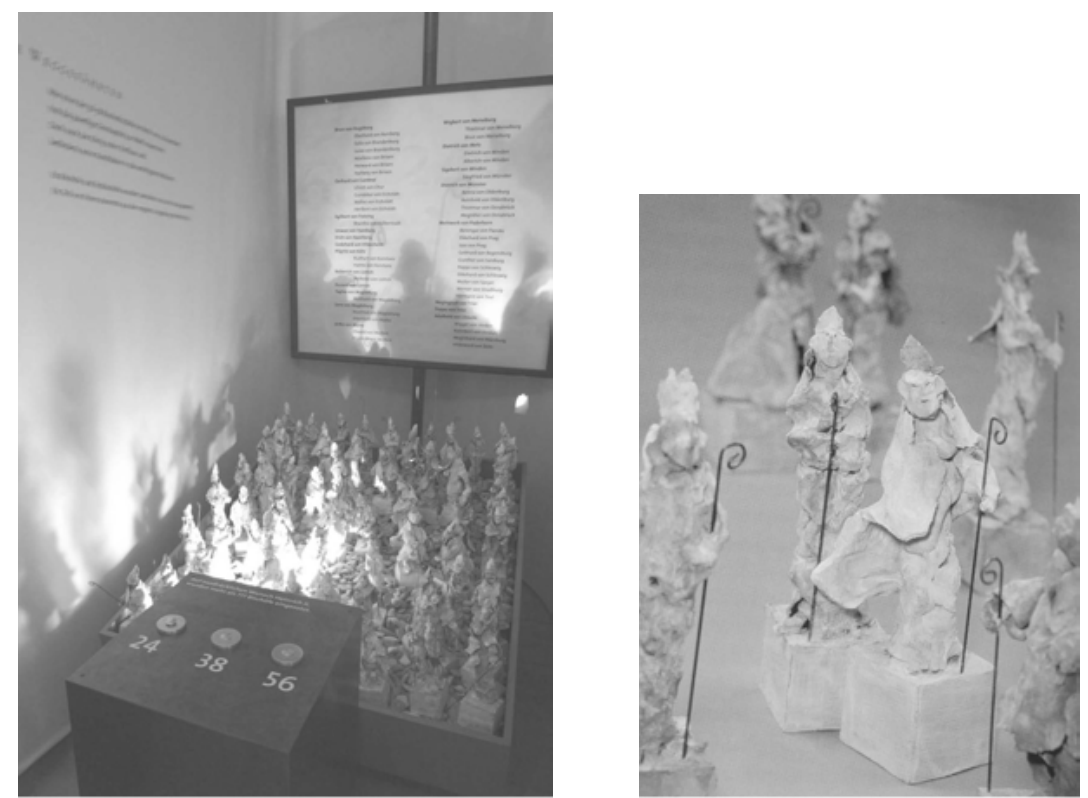

Abbildung 64/65: Inszenierung „Treue Weggefährten Heinrichs II.“ in einer Koje des Raumes „Unterwegs im Reich“von Rosemarie Zacher.

Die Keramikfiguren dienten der Verlebendigung des inneren Zirkels um Heinrich II. Die Absicht bestand darin, mit den Figuren skizzenhafte Entwürfe einer nicht wieder belebbaren Vergangenheit zu schaffen, die über die bloße Rekonstruktion hinaus sogar individuelle Züge trägt. Die handgeformten Plastiken verweisen auf die Menschen ihrer Zeit als Schlüssel zu einer weit zurückliegenden und fremd erscheinenden Epoche:

„Der Joviale, der zurückhaltend Vorsichtige, der Taktierer, der mürrisch Verstockte, der Eingeweihte, der Skurrile, die graue Eminenz sind hier versammelt in ihrer Gegenwart." (Brockhoff, Evamaria in: Kirmeier u.a. 2002., S. 241). 
Die Dargestellten verweisen auch auf unsere Gegenwart: Dies drückt sich in ihrem Erscheinungsbild aus. Die Spuren des Herstellungsprozesses bleiben durch Fingerabdrücke im gekneteten Lehm bestehen.

„Die kalkig gesinterte Patinierung verbirgt nicht, dass es sich hier um eine Suche nach dem Menschlichen im Menschen handelt, wobei ein heiterironischer Grundzug, wie er sich im Werk von Rosemarie Zacher häufig feststellen lässt, den cantus firmus der Personengruppe bildet.“ (ebd.)

Wie bereits festgestellt, wurden mit dieser Einheit zwei verschiedene Ziele verfolgt. Einerseits dienten diese Bischöfe dem didaktischen Ziel der Illustration ihrer großen Zahl. Andererseits war dies eine zeitgenössische künstlerische Interpretation, die sich mit den menschlichen Zügen der Bischöfe befasste. Sie versuchte den entindividualisierten Bischöfen, reduziert auf eine blanke Zahl, die Anonymität zu nehmen und wieder einen individuellen Charakter zu verleihen. Präsentiert wurden die Bischöfe kniehoch in einer Ebene dicht aneinandergereiht mit gleichmäßiger Beleuchtung. Dies förderte zwar das didaktische Anliegen, der künstlerische Ausdruck hingegen konnte auf diese Art kaum erfahren werden. Damit der Detailreichtum der individuellen Charaktere der Bischöfe hätte sichtbar werden können, wäre eine andere Präsentation, beispielsweise in verschiedenen Ebenen jeweils auf einzelnen Sockeln mit Spotlichtern beleuchtet, nötig gewesen. Dies hätte jedoch dem Ziel der Präsentation der hohen Zahl widersprochen. Die Wahrnehmung des Besuchers wäre in eine andere Richtung gelenkt worden. Die Wahlmöglichkeiten der Aufmerksamkeit traten in Konkurrenz, und so nahm man in Kauf, dass die Figuren in ihrer Individualität zurücktraten.

Deshalb fehlte auch eine Objektbeschriftung mit einem Hinweis auf die Künstlerin und ihre Arbeit. Dies wäre allerdings wichtig gewesen, um den Besuchern den Wechsel vom narrativen Erzählprinzip hin zur individuellen, künstlerischen Annäherung an das historische Thema deutlich zu machen. Ein klärender Kommentar hätte dem Besucher transparent machen können, dass diese künstlerische Interpretation eine ergänzende Sichtweise zur historisch-archivalischen Rekonstruktionsarbeit darstellt.

Als methodische Maßnahme der Differenzierung boten sich aufgrund der räumlichen Situation mit unterschiedlichen Ausstellungsorten ideale äuBere Bedingungen an und ermöglichten eine klare räumliche Trennung zwischen einer objektorientierten Präsentation in Abgrenzung zu den 
inszenierten Bereichen. Damit konnte bereits durch die unterschiedlichen Ausstellungsbereiche eine konsequente äußere Differenzierung umgesetzt werden. Die vorrangig an den kostbaren musealen Exponaten interessierten Besucher konnten ihre Interessen in den beiden Schatzkammern des Diözesanmuseums sowie in der Staatsbibliothek befriedigen. Damit wendeten sich diese zwei Bereiche primär an das Fachpublikum. Im Gegensatz dazu sollte mit der Rekonstruktion des Mittelalterlichen Gehöfts die „Zielgruppe der Nicht-Museumsbesucher" ${ }^{\text {“140 }}$ über die haptisch - sinnliche Ebene angesprochen und dieser damit eine emotionale Einstimmung ermöglicht werden. Auch der inszenierte Parcours durch die Alte Hofhaltung war für ein breites Publikum konzipiert, gemäß dem Auftrag des Hauses der Bayerischen Geschichte, das historische Bewusstsein in der gesamten bayerischen Bevölkerung zu mehren.

„Wir wollen die Nicht-Akademiker ansprechen. Der informierte Besucher ist ein begehrter Ausstellungsbesucher, weil er zum einen sicher kommt und zum anderen einen Katalog kauft. Aber jeder, den ich zusätzlich gewinnen kann, der normalerweise in keine Ausstellung geht, ist mir persönlich wichtiger." (ebd.)

Als spezielles Angebot für die jüngeren Besucher gab es darüber hinaus den Kinderpfad (siehe Abb. 39/40). ${ }^{141}$ Die Alte Hofhaltung wandte sich an das breite Publikum. Dementsprechend wurde dort versucht, gemäß einer inneren Differenzierung den unterschiedlichen Interessenslagen gerecht zu werden, indem - wie bereits dargestellt - unterschiedlichste Formen der Aneignung angeboten wurden, die alle Sinne ansprachen. Den Wissensbedarf nach weiterführenden Informationen deckte zum Beispiel das gestaffelte Angebot an Texten. Für Eilige standen die kurz gefassten Raumtexte zur Verfügung, wer mehr wissen wollte konnte weiterführende Hintergrundinformationen über die PC-Stationen abrufen.

140 Interview mit Herrn Dr. Josef Kirmeier, Projektleitung der Landesausstellung „Kaiser Heinrich II. 1002-1024“ des Hauses der Bayerischen Geschichte, am 17. Oktober 2001.

141 Beschreibung des Kinderpfades siehe Kapitel 6, S. 314. 


\section{Ergebnisse der Besucherbefragungen}

Die künstlerische Inszenierung „Treue Weggefährten Heinrichs II.“ bewerteten die Besucher sehr unterschiedlich, ohne eine klare Befürwortung oder Ablehnung, jedoch mit differenzierten Antworten unter Abwägung unterschiedlicher Aspekte. Der hauptsächliche Grund für den Besuch einer Geschichtsausstellung besteht für einen historisch interessierten Menschen darin, zusätzliche Information über die Historie zu gewinnen: Aus einem Fantasieprodukt jedoch könne man nichts über Geschichte lernen, so die Meinung dieser Interessensgruppe. Der Hauptgrund für die Ablehnung dieses künstlerischen Elements bestand darin, dass aufgrund mangelnder Authentizität kein Bezug zu Heinrich II. gesehen wurde. Unklar war, mit welcher Motivation künstlerische Elemente in eine historische Ausstellung integriert werden. Würde ein Interesse an Kunst bestehen, dann wäre man in eine Kunstausstellung und nicht in eine historische Ausstellung gegangen.

„Der Sinn der Fahrt nach Bamberg ist das Interesse an der Geschichte Heinrichs II. Ohne die Legitimität dieser Form bestreiten zu wollen: Da ich mein Aufnahmevermögen ökonomisch nützen muss, lasse ich Dinge dennoch weg, die mir persönlich nicht wichtig sind.“ (Senior, geb. 1920)

Die allgemein visuell orientierten Menschen befürworteten dieses Element, weil es Abwechslung bietet und neugierig macht. Die Ausstellung wirke weniger streng. Im Rundgang bedeutet dies Erholungsphasen, da es hier nicht nötig sei, sich Information anzulesen, sondern diese spielerisch mitgenommen werden können, ohne sich nochmals intensiv mit einem Thema befassen zu müssen.

„Dies ist schön.“ (Lehrerin, geb. 1948)

"Auf poetische Art wird der Mangel an Archivalien ausgeglichen und ein Weg zur Visualisierung von Vergangenheit gefunden." (Germanist, geb. 1970)

Einer generellen Befürwortung des Einsatzes von Künstlern als Gestaltern stehen viele positiv und zugleich kritisch gegenüber. Es müsse darauf geachtet werden, in welcher Formensprache dieser das Kunstwerk umsetzt. So dürfe es weder zu abstrakt werden, da die Aussage entschlüsselbar bleiben solle, genauso wenig solle es aber zu konkret sein, um die Offenheit der Deutung zu gewährleisten. 
Aufgrund der besonderen Situation des direkten Nebeneinanders von einem inszenierten Bereich im Vergleich zur objektorientierten Präsentation drängte sich die Frage geradezu auf, wie dieses Nebeneinander vom Publikum aufgenommen wurde und welcher Präsentationsform der Vorzug gegeben wurde. Diese Frage stellten sowohl die SIM-Untersuchung wie auch ich in den persönlichen Besucherinterviews.

Die SIM-Studie untersuchte, wie die Ausstellungsbesucher die Einteilung in fünf Ausstellungsbereiche mit dem Dom, dem Mittelalterlichen Gehöft, der Alten Hofhaltung, der Staatsbibliothek und dem Diözesanmuseum werteten. Eine klare Mehrheit von $78 \%$ hielt dieses Konzept für gut, mit der Begründung eine bessere Möglichkeit der Pausengestaltung zu haben $(16 \%)$ und auch größere Abwechslung zu erleben (Fröhlich/Nöthen 2003, S. 60). ${ }^{142}$

Um ein differenziertes Bild zu erhalten, forderte die SIM-Untersuchung das Ausstellungspublikum auf, die fünf Ausstellungsbereiiche in eine Rangfolge zu bringen. Dabei zeigte sich, dass die Alte Hofhaltung mit einem mittleren Rangwert von 1,82 am besten bewertet wurde, gefolgt vom Diözesanmuseum $(2,11)$ und der Staatsbibliothek $(2,47)$. Den letzten Rang nahm das Mittelalterliche Gehöft ein (ebd., S. 62). ${ }^{143}$ Bestätigt wurde mit der SIM-Untersuchung die Annahme, dass Personen mit geringerem Bildungsabschluss inszenierte Formen bevorzugen bzw. dass objektorientierte Präsentationen mehr für das Fachpublikum ausgerichtet sind.

„Die Alte Hofhaltung wurde von den Befragten ohne bzw. mit Hauptschulabschluss am besten bewertet, wohingegen die Staatsbibliothek von den Akademikern den Vorzug erhielt. Das Mittelalterliche Gehöft bekam einen um so höheren Rangplatz zugeteilt, je niedriger der Bildungsabschluss der Befragten war.“ (ebd., S. 63)

Ein ähnliches Ergebnis zeigte sich auch im Vergleich der fünf Ausstellungsbereiche bezüglich des Besucherinteresses an Kunst und Malerei. Den Niedriginteressierten gefiel die Alte Hofhaltung häufiger, wohingegen die Staatsbibliothek eher von den Hochinteressierten bevorzugt wur-

142 Die Besucher konnten zwischen drei Bewertungskategorien wählen: Halte ich für gut, teils/teils, halte ich nicht für gut. In einer offenen Antwort konnten die Besucher ihre persönlichen Gründe nennen, weshalb sie das Konzept für gut bzw. nur teilweise gut bzw. nicht für gut hielten.

143 Die Besucher sollten dem Ausstellungsbereich, der am besten gefiel den Rang 1 zuteilen, demjenigen der am zweitbesten gefiel den Rang 2 usw. 
de (ebd., S. 65). Auch die Häufigkeit der Ausstellungsbesuche hat laut SIM-Untersuchung einen Einfluss auf die Beurteilung der fünf Ausstellungsbereiche. Gelegenheitsbesucher wiesen der Alten Hofhaltung und dem Mittelalterlichen Gehöft im Schnitt höhere Ränge zu, wohingegen die habituellen Besucher der Staatsbibliothek den Vorzug gaben (ebd.).

Die Ergebnisse lassen laut SIM-Studie klar erkennen, dass unterschiedliche Besuchergruppen von jeweils anderen Ausstellungsteilen angesprochen wurden. Dementsprechend können über die Auswahl und Gestaltung der Ausstellungsteile gezielt bestimmte Besuchertypen angesprochen und $\mathrm{zu}$ einem Ausstellungsbesuch angeregt werden (ebd., S. 71).

Diese Ergebnisse können durch meine persönlichen Interviews tendenziell gestützt werden. Bestätigt werden kann die These der SIMUntersuchung, dass Personen mit geringerem Bildungsabschluss eher von inszenierten Formen angesprochen bzw. dass objektorientierte Präsentationen vom Fachpublikum bevorzugt werden. Wie jedoch in den persönlichen Interviews auch deutlich wurde, bedeutet dies in der Umkehrung nicht, dass Besucher mit hohem Bildungsabschluss inszenierte Formen ablehnen. Auch hier gab es unterschiedliche Positionen von lobender Erwähnung bis hin zu abwertenden Kommentaren. Nicht allein der Bildungsabschluss ist das entscheidende Kriterium für die Bevorzugung bestimmter Präsentationsformen, sondern weitere Komponenten wie persönliche Vorlieben und Interessen beeinflussen die Bewertungen.

Im Hinblick auf die Gestaltung wurde die Mischung der Präsentationsarten positiv hervorgehoben. Die historisch orientierten Menschen könnten zwar auf die inszenatorischen Elemente verzichten, dieses jedoch gefällt gerade den visuell orientierten Menschen. Sie schätzten die Unterschiedlichkeit des Informationsangebots auf verschiedenen sinnlichen Ebenen. Auch die Wege zwischen den einzelnen Ausstellungsorten wurden als angenehme Abwechslung empfunden, die der oft zitierten Museumsmüdigkeit entgegenwirkt.

„In der Alten Hofhaltung ist jeder Raum für sich eine kleine ExtraAusstellung, das Raumerlebnis wechselt und hält wach, bei der Art der Präsentation wie im Diözesanmuseum macht man irgendwann zu." (Betriebswirt, geb. 1957)

Die unterschiedlichen Präferenzen bezüglich der Präsentationsform lassen sich ebenfalls den verschiedenen Gruppen zuordnen. Eine klare Bevorzugung eines der zwei Präsentationskonzepte kristallisierte sich je- 
doch nicht heraus. Jede Ausstellungsform fand in Abhängigkeit von Bildung, Vorwissen und persönlichen Vorlieben ihre Befürworter.

Tendenziell kann festgestellt werden, dass der Typus des allgemein visuell orientierten Menschen die Alte Hofhaltung bevorzugt. Historisch orientierte Menschen halten diese Form der Darstellung für problematisch. Bei einer Bewertung der unterschiedlichen Präsentationsarten fließt auch die Toleranz der Besucher sowie die aktuelle Stimmung mit ein. Manche Befragten konnten den ironisierenden Elementen der Alten Hofhaltung persönlich nichts abgewinnen, ließen diese aber als solche gelten. Andere konnten sich sehr dagegen ereifern. Diejenigen, die das Präsentationskonzept der Alten Hofhaltung bevorzugten, gaben folgende Gründe an:

- Das Geschichtsinteresse wird bedient.

- Das ironische Element lockert den Rundgang auf, denn „vor Ehrfurcht erstarren ist nicht mehr zeitgemäß.“

- Die Möglichkeit zu Aktivität sorgt für eine längere Aufenthaltszeit.

- Durch die Inszenierung entsteht ein bildlicher Eindruck. Dadurch wird die Erinnerung plastischer, vom Gesamteindruck bleiben folglich mehr Bilder in Erinnerung.

- Die Information wird zwischen den Zeilen vermittelt, es gibt nicht nur Objekte, sondern Themenkomplexe.

- Durch die Beanspruchung aller Sinne ist die Vermittlung nicht so trocken. Es ist lebendig und macht Spaß.

- Die Gestaltung zeugt von Einfallsreichtum.

Ein anderer Teil der Besucher befürwortet generell Inszenierungen, steht jedoch der Art und Weise, wie dies in der Alten Hofhaltung der Fall war, eher ablehnend gegenüber. Das abgebrannte Mittelalterliche Gehöft hätte deren Vorstellungen eher entsprochen. Basierend auf wissenschaftlichen Forschungen könnten Inszenierungen akzeptiert werden, da diese dann $\mathrm{zu}$ einem besseren Vorstellungsvermögen beitragen. Inszenierungen sollten nach Meinung dieser Besuchergruppe wiedergeben, wie es zur damaligen Zeit war, wie die Menschen vielleicht Dinge gesehen oder empfunden haben könnten.

Die Befürworter der objektorientierten Präsentation im Sinne des Diözesanmuseum gaben folgende Gründe an:

- Die Objekte können ohne Ablenkung in Ruhe betrachtet werden. 
- Der ästhetische Genuss beim Betrachten der Originalobjekte steht im Vordergrund, die Historie ist weniger wichtig, diese kann in Ruhe daheim im Katalog nachgelesen werden.

- Die Würde der Objekte soll gewahrt bleiben, aus diesem Grund können die sakralen Objekte nicht in einer inszenierten Form mit witzigem Unterton wie in der Alten Hofhaltung präsentiert werden.

Die salomonische Lösung in der Kombination unterschiedlicher Präsentationskonzepte hielten die meisten Besucher für das Beste. Das Nebeneinander wurde als angenehm empfunden, da unterschiedliche Interessensgebiete abgedeckt werden konnten.

„Die Mischung macht's! Man kann nicht sagen, entweder oder, sondern jede Präsentationsform hat in seinem Wollen ihre Berechtigung. Dies ist abhängig von den Exponaten, Inhalten und Zielen, hierfür gibt es keine Pauschalantwort. Wirklich differenzierte Vermittlung geht nur über strukturierten Unterricht." (Studentin, Vergleichende Sprachwissenschaft, geb. 1981)

\subsection{Analyse unter den Dimensionen metakommunikativer Aspekte}

Mit diesem Kapitel soll der Blick auf Zusammenhänge geworfen werden, die sich nicht direkt auf Objekte und deren Geschichten beziehen. Damit geraten die Metafunktionen von Ausstellungen ins Blickfeld. Kulturhistorische Ausstellungen lassen sich gegenwärtigen Situationen sowie aktuellen politischen und wirtschaftlichen Interessenslagen anpassen. Der Ausstellungsbetrieb ist daher besonders geeignet für die „Forcierung von Metafunktionen“"144, denn Ausstellungen sind nicht nur als Foren für politische Darstellung, sondern darüber hinaus auch als Wirtschaftsfaktor relevant.

\section{Die politische Dimension}

Das Haus der Bayerischen Geschichte als geschichtliche Ausstellungsund Publikationszentrale versteht sich als staatliche Institution, die im Auftrag staatlicher Organe wie durch eigene Sacharbeit tätig wird (Vollhardt 2003, S. 152). Bereits während der langen Entstehungsphase vor

144 Fliedl zitiert in Schober 1994, S. 55. 
der formellen Gründung des Hauses zeugen die Diskussionen und kritische Presseäußerungen von der Befürchtung, dass dieser Ort zur bayerischen Selbstpräsentation politisch funktionalisiert werden könne (ebd., S. 89). ${ }^{145}$ So wurde zum Beispiel das Vorhaben, den Sitz des Instituts in der Bayerischen Staatskanzlei in München zu verwirklichen, aufgrund öffentlicher Proteste revidiert. Die SPD-Opposition im Landtag kritisierte heftig die auf dem Gelände vorgesehene Kombination von Politik und Geschichte und sprach von einem ,zum Wurmfortsatz der Staatskanzlei degeneriert[en], ${ }^{146}$ Haus der Bayerischen Geschichte. Auch der SPD-Abgeordnete Schmolcke sprach von einem Selbstbeweihräucherungsinstitut, das sich die Staatskanzlei zu machen anschicke.

,[Die] räumliche Nähe zwischen der unionsgeführten Staatsregierung und der Geschichtsbehörde suggeriere sozusagen die Identität von bayerischer Geschichte und bayerischer Gegenwart im Zeichen der Staatspartei CSU, affirmiere damit die bestehenden Parteienverhältnisse und lasse auch eine inhaltliche Kongruenz befürchten.“147

Da die ursprüngliche Leitidee einer zentral angesiedelten, fest installierten Dauerausstellung zur geschichtlichen Selbstdarstellung Bayerns aufgegeben wurde, entfiel auch die Notwendigkeit nach einer repräsentativen baulichen Manifestation. Die Aufgabe der Konzeption und Durchführung von Wechselausstellungen in jeweils verschiedenen Städten konnte auch dezentral erledigt werden. So befindet sich der heutige Sitz des Hauses der Bayerischen Geschichte in Augsburg in einem neutralen Bürogebäude in der Nähe des Bahnhofs.

145 Auch das im Jahr 2002 eröffnete Haus der Geschichte Baden-Württemberg hat eine über zwei Jahrzehnte dauernde Entstehungsgeschichte. Es stand von Anfang unter Ideologieverdacht. Dies führte zu Verzögerungen bei der Verwirklichung des Vorhabens. „Die LandtagsOpposition keuchte unter nächtlichen Alpträumen, in denen das Geschichtshaus als Ruhmeshalle der Landes-CDU erschien." Vgl. Ruf, Reiner: Eine schwere Geburt - Schau für die Sinne - und keine historische Sinnstiftung. http://www.suedwest-aktiv.de (letzter Zugriff: 13. 12.02).

146 Böddrich (SPD) zitiert in Vollhardt, 2003, S. 154.

147 Schmolcke zitiert in Vollhardt 2003, 154. Bereits zuvor war auch in der Presse befürchtet worden, dass unter der Ägide des Ministerpräsidenten Strauß eine Propagandaschau im Sinne des „,schönen neuen Bayern“ entstehe. Hackelsberger, Christoph: Der Hofgarten, Besitz der Bürger. In: Süddeutsche Zeitung vom 08./09.12.84. 
Diese Diskussion um den Sitz des Instituts verweist jedoch auf den tatsächlichen Zusammenhang von Politik und Öffentlichkeitsarbeit. So geht auch Grimm, der Direktor des Hauses der Bayerischen Geschichte, in der Jubiläumsschrift zum zwanzigjährigen Bestehen auf diese Problematik ein. Sensibilisiert durch die zahlreichen Kontroversen im Vorfeld der Gründung des Hauses wurde dem anfänglichen Vorwurf kritischer Beobachter einer politischen Einflussnahme der Bayerischen Staatskanzlei bewusst entgegengetreten. Durch Themenwahl sowie inhaltliche Gestaltung der Ausstellungen sollte das Gegenteil bewiesen werden (Grimm 2003, S. 17). ${ }^{148}$

Für die Mitarbeiter des Hauses und die öffentliche Präsentation gilt, dass Texte weder den wissenschaftlichen Anspruch einzelner Verfasser hervorheben noch „staatsamtliche Definitionen“ sein dürfen. Vielmehr ist darauf zu achten, dass die abgesicherte Information den „ForumsCharakter des Hauses“" gewährleistet (ebd.). Orientiert an zeigbaren Gegenständen und auf nachvollziehbare Lebenszusammenhänge ausgerichtet sollen die Ausstellungen Neugier wecken (ebd., S. 19). Mit einer kulturgeschichtlichen Betrachtung soll ein Perspektivenwechsel erreicht werden, der die bayerische Geschichte nicht als abgrenzbare Entwicklung betrachtet, ,sondern als die in Bayern stattgehabte, von Bayern gestaltete und erlittene Geschichte." (ebd., S. 19). Jedoch auch die Zwiespältigkeit der Geschichte, die fern ,aller unberechtigten Selbstfeier zu vergegenwärtigen ist“, soll laut Grimm thematisiert werden.

„Neben der Entdeckung des Vorbildlichen steht die Konfrontation mit dem Abgründigen, neben dem Stolz auf Entfaltungsmöglichkeiten der eigenen Kultur steht die Mahnung des ,Nie wieder!‘. [...] Nicht die Selbstbestätigung in lieb gewonnenen Traditionen steht hinter dem Auftrag, bayerische Geschichte darzustellen, sondern die Frage nach den Möglichkeiten und Verpflichtungen, die Bayern als deutsches Bundesland und Region Europas für sich und alle Menschen, die mit ihm zu tun haben, mitbringt." (ebd., S. 19ff.)

Das Haus der Bayerischen Geschichte verfolgt damit die Intention, Geschichtsbewusstsein zu fördern, jedoch ohne staatspolitische Vereinnahmung. Trotz der angestrebten politischen Neutralität ist das Haus der

148 Die Themen der Ausstellungen wurden von Kooperationspartnern aus dem ganzen Land angeregt, von Fraktionen des Landtags ebenso wie von regionalen Mandatsträgern, und wurden dann den Austarierungsgremien wie Ausstellungskuratorien und dem Beirat des Hauses vorgelegt. Vgl. Grimm 2003, S. 17. 
Bayerischen Geschichte auf die Unterstützung der Staatskanzlei angewiesen. Da das Institut keine eigenen Objektsammlungen besitzt, kann es bei Leihverhandlungen mehr Schwierigkeiten haben, als dies bei Museen mit bedeutenden Objektbeständen der Fall ist. Deshalb sichert die Anbindung an die Staatskanzlei und das Wissenschaftsministerium die Wahrnehmung des staatlichen Auftrags.

Unter dieser politischen Dimension soll nun die Heinrichsausstellung betrachtet werden. Bereits bei den Überlegungen im wissenschaftlichen Konzept zum Titel dieser Ausstellung spiegeln sich nationale Erwägungen wieder. Schneidmüller/Weinfurter schlagen als Titel „Bayerns Triumph - Europas Glanz/Zierde“149 vor. Dies erfolgte mit der Begründung, dass sich darin deutliche Voraussetzungen und Ziele herzoglicher und kaiserlicher Politik am Beginn des zweiten Jahrtausends spiegeln würden. Die Wortwahl begründen sie auch damit, dass dies nicht, wie vielleicht vermutet, eine Erfindung bayerischer Geschichtspolitik sei, sondern auf zeitgenössischen Kommentaren basiert:

„Der Satz, daß Bayern in Heinrich II. triumphiert, wird dem italienischen Reichsbischof Geovon Vercelli verdankt (Triumphat Baioaria = Bayern triumphiert, MGH. Poetae latini 5, S. 482). Das Lob Heinrichs als Schmuck, Zierde oder Glanz (DECUS EUROPAE) hat sich auf der Inschrift des Sternenmantel Heinrichs II. erhalten.“ (ebd. S. 5)

Mit diesem Titel wären zwei Aussagen italienischer Anhänger Heinrichs II. vereinigt. Gleichzeitig wiesen Schneidmüller/Weinfurter auch darauf hin, dass dieser Titel sicherlich Diskussionen über bayerischen Geschichtsstolz hervorrufen könne, jedoch aufgrund der Authentizität einen Vorteil gegenüber anders lautenden „Kunsttiteln“ hätte (ebd.). Dieser Vorschlag wurde von den Entscheidungsträgern des Hauses der Bayerischen Geschichte nicht aufgegriffen. Dem neutralen Titel „Kaiser Heinrich II. 1002-1024“" wurde der Vorzug gegeben. Stattdessen fanden diese zeitgenössischen Äußerungen aber Anwendungen als Raumtitel. Im Raum „Der Kaiser“ stand „Decus Europae - Zierde Europas“ in weißer Schrift auf der Cortenstahl-Ummantelung der zentralen Mittelsäule (siehe Abb. 43). Im Raum „Der neue König“ war der archivalische Raumtitel „Triumphat Baioaria - Bayern triumphiert“ in schwarzer Schrift in

149 Offen blieb zunächst die Übersetzung von decus als Glanz oder Zierde. Beides war philologisch möglich. „Zierde klingt feiner, aber auch altertümlicher, Glanz plakativer, eingängiger, aber vielleicht auch aufdringlicher.“ Vgl. Schneidmüller/Weinfurter 1999, S. 5. 
Bauchhöhe auf dem beigefarbenen Vitrinenunterbau angebracht (siehe Abb. 59). Darüber war in der Vitrine das Exponat die „Nachbildung der Heiligen Lanze“, die als Christusreliquie und Herrschaftszeichen mit höchster Symbolkraft beladen ist. ${ }^{150}$

Auch die Eröffnungsrede zur Landesausstellung des Bayerischen Staatsministers Zehetmair war nicht frei von bayerischem Patriotismus. Sie begann mit dem Hinweis darauf, dass genau vor tausend Jahren erstmals ein bayerischer Herzog zum König und später zum Kaiser des mittelalterlichen Römischen Reiches gewählt wurde.

„Ich sage ganz bewusst, dass Heinrich bayerischer Abstammung war, auch wenn er noch manchmal mit Blick auf seinen sächsischen Großvater von Sachsen vereinnahmt wird. [...]. Mit Heinrich II. war für die Bayern endlich einer der Ihren Träger des Reichs geworden, [...]. ${ }^{151}$

Diese Ausstellung wurde während des Wahlkampfes zum Bundestag eröffnet. Ministerpräsident Stoiber kandidierte für das Amt des Bundeskanzlers. Mit einem Wahlsieg hätte erstmals ein bayerischer Politiker dieses Amt inne gehabt. So spiegelte sich dieser aktuelle Zusammenhang auch in den Pressekommentaren:

„Ob diese Ausstellung etwas mit der zweiten derzeit stattfindenden Baiuvarisierung Deutschlands zu tun habe, wurde Kunstminister Zehetmair gestern am Rande der Ausstellung gefragt. Da schluckte der ansonsten so eloquente Bayer erst einmal. Natürlich bezweifle er als Mann der CSU nicht, dass Herr Stoiber sich bestens als Diener des Staates eigne.“152

In noch deutlichere Worte fasste diesen Zusammenhang die Schlagzeile „Wie ein Bayer von Deutschland Besitz ergriff. Kaiserkandidat vor tausend Jahren: die Bamberger Ausstellung über Heinrich II.“" ${ }^{153}$ Obgleich in dem Artikel keine Verknüpfung zum Kanzlerkandidat Stoiber herge-

150 Siehe Kapitel 5, S. 239f. sowie Kapitel 6, S. 347f.

151 Rede des Bayerischen Staatsministers für Wissenschaft Forschung und Kunst, Hans Zehetmair, anlässlich der Eröffnung der Bayerischen Landesausstellung 2002 „Kaiser Heinrich II. 1002 - 1024“ am 8. Juli 2002 in Bamberg. Schriftlicher Abdruck der Presseinformation. S. 1.

152 Kirch, Raimund: Wie Bamberg zum Zentrum des Reiches wurde. In: Nürnberger Zeitung vom 09.07.02.

153 Schostack, Renate: Wie ein Bayer von Deutschland Besitz ergriff. In: Frankfurter Allgemeine Zeitung vom 23.07.02. 
stellt wurde, verwies dieser dennoch subtil auf vergleichbare Ambitionen.

Das Ziel dieser Landesausstellung bestand unter anderem darin, den im kollektiven Gedächtnis vergessenen Herrscher Heinrich II. wieder in Erinnerung zu rufen und damit auch auf die Leistungen dieses Herrschers bayerischer Abstammung zu verweisen. Mit den Raumtiteln „Der neue König - Triumphat Baioaria - Bayern triumphiert“ sowie „Der Kaiser - Decus Europae - Zierde Europas" wird unmissverständlich auf die historische Bedeutung Bayerns verwiesen. Berechtigt erscheint in diesem Kontext deshalb die Feststellung, dass diese Landesausstellung auch der Selbstdarstellung Bayerns diente.

Kulturhistorische Ausstellungen übernehmen integrierende Funktion, indem sie Identifikationsangebote bereit stellen. Sie bieten beispielsweise „national oder territorial gefärbte Wir-Identitäten“ oder „Identifikationsmöglichkeiten mit Herrscherdynastien“. (Schober 1994, S. 58ff.). In diesen Fällen dienen nach Ansicht von Schober Ausstellungen der Projektion von Wunschvorstellungen der Gegenwart in die Vergangenheit. Die Identifikationsangebote werden dabei den je aktuellen politischen Interessenslagen angepasst (ebd.).

Weiterhin stellt Schober fest, dass neben diesen Regionalidentitäten gegenwärtig auch verstärkt versucht wird, über Ausstellungen europäische Identität zu vermitteln. ${ }^{154}$ Auch dies trifft auf die Heinrichsausstellung zu. Wie bereits an mehreren Stellen erwähnt, wurde mit dem Raum „Der Kaiser“ die europäische Bedeutung des Herrschers illustriert. Auch im Kontext der weiteren großen Mittelalterausstellungen zur Jahrtausendwende kann diese Feststellung untermauert werden. Die Ausstellung „Europas Mitte um 1000“ thematisierte die mit dem Eintritt der Westslawen und Ungarn in den abendländischen Kulturkreis beginnende Genese der Mitte Europas. ${ }^{155}$

„Heute, an der Wende vom zweiten zum dritten Jahrtausend, gewinnt die Frage nach dem gemeinsamen, die Ausbildung nationaler Vielgestaltigkeit und Individualität tragenden Fundament an Bedeutung. Polen, Tschechen und Un-

154 Dieses war beispielsweise in der von Fiat finanzierten Großinszenierung „i celti - la prima Europa“ der Fall, die 1991 im Palazzo Grassi in Venedig stattfand. In dieser wurde das heutige Europa in die Zeit der Kelten zurückprojiziert, wobei diese als erste Europäer identifiziert wurden. Vgl. Schober 1994, S. 59.

155 Siehe Kapitel 5, Anm. 52 und 67. 
garn wurden um das Jahr 1000 Teil eines sich zur geistig-kulturellen Einheit formenden Europa, [...]. Der Blick in die europäische Vergangenheit eröffnet so den Blick in die europäische Zukunft. ${ }^{156}$

Jedoch ist, wie Helzel beobachtete, die Tendenz bemerkbar, dass bei den Ausstellungen zu den wichtigen mittelalterlichen Kaisergeschlechtern der Salier, Staufer und Ottonen in den vergangenen Jahrzehnten die nationale Erinnerung hinter der europäischen Ausrichtung verschwindet. $^{157}$

An Bedeutung gewinnen auch touristische und damit ökonomische Gesichtspunkte. Die Ausstellung „Otto der Große, Magdeburg und Europa“ war mit täglich fast zweitausend Besuchern ein enormer Erfolg. Gelobt wurde das aktive Standortmarketing, das den Magdeburger Tourismuseinrichtungen nie gesehene und erlebte Zuwachsraten bescherte (ebd., S. 288). Mit Blick auf die Ottonen-Ausstellung kritisiert Helzel, dass bei aller Europa-Orientierung die Rezeption der Vergangenheitsbilder eines Jahrtausends keinen Widerhall in der Ausstellung fand. Ohne Objekte in der Ausstellung thematisierte lediglich Fried am Schluss des EssayBandes dieses Thema. Als einziger stellte er über eine Rezeptionsanalyse eine Verbindung zwischen den historischen Ottonen und der Gegenwart her, die schließlich zoomend an die unmittelbare, nationalsozialistische Vergangenheit heranreicht. ${ }^{158}$ Doch wegen dieser Erinnerung wäre man, wie Helzel einschränkend anmerkt, nicht so massenhaft nach Magdeburg gepilgert. „So bleibt das restaurierte Wandgemälde von 1906 im Ausstellungsgebäude mit Otto dem Großen als Krieger und Sieger über Slawen und Wenden stumm.“ (Helzel 2004, S. 290).

156 Wieczorek, Alfried, Kretzschmar, Ulrike: Exposé zum Ausstellungsprojekt „Europas Mitte um 1000“. Stand: 11.05.99, Mannheim, 1999.

157 Helzel, Frank: Ein König, ein Reichsführer und der Wilde Osten. Heinrich I. (919 - 936) in der nationalen Selbstwahrnehmung der Deutschen. Bielefeld, 2004, S. 287.

158 Siehe Kapitel 2, Anm. 40-46 sowie Kapitel 5, Anm. 66. 


\section{Die ökonomische Dimension}

Eine weitere Metafunktion von Ausstellungen stellt die wirtschaftliche Seite dar. Transportfirmen, Verlage, Reisebüros, Verkehrsunternehmen, Hotel- und Restaurantbetriebe, Bauunternehmen, Andenkenläden, Boutiquen u.s.w. profitieren von diesen kulturellen Großveranstaltungen. Somit bilden die Landesausstellungen neben dem Bildungsauftrag des Hauses der Bayerischen Geschichte eine Möglichkeit, den Tourismus und Einzelhandel in den Regionen zu fördern. ${ }^{159}$ Die Heinrichsausstellung hatte aufgrund der unerwartet hohen Besucherzahlen einen nachhaltig positiven Einfluss auf Handel, Gewerbe und Hotellerie in Bamberg und Umgebung. Bei der Stadt Bamberg deckten die Einnahmen alle Ausgabenposten und sogar ein Überschuss konnte verbucht werden. ${ }^{160}$

„Auch der Einzelhandel profitierte unmittelbar vom Heinrich-Boom, der Bamberg erfasste. Mit Ideenreichtum machte die Bamberger Geschäftswelt Heinrich und Kunigunde zum kulinarischen Wirtschaftsfaktor: HeinrichPralinen, Kaiser-Heinrich-Brot, Kunigundenkringel oder das Kaiser-HeinrichBier waren wahre Verkaufsschlager.“161

159 Die Ausstellung hatte einen staatlichen Etat von 1,3 Mio. Euro. Die Stadt stellte die Räume kostenlos zur Verfügung und beteiligte sich an Begleitkosten mit 70.000 Euro. Hinzu kam eine Förderung durch die Oberfrankenstiftung in Höhe von 150.000 Euro. Dieser für Mittelalterausstellungen äußerst geringe Finanzansatz war nur in diesem speziellen Fall möglich, weil Kaiser Heinrich der Stadt Bamberg eine Vielzahl von Exponaten geschenkt hat, die sich zum großen Teil noch hier befinden. Die Ausstellung konnte so zu einem erheblichen Teil mit Exponaten der drei beteiligten Institutionen Staatsbibliothek, Diözesanmuseum und Historisches Museum bestritten werden. Dies sparte erheblich an Versicherungs- und Transportkosten. Vgl. Kirmeier 2003, S. 4

160 Lauer, Herbert: Landesausstellung „Heinrich II.“ als Wirtschaftsfaktor/Stellungnahme der Stadt Bamberg. In: Haus der Bayerischen Geschichte (Hrsg.): Expertentagung „Ausstellung und Tourismus“ vom 26. bis 27. Febr. 2003 in Kloster Banz. 2003, S. 15.

161 Auch die Zahl der Gästeankünfte stieg ab Beginn der Ausstellung deutlich an, die Hotels waren bis weit ins Umland ausgebucht. N.N: „Bamberg hat gar nichts Besseres passieren können.“ Landesausstellung „Kaiser Heinrich II.“ endete mit Rekordergebnis. http://www.bamberg.de/ rathaus/journal/021101t1/htm (letzter Zugriff: 30.11.04). 
Der große Erfolg der Landesausstellung lässt sich auf ein Bündel von Faktoren zurückführen. Allein das reizvolle Ambiente um den Bamberger Dom besitzt an sich bereits hohe Attraktivität. Professionelle Pressearbeit wie auch das umfangreiche Rahmenprogramm lockten viele Besucher an. Einen weiteren Baustein für die positive Resonanz bildete das besucherorientierte Ausstellungskonzept, welches insbesondere in der Alten Hofhaltung und mit dem Gehöft auf eine populäre Form der Wissensvermittlung setzte. Dieser am breiten Publikum orientierte Weg führte insbesondere beim kritischen Fachpublikum zu höchster, zum Teil auch polemischer Kritik und Ablehnung.

„Die Grenzen zwischen wertvollem Exponat, Vitrinen und improvisierter Präsentationsarchitektur werden dabei mit aller Gewalt vermischt, etwa indem man zur Betrachtung von Exponaten kleine Türen in einer MDF-Platte öffnen muss. [...] Beschallungen mit Klischeegeräuschen, interaktive Computersimulationen, geneigte Rampen mit naturnaher Beschichtung, Fühlkästen und Riechlöcher inszenieren eine umfassende Inanspruchnahme aller Sinne. [...] Es entsteht ein Potemkinsches Dorf der hyperreal gewordenen Historie, eine Art didaktischer Geisterbahn, ohne jeden inneren Bezug zur Anmutung und Präsenz der ausgestellten Objekte.“162

Diese exemplarisch herausgegriffene Meinung steht stellvertretend für kritische Kommentare, die insbesondere den inszenierten Parcours in der Alten Hofhaltung betrafen. ${ }^{163}$ So stellt sich nun die Frage, ob der Vorwurf der Trivialisierung und Disneysierung an das Haus der Bayerischen Geschichte gerechtfertigt ist. Wurden mit der Inszenierung in der Alten Hofhaltung die Grenzen überschritten? Insbesondere der oft als flapsig empfundene Papstfilm bewirkte sehr unterschiedliche Reaktionen.

Raum: „Der Friedenskuss“,

Filmsequenz: „Nachrichtensendung zum Papstbesuch in Bamberg“

Im Raum „Der Friedenskuss“ illustrierte ein unter der Regie von Rainer Lewandowski entstandener Film das historische Ereignis des Besuchs des Papstes Benedikt VIII. in Bamberg zur Osterzeit im Jahr 1020 ${ }^{164}$ In Analogie zu aktuellen Nachrichtensendungen kündigte eine Fernseh-

162 Schebler, Gerhard: Im und wider das Museum führen. (unveröffentl. Skript) Hauptseminararbeit an der Ludwig- Maximilians-Universität, Fakultät Kunstpädagogik, München 2004, S. 19.

163 Auch im Besucherbuch finden sich derart negative Kommentare.

164 Kirmeier u.a. 2002, S. 234, Nr. 85 B. 
sprecherin einen Filmbericht über den Papstbesuch an, der über die Ankunft des Papstes, die Vertragsverhandlungen sowie das Festbankett informierte. In karikierender Weise agierten die Schauspieler in extrem übersteigerter Mimik und Gestik. Nach Ende des Filmberichts folgte die Wettervorhersage. Gezeigt wurde dieser Film auf einer Monitorwand mit je vier Bildschirmen in drei Reihen. Die Filmbilder liefen über die gesamten auf- und aneinandergereihten Monitore, so dass die Seitenränder der Bildschirme ein unterbrochenes Bild erzeugten.

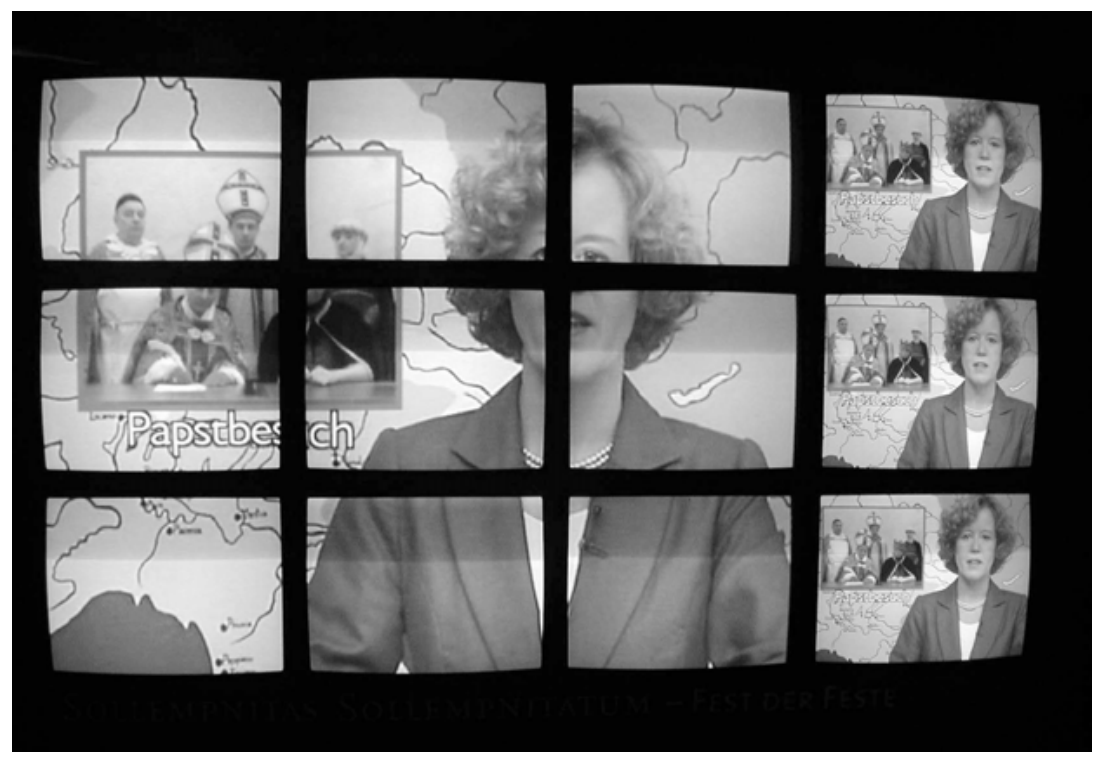

Abbildung 66: Filmsequenz, „Nachrichtensendung zum Papstbesuch in Bamberg “im Raum der „Friedenskuss“.

Durch diese Irritation sollte der Besucher erkennen, dass es sich hierbei um keine Dokumentation im traditionellen Sinne, sondern eine humorvolle Interpretation des historischen Berichts handelte. Die zugehörige archivalische Handschrift „Bericht des Diakons Bebo zum Papstbesuch in Bamberg" ${ }^{\text {"165 }}$ befand sich in einer Vitrine in der Mitte des Raumes. In diesem Widmungsbrief berichtet Bebo als Augenzeuge über den Besuch von Papst Benedikt VIII. in Bamberg. Dieser Raum erfüllte in der Ausstellungsdramaturgie ein Bindeglied zwischen dem Raum „Der Kaiser“

165 Ebd., S. 233, Nr. 85 A. 
und dem letzten Raum „Unterwegs im Reich“. Diese eher untergeordnete Funktion in der Ausstellungsdramaturgie stand im Widerspruch zur großen Aufmerksamkeit seitens der Besucher, die diese Medieninstallation erfuhr.

„Dies war wirklich nur als Persiflage oder ironischer Bruch zu den Objekten gedacht. Der Film zieht mehr Aufmerksamkeit auf sich als teilweise die hochwertigen Objekte.“166

Eine Verwechslung mit einer ernsthaften Dokumentation wurde sowohl durch die Brechung des Bildes mittels Anordnung der Monitore wie auch durch die karikierende Schauspielerei verhindert. Dennoch ist zu bedenken, was offensichtlich die Aufmerksamkeit der Besucher auf sich zieht. Es vollzog sich eine Bedeutungsverschiebung weg von den musealen Exponaten hin zu den leicht konsumierbaren, bewegten Bildern des Films. Die in der Vitrine liegenden Handschrift, in der Diakon Bebo über den Papstbesuch berichtet, erhielt meist lediglich flüchtige Blicke. Im Gegensatz dazu tritt dieser Film sowohl akustisch wie auch visuell dominant in den Vordergrund. Der humoristische Film bediente das Unterhaltungsbedürfnis der Besucher und sorgte für Auflockerung im Rundgang.

In den persönlichen Interviews der Besucherbefragung führte dieser Film zu extrem unterschiedlichen Bewertungen. Die historisch orientierten Menschen lehnten diese Form der Präsentation ganz klar ab. Die karikierende Darstellung wurde als überzeichnet und folglich wenig überzeugend empfunden. Der Kontrast zum restlichen Umfeld war zu groß.

„Dies lässt an nötiger Seriosität vermissen, um der Thematik gerecht zu werden." (Soldat, geb. 1952)

„Dieser Film ist zu karikierend und dem kirchlichen Thema nicht angemessen.“ (Hausfrau, geb. 1956)

„Der Fressfilm bemüht sich, die Begebenheit darzustellen, doch spricht dies nicht an." (Physikerin, geb. 1930)

Dies stand im Gegensatz zu dem Typus der allgemein visuell orientierten Menschen, denn diese betrachteten den Film als willkommene Ab-

166 Interview mit Herrn Dr. Christian Lankes, wissenschaftlicher Mitarbeiter beim Haus der Bayerischen Geschichte, am 6. Juli 2002. 
wechslung. Sie zeigten sich überrascht, solch ein Moment in einer historischen Ausstellung vorzufinden:

„[...] witzig, nicht nur ernst, sondern locker“ (Verkäuferin, geb. 1953)

,[...] eine originelle Umsetzung des historischen Themas“ (Hausfrau, geb. 1957)

\section{Raum „Unterwegs im Reich“, Inszenierung zum Thema Reisekönigtum} „Heuschreckenplage“ (siehe Abb. 67-71)

Eine ebenfalls kontrovers beurteilte Inszenierung befand sich im Raum „Unterwegs im Reich“. Eine sich über drei Kojen ausbreitende Inszenierung mit giftgrünen Plastikheuschrecken, die an Stoffbahnen hingen und sich am Boden verteilten, illustrierte eine Beschreibung aus der Chronik von Thietmar von Merseburg ${ }^{167}$, der 1002 von Verpflegungsproblemen in Paderborn berichtete und die unersättliche Habgier der Bayern kritisierte (siehe Abb. 69). Mit dieser Inszenierung wurde der Besuch des Herrschers mit seinem Gefolge von schätzungsweise 300 bis 1000 Menschen mit einer Heuschreckenplage verglichen. ${ }^{168}$

Ergänzt wurden die Heuschrecken mit einer Zeichnung auf der Stoffbahn, die den langen Tross der Gefolgschaft Heinrichs II. darstellte (siehe Abb. 67). In Anlehnung an die graphische Darstellung von Fahrplänen wurde der Terminkalender des Königs vom 25.12.1002 bis zum 25.12.1003 mit verschiedenen Stationen unter Angabe von Ort und Datum innerhalb eines Jahres aufgezeigt (siehe Abb. 68). Ebenfalls auf der Stoffbahn beschrieb ein Zitat aus den Quedlinburger Annalen, wie eine Seuche das kaiserliche Heer 1022 in Italien dezimierte (siehe Abb. 71). Ein weißer, stilisierter Thron in Form eines Sattels, auf einem Podest in der Mitte einer Koje platziert, symbolisierte das Reisekönigtum mit Heinrich II. als reisender Herrscher auf dem Pferd (siehe Abb. 70).

In den persönlichen Interviews zeigte sich auch hier, wie unterschiedlich das Urteil zu denselben Ensembles ausfallen kann. Neben absoluter Ablehnung und der Bewertung als eine Anbiederung an die Spaßgesellschaft ohne wissenschaftlichen Anspruch stand die Freude am

167 Ebd., S. 183, Nr. 56. Der wichtigste Chronist für die Zeit Heinrichs II. ist der dem Herrscher nahe stehende Thietmar, Bischof von Merseburg.

168 Dieser Vergleich mit einer Heuschreckenplage ist kein historisches Bild, sondern eine aktuelle Erfindung der Ausstellungsmacher. 
humorvollen Element und das Lob für eine gelungene Visualisierung und Erinnerungshilfe. ${ }^{169}$

Bei beiden Visualisierungen stellt sich die Frage, ob sie adäquate Formen für die Illustrierung historischer Sachverhalte darstellen können. Die Heuschrecken überraschten, ließen schmunzeln, bei manchen erzeugten sie vielleicht ein leichtes Schaudern, ohne jedoch ernsthaft zu irritieren, teils stießen sie auf Gleichgültigkeit oder auch Ablehnung. Ebenso zeigte sich beim Papstfilm unterschiedliche Akzeptanz durch das Publikum. Der Papstfilm kann als eine Antwort auf die Mediengesellschaft gewertet werden. Er bediente das Unterhaltungsbedürfnis und fand somit auch zahlreiche Befürworter unter den Besuchern. Würde sich die Ausstellung auf diese Form der Vermittlung beschränken, so wäre es gerechtfertigt, davon zu sprechen, dass der Bildungsanspruch zu Gunsten von populären Formen geopfert wurde.

Diese Bewertung würde jedoch der Ausstellung im Gesamten nicht gerecht werden. Für die Beurteilung dieser Frage ist auch ausschlaggebend, wie einzelne, eben auch diese populären Elemente in den Gesamtkontext eingebunden sind. Dies bedeutet, dass nicht nur die fachwissenschaftlichen Kriterien für eine Bewertung relevant sind, sondern auch gemäß eines kommunikativen Ansatzes besucherorientierte Anliegen einfließen sollten. ${ }^{170}$ Insbesondere Landesausstellungen werden für ein breites Publikum konzipiert. Aus diesem Grund ergibt sich die Notwendigkeit, im Konzept zu berücksichtigen, wie potentielle Besucher erreicht werden können. Ausstellungen unter dem hohen Anspruch der Wissenschaftlichkeit zu konzipieren und gleichzeitig den Interessen eines heterogenen Publikums gerecht zu werden, ist ein kaum lösbarer Anspruch, dennoch existiert dieses Anliegen.

Für die Heinrichsausstellung kann festgehalten werden, dass sie Elemente integrierte, wie sie sich auch bei kommerziellen Anbietern finden lassen. Sie setzte damit auf Methoden und Medien, die in erprobter Weise auf Breitenwirkung zielen. Diese Funktion erfüllte allem voran das

169 Angemerkt wurde jedoch, dass zur besseren Verständlichkeit der Heuschreckeninszenierung ein Hinweis auf diesen bildhaften Vergleich irgendwo hätte stehen sollen.

170 Kritisch angemerkt werden muss auch, dass bei manch negativen Kommentaren emotionale Befindlichkeiten in den Vordergrund treten und diese dann als Maßstab für die Beurteilung des Gesamten herangezogen werden. 
Mittelalterliche Gehöft. Es wurde auch im Hinblick auf das Erreichen der Zielgruppen der Nicht-Museumsbesucher konzipiert.

„Die Zielgruppe der Nicht-Museumsbesucher war auch der Anlass für das Gehöft auf dem Domplatz. Ich kann mir durchaus vorstellen, dass am Stammtisch über die Ausstellung geredet wird. Und für viele Bamberger, die normalerweise nicht dorthin gehen würden, ist dies der Anlass zu kommen. Daraus wird ein Gesprächsstoff. “171

In der Landesausstellung konnten zum Beispiel - wie dies auch beim Ritterturnier in Kaltenberg möglich war - Schafe gestreichelt werden. Im Unterschied jedoch befand sich in Kaltenberg der Streichelzoo bei einem Gastzelt, dessen Außenfassade als künstliche Burg aus Plastikplanen gestaltet war. Währenddessen erhob sich in Bamberg hinter dem Streichelzoo beim Mittelalterlichen Gehöft die Kulisse des Bamberger Doms.
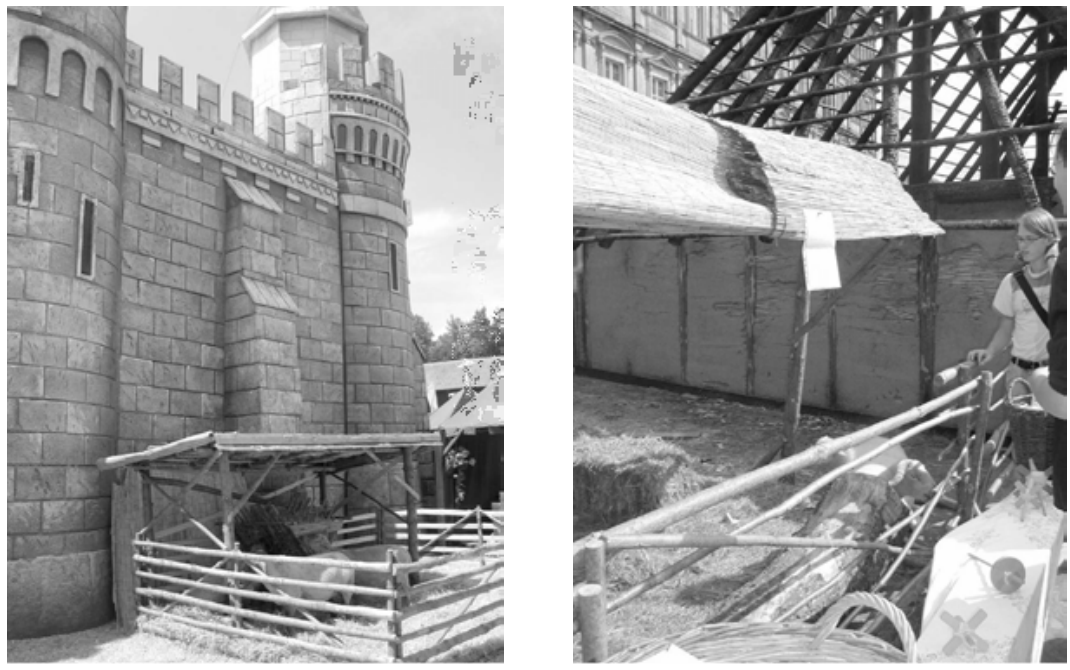

Abbildung 72/73: Streichelzoo mit Schafen sowohl beim Ritterturnier in Kaltenberg (links) als auch beim Mittelalterlichen Gehöft in Bamberg (rechts).

171 Interview mit Herrn Dr. Josef Kirmeier, Projektleitung der Landesausstellung „Kaiser Heinrich II. 1002-1024“ des Hauses der Bayerischen Geschichte, am 17. Oktober 2001. 
Auch das umfangreiche Begleitprogramm zur Landesausstellung mit Handwerksvorführungen erinnerte an das Angebot von kommerziell orientierten mittelalterlichen Märkten. ${ }^{172}$

Während jedoch die kommerziellen Anbieter ihr Angebot auf diese sinnliche Komponente zentrieren, erfüllte dies in der Landesausstellung eine hinführende Funktion mit dem Ziel, Neugier zu wecken und dazu zu bewegen, sich auf das weitere Angebot der Ausstellung einzulassen. Dem intensiven Studium und konzentrierten Betrachten der Exponate konnten sich die Besucher im Diözesanmuseum und der Staatsbibliothek widmen, ohne durch inszenatorische Einbauten abgelenkt zu werden.

Mit Inszenierungen findet somit auf ästhetischer Ebene eine Annäherung statt. Jedoch lassen sich auch hier bei genauerer Betrachtung der gestalterischen Umsetzung Unterschiede aufzeigen. Die Ziele der Inszenierungen in der Landesausstellung bestanden nicht darin, ein Ambiente „so authentisch wie nur möglich“"173 zur Schaffung ,einer Kontrastwelt mit Paradiescharakter“"174 zu kreieren. Die Rekonstruktion des mittelalterlichen Gehöfts basierte auf wissenschaftlichen Forschungen. Nach dem ursprünglichen Konzept hätte es zwar dort Schauwerkstätten mit Rekonstruktionen von Handwerksgeräten gegeben, doch wäre dies in einer musealen Präsentationsform erfolgt, ergänzt mit Objektbeschreibungen sowie Informationstafeln. Diese museale Präsentationsform im rekonstruierten Pfostenhaus wäre somit einem rein kommerziellen Anliegen, ein möglichst perfektes Ambiente zum Eintauchen in die Vergangenheit der mittelalterlichen Welt zu schaffen, hinderlich gewesen.

Weder mit der Heuschreckeninszenierung noch mit dem Papstfilm wurden klischeehafte Mittelaltervorstellungen bedient. Mit den unterschiedlichen Inszenierungen entstanden Raumbilder, die in ihrer Umsetzung Zuspruch oder Ablehnung fanden, jeweils abhängig von persönlichen Wertschätzungen. Die Raumbilder dienten der Illustrierung der Herrscherpersönlichkeit und des Umfelds von Heinrich II., und damit wurde dem Bildungsziel des Hauses der Bayerischen Geschichte entsprochen.

Kritisch angemerkt sei dennoch, dass eine Thematisierung der Konstrukthaftigkeit der Vergangenheitsbilder keinen Raum fand. In einer geschlossenen Erzählung wird der Parcours durch die Alte Hofhaltung mit den Schnitzfiguren aus dem 16. Jahrhundert geschlossen. Irritieren-

172 Beschreibung des Ritterturniers in Kaltenberg siehe Kapitel 5, S. 243.

173 Vgl. König 2004, S. 24. Siehe auch Kapitel 5, S. 249.

174 Vgl. Kagelmann 1998, S. 79. Siehe auch Kapitel 4, S. 244. 
de, kontroverse oder kritische Fragen in Hinblick auf den Heinrichskult in der Gegenwart blieben offen.

\subsection{Zusammenfassung}

Mit rund 206.000 Besuchern zählte diese Ausstellung im Hinblick auf die Besucherzahlen zu den erfolgreichsten Projekten des Hauses der Bayerischen Geschichte. (Haus der Bayerischen Geschichte 2003, S. 52). Das besucherorientierte Konzept versuchte, viele Ansprüche an einem Ausstellungsort zu vereinen. Sowohl der Fachwissenschaftler wie auch das Laienpublikum sollten angesprochen werden, wobei dem Letzteren ein höherer Stellenwert eingeräumt wurde. Die ideale Situation vor Ort in Bamberg ermöglichte es, an verschiedenen Orten unterschiedliche Präsentationskonzepte zu verwirklichen und diese miteinander zu vergleichen. Als deutliches Ergebnis der Untersuchung kann festgestellt werden, dass keinem Konzept der Vorzug gegeben werden kann.

Die Bewertung der unterschiedlichen Präsentationsformen durch die Besucher war von persönlichen Präferenzen abhängig. Dabei ist sehr bemerkenswert, dass völlig unterschiedliche Aspekte als positiv empfunden und auch extrem gegensätzlich beurteilt wurden. Dementsprechend kann die salomonische Lösung der Trennung zwischen Inszenierung und objektorientierter Präsentation als gute Methode gewertet werden, unterschiedliche Besuchergruppen zu erreichen und diese somit auch mit weiterführenden Aspekten zu konfrontieren. ${ }^{175}$ Die Befragung

175 Dieses Ergebnis bestätigt auch eine Karlsruher Untersuchung, die ebenfalls zwei Ausstellungen verglich, die sich unterschiedlicher Präsentationsmethoden bediente. Unter dem gemeinsamen Thema „Spätmittelalter am Oberrhein" gab das Badische Landesmuseum einen facettenreichen Einblick in das städtische Leben des späten Mittelalters und inszenierte die Exponate unter Einsatz von Innenarchitektur, Modellen und audiovisuellen Medien. Im Gegensatz dazu zeigte die Staatliche Kunsthalle die Blüte spätgotischen Kunstschaffens. Dort wurden die hochrangigen Werke in einer kunsthistorisch objektorientierten Präsentation gezeigt. In beiden Fällen bewertete das Publikum die Ausstellung im allgemeinen positiv, jedoch wurde keiner Präsentationsform eindeutig der Vorzug gegeben. Diplomatisch wurde relativiert, ,dass beide Ausstellungen auf ihre Art gut, aber doch zu unterschiedlich seien, als dass man sie miteinander vergleichen könne.“ Vgl. Klein, Hans-Joachim: Gemischtes Doppel. Evaluation der Ausstellungen Spätmittelalter am Oberrhein in der Staat- 
bestätigte, dass es nicht den typischen Museumsbesucher gibt. Es gibt sowohl die flanierenden Besucher, die den Unterhaltungswert der Ausstellung schätzen, genauso aber auch die spezifisch Interessierten, die weite Wege auf sich nehmen, angezogen vom historischen Thema der Ausstellung oder um beispielsweise herausragende Exponate zu sehen.

Auf die Frage, wie zukünftige Ausstellungen aussehen sollten, betonten die Besucher, dass keinesfalls auf Originalobjekte verzichtet werden könne, da diese für die Authentizität grundlegend seien. Das Erzählen der Geschichte müsse anhand von Objekten erfolgen. ${ }^{176}$ Das Präsentationskonzept der Alten Hofhaltung aber wurde trotz einiger Kritik größtenteils als Weg in die richtige Richtung bezeichnet.

Außerdem wurde durch die persönlichen Interviews bestätigt, dass Ausstellungsbesuche ganzheitliche Erlebnisse sind. In die Bewertung der Ausstellung flossen nicht nur Kommentare zu Inhalt und Gestaltung ein. Unabhängig von subjektiven Interessen stand die Befriedigung des Bedürfnisses nach einer angenehmen Atmosphäre in den Ausstellungsräumen an vorderster Stelle. Getrübt wurde jedoch bei vielen Befragten das positive Erlebnis durch die Enge und das schlechte Klima im Ausstellungsareal der Alten Hofhaltung. Das wunderbare Gesamtambiente um den Bamberger Dom sowie in der Alten Hofhaltung mit Biergarten und einem Angebot an mittelalterlichen Speisen trug dennoch zu einem schönen Gesamterlebnis bei. Auch das abwechslungsreiche Rahmenprogramm belebte den Ausstellungsort.

Überraschend war, dass bei einem Teil der Besucher ein hohes Maß an Sensibilität gegenüber Ausstellungsgestaltung existiert und erfahrene Ausstellungsbesucher eine Art persönliche Ausstellungskompetenz entwickeln. Dies bedeutet, dass sie ihre Aufnahmefähigkeiten gut einschätzen können. Sie wissen, dass mit dem Besuch einer Ausstellung letztlich nur ein facettenhafter Einblick möglich ist und Hintergründe nur über das weitere Studium von Büchern erarbeitet werden können. Folglich kritisieren sie nicht die Kürze der Texte, sondern konzentrieren sich auf Objekte und wissen gute Gestaltung zu schätzen.

lichen Kunsthalle und im Badischen Landesmuseum, beide Karlsruhe, Karlsruhe 2002, S. 105.

176 Der Wunsch nach Authentizität der ausgestellten Objekte zeigte sich auch bei dem Ausstellungsprojekt „Museum der Souvenirs der sechziger Jahre“ des Künstlers Guillaume Bijl. Siehe Kapitel 4, S. $222 \mathrm{f}$. 
